\title{
Investigation of antiarrhythmic and proarrhythmic mechanisms in modified systems with molecular biological methods
}

\author{
András Horváth, MSc
}

\section{PhD Thesis}

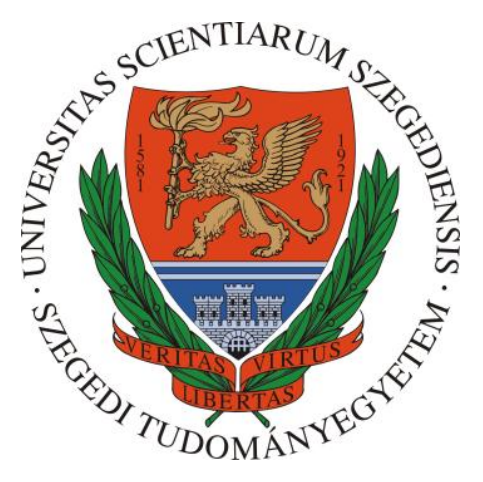

Supervisors:

László Virág, $P h D$ and Norbert Jost, $P h D$

Department of Pharmacology and Pharmacotherapy Faculty of Medicine

University of Szeged

Szeged

Hungary

2018 


\section{Table of contents}

1 LIST OF PUBLICATIONS RELATED TO THE SUBJECT OF THE THESIS .................. 3

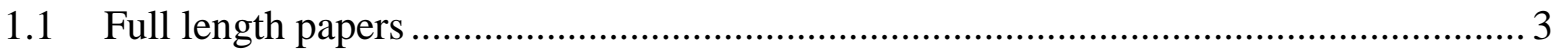

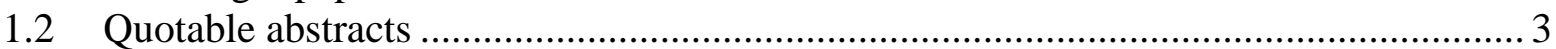

1.3 Other publications not related to the subject of the thesis....................................... 4

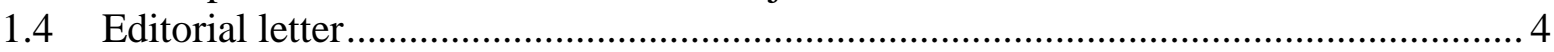

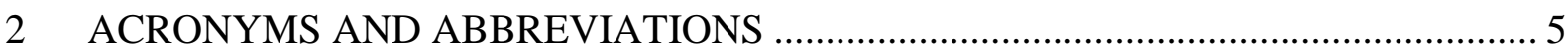

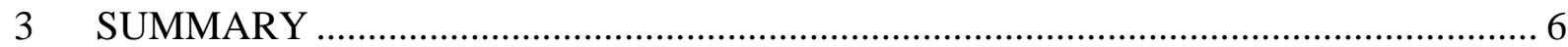

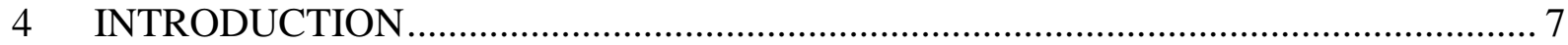

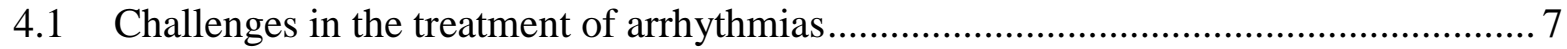

4.2 The cardiac action potential and its underlying currents.......................................... 9

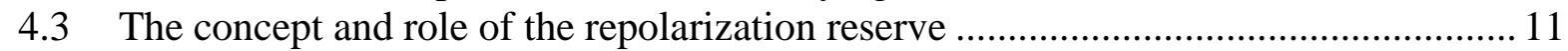

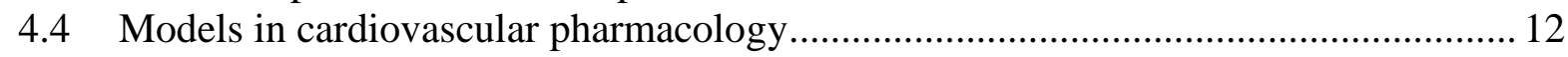

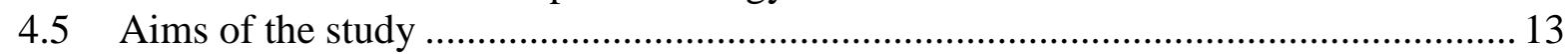

$5 \quad$ METHODS

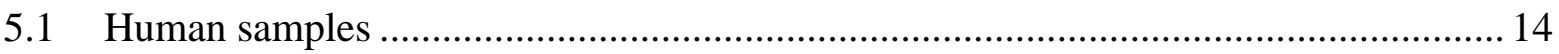

5.2 Differentiation of hiPSC-CM and EHT generation................................................ 14

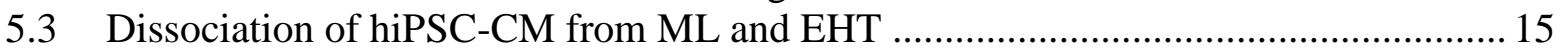

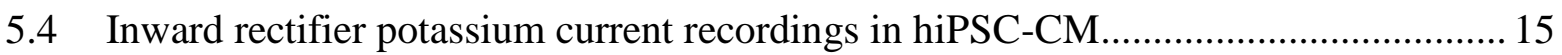

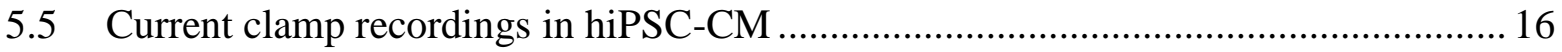

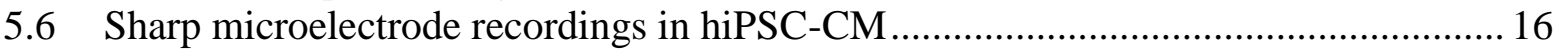

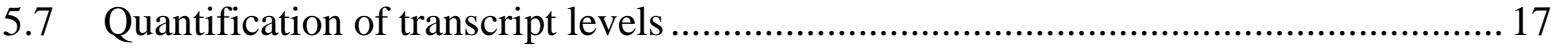

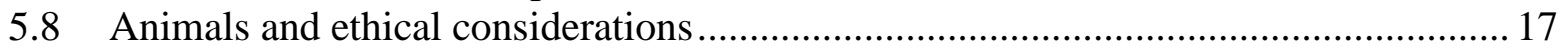

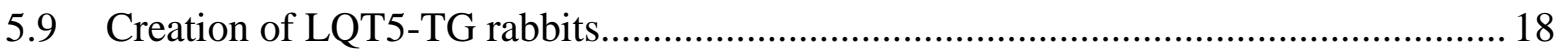

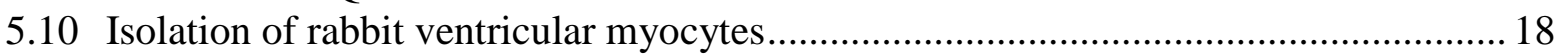

5.11 Voltage-clamp measurements on rabbit ventricular cardiomyocytes .......................... 19

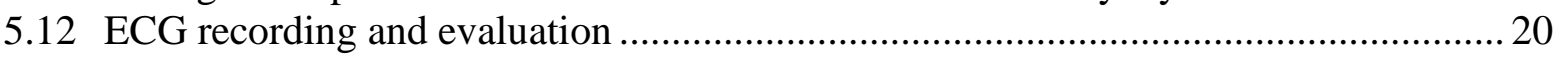

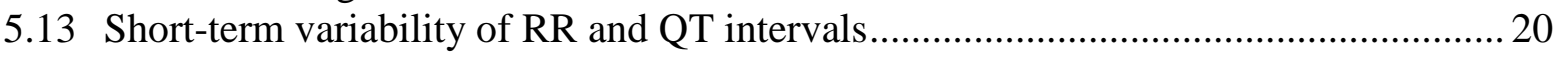

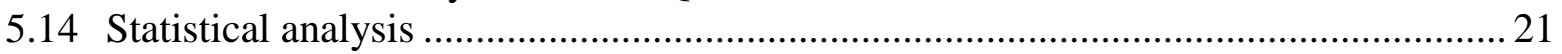

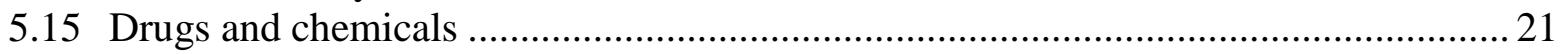

6 RESULTS

6.1 hiPSC-CM can possess large inward rectifier potassium currents ........................... 21

$6.2 \mathrm{I}_{\mathrm{K} 1}$ in hiPSC-CM is conducted via highly $\mathrm{Ba}^{2+}$-sensitive Kir channels ....................... 23

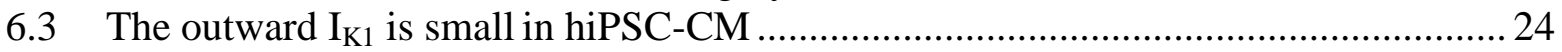

6.4 Acetylcholine-activated potassium currents $\left(\mathrm{I}_{\mathrm{K}, \mathrm{ACh}}\right)$ are not expressed in hiPSC-CM 26

6.5 RMP and AP measurements in single cells and intact tissues ..................................2

6.6 Potassium currents in healthy and LQT5-TG rabbit ventricular myocytes.................. 31

6.7 ECG parameters and arrhythmias in healthy and LQT5-TG rabbits............................ 33

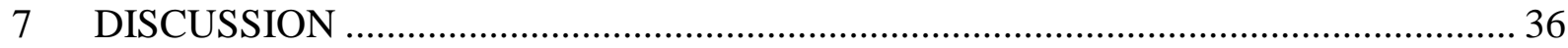

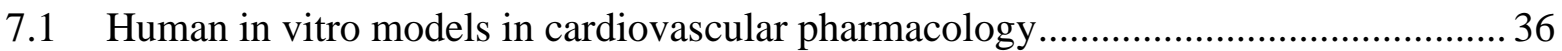

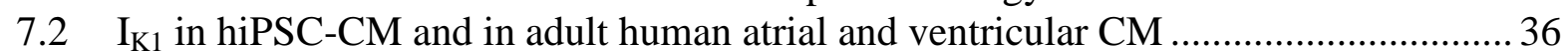


7.3 Measured RMP can differ in hiPSC-CM due to technical issues

7.4 Discrimination of atrial and ventricular cells by $\mathrm{I}_{\mathrm{K}, \mathrm{ACh}}, \mathrm{I}_{\mathrm{K} 1}, \mathrm{RMP}, \mathrm{APD}_{90}$ and repolarization fraction

7.5 Animal models in cardiovascular pharmacology .....

7.6 Effects of the G52R-KCNE1 mutation on repolarizing potassium currents in left ventricular myocytes, obtained from WT and LQT5-TG rabbit hearts.

7.7 The in vivo results show that LQT5-TG rabbits are sensitive to arrhythmia provocation

7.8 Potential role of the two introduced models in the future

8 CONCLUSIONS AND POTENTIAL SIGNIFICANCE

9 ACKNOWLEDGEMENTS

10 REFERENCES

11 ANNEX 


\section{List of publications related to the subject of the thesis}

\subsection{Full length papers}

I. Horváth A, Lemoine MD, Löser A, Mannhardt I, Flenner F, Uzun AU, Neuber C, Breckwoldt K, Hansen A, Girdauskas E, Reichenspurner H, Willems S, Jost N, Wettwer E, Eschenhagen T, Christ T, Low resting membrane potential and low inward rectifier Potassium currents are not inherent features of hiPSC-derived cardiomyocytes.

STEM CELL REPORTS 10:(3) pp. 822-833. (2018)

IF (2017): 7.338 (Q1/D1)

Number of citations: 1

II. Major P, Baczkó I, Hiripi L, Odening KE, Juhasz V, Kohajda Z, Horváth A, Seprényi G, Kovács M, Virág L, Jost N, Prorok J, Ördög B, Doleschall Z, Nattel S, Varró A, Bősze Z, A novel transgenic rabbit model with reduced repolarization reserve: long QT syndrome caused by a dominant-negative mutation of KCNE1 gene.

BRITISH JOURNAL OF PHARMACOLOGY 173:(12) pp. 2046-2061. (2016)

IF: (2015) 5.259 (Q1/D1)

Number of citations: 7

\subsection{Quotable abstracts}

I. Horváth A, Uzun A, Vollert I, Breckwoldt K, Neuber C, Hansen A, Varró A, Eschenhagen T, Christ T, Mesterséges izomszövetekböl izolált pluripotens őssejtekböl származtatott szívizomsejtek elektrofiziológiai tulajdonságai (Electrophysiological properties of human induced pluripotent stem cell derived cardiomyocytes isolated from engineeredheart tissues). CARDIOLOGIA HUNGARICA 45:(Suppl. D) pp. D31-D32. (2015)

II. Horváth A, Uzun A, Mannhardt I, Breckwoldt K, Keuber C, Löser A, Hansen A, Jost N, Varró A, Eschenhagen T, Christ $\mathrm{T}$, Befelé egyenirányító ionáramok human indukált pluripotens össejtekből származtatott szívizomsejtekben (Inward rectifier ion currents in human induced pluripotent stem cell-derived cardiomyocytes).

CARDIOLOGIA HUNGARICA 46:(Suppl.F) pp. F47-F48. (2016)

III. Horváth A, Gurr K, Ismaili D, Mannhardt I, Ulmer B, Hansen A, Eschenhagen T, Christ $\mathrm{T}$, Properties of the sodium-calcium exchanger and the $\mathrm{Na}^{+} / \mathrm{K}^{+}$-ATPase in human induced pluripotent stem cell-derived cardiomyocytes.

EP EUR.;19: iii7-iii7. (2017)

IV. Horváth A, Gurr K, Ismaili D, Mannhardt I, Ulmer B, Hansen A, Jost N, Eschenhagen T, Christ $\mathrm{T}$, A nátrium-kalcium cseremechanizmus és a $\mathrm{Na}^{+} / \mathrm{K}^{+}$-ATPáz vizsgálata humán indukált pluripotens össejtekböl származtatott szívizomsejtekben (Investigation of the sodium-calcium exchanger and the $\mathrm{Na}^{+} / \mathrm{K}^{+}$-ATPase in human induced pluripotent stem cellderived cardiomyocytes).

CARDIOLOGIA HUNGARICA 47:(Suppl.C) p. C48. (2017) 


\subsection{Other publications not related to the subject of the thesis}

I. Corici C, Kohajda Z, Kristóf A, Horváth A, Virág L, Szél T, Nagy N, Szakonyi Zs, Fülöp F, Muntean DM, Varró A, Jost N, L-364,373 (R-L3) enantiomers have opposite modulating effects on I-Ks in mammalian ventricular myocytes.

CANADIAN JOURNAL OF PHYSIOLOGY AND PHARMACOLOGY 91:(8) pp. 586-592. (2013)

IF: (2012): $1.556(\mathrm{Q} 3)$

Number citations: 2

II. Jost N, Nagy N, Corici C, Kohajda Zs, Horváth A, Acsai K, Biliczki P, Levijoki J, Pollesello P, Koskelainen T, Otsomaa L, Tóth A, Papp JGy, Varró A, Virág L, ORM-10103, a novel specific inhibitor of the sodium/calcium exchanger, decreases early and delayed afterdepolarization in the canine heart.

BRITISH JOURNAL OF PHARMACOLOGY 170:(4) pp. 768-778. (2013)

IF (2012): 5.067 (Q1/D1)

Number of citations: 22

III. Uzun AU, Mannhardt I, Breckwoldt K, Horváth A, Johannsen SS, Hansen A, Eschenhagen $\mathrm{T}$, Christ $\mathrm{T}, \mathrm{Ca}^{2+}$-currents in human induced pluripotent stem cell-derived cardiomyocytes effects of two different culture conditions.

FRONTIERS IN PHARMACOLOGY 7: p. 300. (2016)

IF (2016): 4.400 (Q1/D1)

Number of citations: 5

IV. Kohajda Z, Farkas-Morvay N, Jost N, Nagy N, Geramipour A, Horváth A, Varga RS, Hornyik T, Corici C, Acsai K, Horváth B, Prorok J, Ördög B, Déri Sz, Tóth D, Levijoki J, Pollesello P, Koskelainen T, Otsomaa L, Tóth A, Baczkó I, Leprán I, Nánási PP, Papp JGy, Varró A, Virág L. The effect of a novel highly selective inhibitor of the sodium/calcium exchanger (NCX) on cardiac arrhythmias in in vitro and in vivo experiments.

PLOS ONE 11(11): e0166041. doi: 10.1371/journal.pone.0166041.eCollection (2016)

IF (2015): 3.057 (Q1/D1)

Number of citations: 2

V. Lemoine MD, Mannhardt I, Breckwoldt K, Prondzynski M, Flenner F, Ulmer B, Hirt MN, Neuber C, Horváth A, Kloth B, Reichenspurner H, Willems S, Hansen A, Eschenhagen T, Christ T, Human iPSC-derived cardiomyocytes cultured in 3D engineered heart tissue show physiological upstroke velocity and sodium current density.

SCIENTIFIC REPORTS 7:(1) p. 5464. (2017)

IF (2016): 4.259 (Q1/D1)

Number of citations: 4

\subsection{Editorial letter}

I. Christ T, Horváth A, Eschenhagen T.: LQT1-phenotypes in hiPSC: Are we measuring the right thing?

PNAS.;112: E1968-E1968. (2015)

Number of citations: 7 


\section{Acronyms and Abbreviations}

AAD: antiarrhythmic drugs

AP: action potential

APD: action potential duration

$\mathrm{APD}_{50}$ : action potential duration at $50 \%$, of repolarization

$\mathrm{APD}_{90}$ : action potential duration at $90 \%$, of repolarization

CCh: carbachol

CHO-K1: Chinese hamster ovary K1 cells

CM: cardiomyocytes

$\mathrm{C}_{\mathrm{m}}$ : cell membrane capacitance

CRISPR/Cas9: clustered regularly interspaced short palindromic repeats

EHT: Engineered Heart Tissue

hERG: human ether-a-go-go gene

hiPSC-CM: human induced pluripotent stem cell-derived cardiomyocytes

$\mathrm{I}_{\mathrm{Ca}, \mathrm{L}}$ : L-type $\mathrm{Ca}^{2+}$ current

$\mathrm{I}_{\mathrm{K} 1}$ : inward rectifier $\mathrm{K}^{+}$current

$\mathrm{I}_{\mathrm{K}, \mathrm{ACh}}$ : Acetylcholine-sensitive $\mathrm{K}^{+}$current

$\mathrm{I}_{\mathrm{Kr}}$ : rapid component of the delayed rectifier $\mathrm{K}^{+}$current

$\mathrm{I}_{\mathrm{Ks}}$ : slow component of the delayed rectifier $\mathrm{K}^{+}$current

$\mathrm{I}_{\mathrm{Na}}: \mathrm{Na}^{+}$current

$\mathrm{I}_{\mathrm{to}}$ : transient outward $\mathrm{K}^{+}$current

KCNE: potassium voltage-gated channel subfamily E member

LQT5: Long QT syndrome type 5

LQT5-TG: Long QT syndrome type 5 transgenic

LQT: Long QT syndrome

LV: left ventricle

LV-CM: left ventricular cardiomyocytes

ML: monolayer

$\mathrm{QT}_{\mathrm{c}}$ : frequency-corrected QT-interval

$\mathrm{RA}$ : right atrium

RA-CM: right atrial cardiomyocytes

$\mathrm{R}_{\mathrm{M}}$ : membrane resistance

RMP: resting membrane potential

$\mathrm{R}_{\text {seal }}$ : seal resistance

STV: short-term variability

$\mathrm{STV}_{\mathrm{RR}}$ : the short-term variability of the RR interval

$\mathrm{STV}_{\mathrm{QT}}$ : the short-term QT-interval variability

TdP: Torsades de pointes

$\mathrm{V}_{\mathrm{cM}}$ : corrected membrane potential

$\mathrm{V}_{\mathrm{mM}}$ : measured membrane potential

VF: ventricular fibrillation

VT: ventricular tachycardia

WT: wild-type 


\section{Summary}

In cardiovascular research, there is a high need to use reliable tools for modelling cardiovascular diseases (LQT, LEOPARD, Andersen-Tawil syndrome) and for cardiovascular drug testing. It is necessary that those models reflect human heart physiology. The most commonly used models are human induced pluripotent stem cell-derived cardiomyocytes (hiPSC-CM) and transgenic animals, which showed promising results to study heart physiology. However, the existing hiPSC-CM and the animal models showed differences in electrophysiological properties due to immaturity and species differences. Therefore, it was of interest to study in detail the electrophysiological properties of the introduced models, hiPSCCM and a Long QT-syndrome type 5 (LQT5) transgenic (LQT5-TG) rabbit model. The major results described in this thesis can be summarized as follows:

- When studying the electrophysiological profile of hiPSC-CM, one of the major concerns is the low inward rectifier potassium current $\left(\mathrm{I}_{\mathrm{K} 1}\right)$ and resting membrane potential (RMP). In our study, hiPSC-CM were cultivated in two different conditions. One was the conventional monolayer (ML), while the other was Engineered Heart Tissues (EHT). In our hiPSC-CM cell line we were able to measure $\mathrm{I}_{\mathrm{K} 1}$ comparable to human adult cardiomyocytes (CM).

- In contrast to previous publications, we were able to measure resting membrane potential (RMP) values in a physiological range using sharp microelectrode in intact EHT. We showed that the low RMP measured by patch electrodes may be prone to error.

- Patch-clamp experiments on ventricular myocytes isolated from LQT5-TG rabbits were performed. The results showed differences in $\mathrm{I}_{\mathrm{Ks}}$ and $\mathrm{I}_{\mathrm{Kr}}$ deactivation kinetics. The deactivation kinetics of the currents were accelerated.

- At baseline, LQT5-TG animals showed slightly, but significantly prolonged heartrate corrected $\mathrm{QT}$ index $\left(\mathrm{QT}_{\mathrm{i}}\right)$ and increased $\mathrm{STV}_{\mathrm{QT}}$. Dofetilide provoked Torsades de Pointes $(T d P)$ arrhythmia in a larger number of LQT5-TG rabbits, paralleled by a further increase in short-term QT-interval variability $\left(\mathrm{STV}_{\mathrm{QT}}\right)$. 


\section{Introduction}

In public health, frequent occurrence of cardiac arrhythmias is a major concern. These arrhythmias can occur due to inherited diseases, (LQT, LEOPARD, Andersen-Tawil syndrome) or as a proarrhythmic effect of drugs, which can lead to ventricular tachycardia/ventricular fibrillation (VT/VF) [1-8]. "Arrhythmia" refers to any change in the normal sequence and/or shape of electrical impulses during the cardiac cycle. These are very important issues, and there is a high need to produce reliable models to study inherited heart diseases, as well as versatile tools for safety pharmacology.

\subsection{Challenges in the treatment of arrhythmias}

Antiarrhythmic drugs (AAD) can be categorized using the Vaughan Williams 4 - level schema or by the mechanistic and clinically relevant Sicilian Gambit. Some AAD have a complex action on the different ion channels, so they do not necessarily fit into any class of the Vaughan Williams classification schema [9]. The Sicilian Gambit classifies the agents based on their arrhythmogenic mechanism of action. This type of classification was introduced in $1991[10,11]$.

\begin{tabular}{|c|c|c|c|}
\hline $\begin{array}{l}\text { Class I } \\
\text { Drugs that delay fast sodium } \\
\text { channel mediated conduction }\end{array}$ & $\begin{array}{l}\text { Class II } \\
\text { Sympathetic } \\
\text { antagonists }\end{array}$ & $\begin{array}{l}\text { Class III } \\
\text { Drugs that } \\
\text { prolong } \\
\text { repolarisation }\end{array}$ & $\begin{array}{l}\text { Class IV } \\
\text { Calcium } \\
\text { antagonists }\end{array}$ \\
\hline $\begin{array}{l}\text { IA } \\
\text { Depress phase } 0 \\
\text { Delay conduction } \\
\text { Prolong repolarisation } \\
\text { Disopyramide, Procainamide, Quinidine } \\
\text { IB } \\
\text { Little effect on phase } 0 \text { in normal tissue } \\
\text { Depress phase } 0 \text { in abnormal tissue } \\
\text { Shorten repolarisation or little effect } \\
\text { Diphenylhydantoin, Lidocaine, } \\
\text { Mexiletine, Tocainide } \\
\text { IC } \\
\text { Markedly depress phase } 0\end{array}$ & $\begin{array}{l}\text { Acebutolol } \\
\text { Betaxolol } \\
\text { Bisoprolol } \\
\text { Bucindolol } \\
\text { Carvedilol } \\
\text { Esmolol } \\
\text { Metoprolol } \\
\text { Nadolol } \\
\text { Propranolol } \\
\text { Timolol } \\
\text { Others }\end{array}$ & $\begin{array}{l}\text { Amiodarone } \\
\text { Azimilide } \\
\text { Bretylium } \\
\text { Dofetilide } \\
\text { Ibutilide } \\
\text { Sotalol } \\
\text { Tedisamil }\end{array}$ & $\begin{array}{l}\text { Diltiazem } \\
\text { Verapamil }\end{array}$ \\
\hline
\end{tabular}




\begin{tabular}{|l|l|l|l|}
\hline Markedly slow conduction & & \\
Slight effect on repolarisation & & \\
Flecainide, Moricizine, Propafenone & & & \\
\hline
\end{tabular}

Figure 1. The Vaughan Williams classification of antiarrhythmic drugs (adapted from [11] ).

Drug treatment of cardiac arrhythmias still remains problematic, because of their inadequate effectiveness and a risk of serious complications, such as cardiac side effects. The physiological and pathophysiological mechanisms of cardiac arrhythmias are still unclear. Due to this, in many cases AAD have proarrhythmic effects. According to these problems, there is a high need to increase our understanding on the underlying mechanism of those cardiac arrhythmias both at the tissue and cellular level. There is also a high need to develop new, safe and effective antiarrhythmic agents [12-14].

Several trials have been carried out to study the possible proarrhythmic effects of the existing antiarrhythmic agents, some studies showed increased mortality due to the side effects of the AAD. The Cardiac Arrhythmia Suppression Trial (CAST) investigated the effects of the existing AAD (Class I/C drugs encainide, flecainide) in patients with asymptomatic, or mildly symptomatic ventricular arrhythmia (six or more ventricular premature beats per hour), after myocardial infarction (Figure 2). The trial was designed to reveal, whether or not the antiarrhythmic agents can reduce the appearance of life threatening arrhythmias in patients with myocardial infarction. After 10 months of follow-up, the results showed an increased incidence of lethal cardiac arrhythmias in the drug-treated groups compared to the placebo. In conclusion, the use of encainide and flecainide was stopped in the trial, and these drugs were considered to be not safe enough anymore to treat patients with

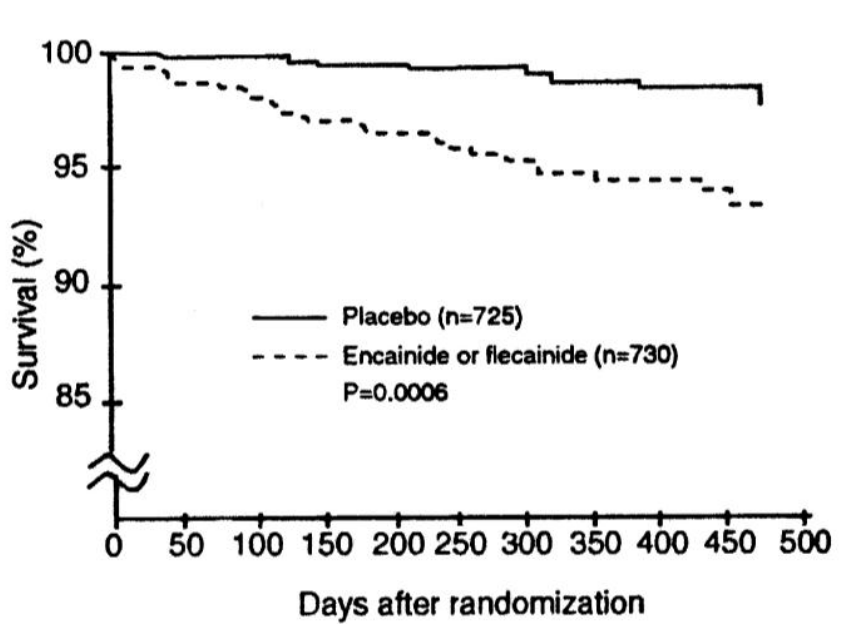
asymptomatic, or minimally symptomatic ventricular arrhythmia after myocardial infarction $[7,8]$.

Figure 2. Higher rate of survival with placebo compared with patients taking encainide or flecainide in the Cardiac Arrhythmia Suppression Trial (CAST, adapted from [8]).

In the meantime, the effects of the class III antiarrhythmic agent d-sotalol was investigated on mortality in high risk patients. The study was named SWORD (Survival With 
Oral d-sotalol), and it revealed that administration of d-sotalol was associated with increased mortality, which was presumed primarily to be due to arrhythmias (Figure 3). The prophylactic use of the potassium channel blocker d-sotalol did not reduce mortality, and was associated with increased mortality in high-risk patients after myocardial infarction [15].

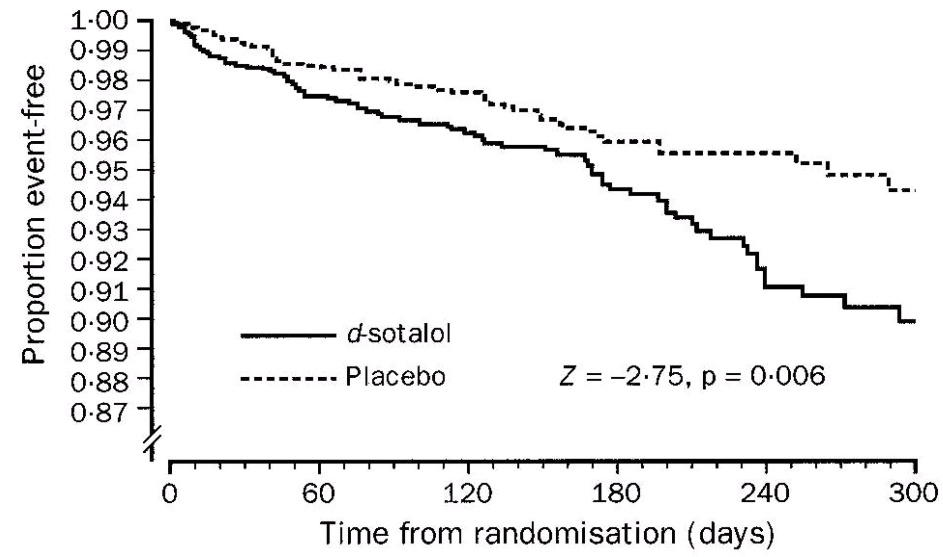

Figure 3. Survival curves with placebo and d-sotalol in the Survival With Oral d-sotalol study (SWORD, adapted from Waldo et al. 1996. [15]).

\subsection{The cardiac action potential and its underlying currents}

In the mammalian heart, the normal pump function critically depends on proper electrical function. The signal for contraction originates from specialized regions, where pacemaker cells are located. From those pacemaker regions the trigger propagates first through the atrial myocardium, transmitted by the atrio-ventricular node, enters the specialized excitation conduction system of the ventricles and finally spreads through the ventricular myocardium. Generation of action potentials are connected to this myocardial electrical activity of the individual cardiac cells, which can be also detected on surface electrocardiograms [16]. The APs are created by the organized activation and inactivation of ion channels that conduct depolarizing, inward $\left(\mathrm{Na}^{+}\right.$and $\left.\mathrm{Ca}^{2+}\right)$ and repolarizing, outward $\left(\mathrm{K}^{+}\right)$ currents. The shape of the APs can differ in various different regions of the heart. These regional differences are due to the region-specific expression pattern of the cardiac ion channels, underlying the unidirectional propagation of the cardiac action potential, which is an essential requirement of maintaining normal cardiac rhythm [17,18]. In the cardiac AP five different "phases", are distinguished (Figure 4). 


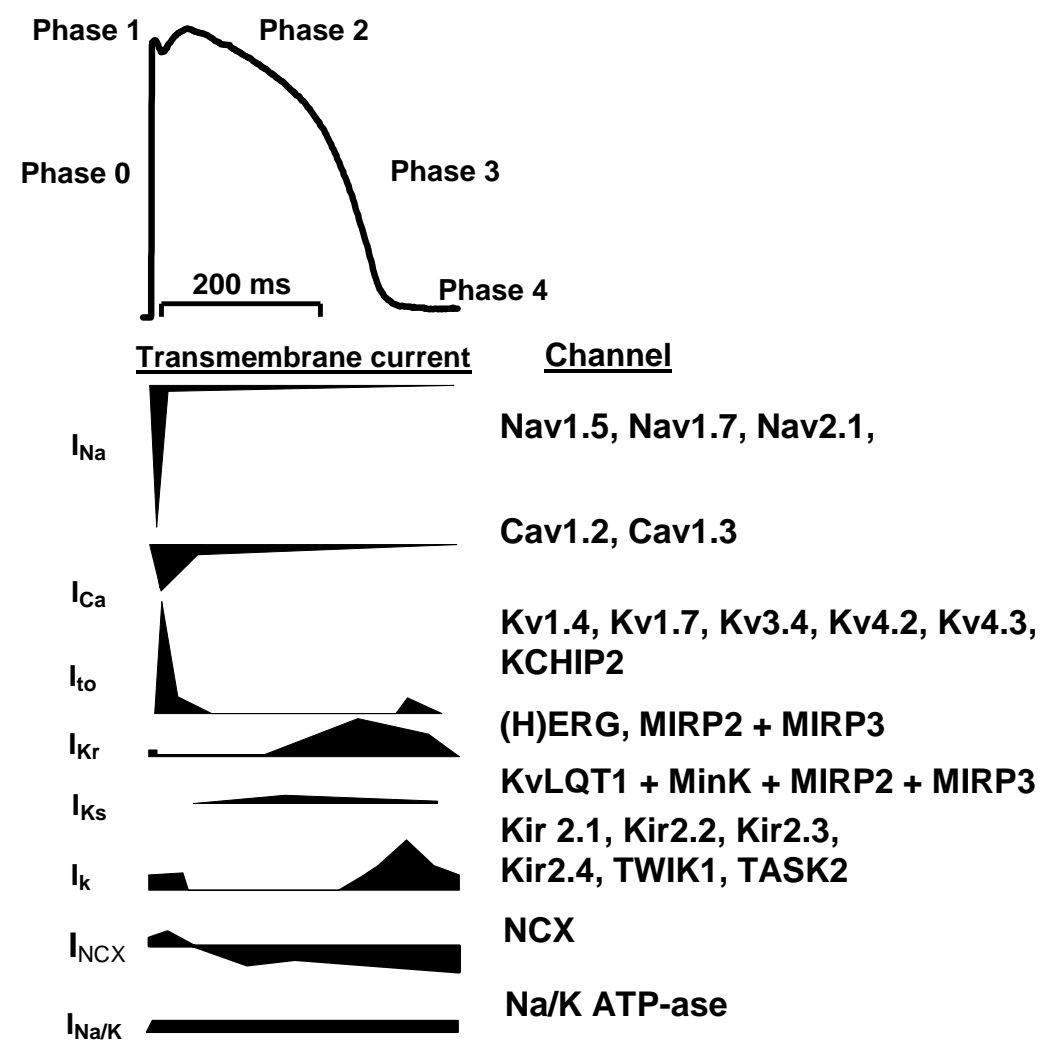

Figure 4. The ventricular action potential and corresponding ion currents. The upper panel shows a representative ventricular AP and phases of the AP kinetics. The underlying ionic currents are shown in the left side of the lower panel in time-match with the AP. The inward currents are depicted as downward deflections. It should be noted that the amplitudes of the currents are not proportional with each other. The channel proteins carrying the current are marked at right side of the lower panel (modified from [19]).

The initial phase (phase 0) is the fast depolarization of the AP. During this phase the fast inward $\mathrm{Na}^{+}$channels are activated. The sodium current $\left(\mathrm{I}_{\mathrm{Na}}\right)$ has a relatively short-lived characteristic (2-3 ms), it creates a large charge influx to membrane depolarization. Beyond activating other currents of the AP (e.g.: $\mathrm{Ca}^{2+}$-current, $\mathrm{K}^{+}$-currents), this phase is responsible for the rapid impulse propagation. The phase 1 repolarization is determined by the transient outward potassium current $\left(\mathrm{I}_{\mathrm{to}}\right)$. The kinetics of this current is similar to the $\mathrm{I}_{\mathrm{Na}}$, it is quickly activated and inactivated during depolarization, but is slower than the sodium current. The magnitude of this phase has an important role in shaping the spike-and-dome configuration of the AP. The expression level of $I_{t o}$ ion channel subunits can differ across the ventricular wall (and therefore the amplitude of $I_{t o}$ as well) [20], the spike-and-dome configuration can be considered a specific "marker" in identifying the epi-, myo, or endocardial origin of the cell. The phase 2 also called "plateau phase", which is a typical property of the cardiac AP. During this phase the inward L-type calcium current $\left(\mathrm{I}_{\mathrm{Ca}, \mathrm{L}}\right)$ and outward potassium currents balance each other. They provide a long-lasting isoelectric phase, which has a crucial role in cell 
contraction. $\mathrm{I}_{\mathrm{Ca}, \mathrm{L}}$ is an important player not only in shaping the action potential, but in initiation of intracellular $\mathrm{Ca}^{2+}$ cycle. When the $\mathrm{I}_{\mathrm{Ca}, \mathrm{L}}$ slowly inactivates, the outward $\mathrm{K}^{+}$ currents are still active, and they start the late repolarization (phase 3). During the phase 3, the rapid and slow components of delayed rectifiers $\left(\mathrm{I}_{\mathrm{Kr}}\right.$ and $\left.\mathrm{I}_{\mathrm{Ks}}\right)$ support a relatively large, outward $\mathrm{K}^{+}$current, having a crucial role in the repolarization. The inward rectifier $\mathrm{K}^{+}$current $\left(\mathrm{I}_{\mathrm{K} 1}\right)$ has a primary role to complete the final phase of the repolarization and stabilize a negative membrane potential. This phase 4 represents the resting membrane potential (RMP) during diastole. The RMP of the ventricular cardiomyocytes is determined by $\mathrm{I}_{\mathrm{K} 1}$ and possibly by the $\mathrm{Na}^{+} / \mathrm{K}^{+}$pump and other background currents. In atrial and Purkinje cells, the expression level of $\mathrm{I}_{\mathrm{K} 1}$ is significantly smaller [21,22], the resting membrane potential is unstable and the depolarization is slow.

\subsection{The concept and role of the repolarization reserve}

In 1998, Dan M Roden introduced a concept, called repolarization reserve. This theory was based on clinical observations [23]. During phase 3, the AP is determined by a combination of four major repolarizing potassium currents including $\mathrm{I}_{\mathrm{Kr}}, \mathrm{I}_{\mathrm{Ks}}, \mathrm{I}_{\mathrm{K} 1}$ and $\mathrm{I}_{\mathrm{to}}$ [24]. Based on clinical [23] and experimental data [24-26], it was observed in the mammalian ventricular muscle (human, dog and rabbit), the loss of one of the mentioned potassium currents does not necessarily cause APD prolongation. This is probably due to the capability of other potassium channels to compensate the loss of the activity of one $\mathrm{K}^{+}$channel. Human, dog and rabbit ventricular myocytes seem to repolarize with a strong safety margin ("repolarization reserve"). This repolarization capacity is crucial to prevent life-threatening arrhythmias. If this mechanism is impaired by factors (cardiac and not cardiac as well), such as drug exposures, heart failure, diabetes mellitus, hypothyroidism, long QT syndromes, genetic diseases like Brugada-syndrome, etc, a minimal or moderate potassium current inhibition can result in dramatic and potentially proarrhythmic prolongation of the ventricular APD. Multiple $\mathrm{K}^{+}$channel block can result in excessive repolarization lengthening by eliminating the repolarization reserve and therefore, it can be associated with increased proarrhythmic risk. 


\subsection{Models in cardiovascular pharmacology}

To understand better the mechanisms of arrhythmias and heart diseases, there is a high need to develop new models for this purpose. Differentiated hiPSC-CM from pluripotent stem cells provide a great opportunity to study human heart physiology and disease modelling. In several reports, hiPSC-CM cell-lines were successfully created, expressing cardiac ion channel mutations or hypertrophic cardiomyopathy [27-31]. These promising results open new avenues to establish personalized treatment options for individual patients, or repair the mutation using gene therapy techniques, such as CRISPR/Cas9 [32]. In the meantime, these cardiomyocytes were successfully used in high throughput systems as well [33]. The practical handling of hiPSC-CM brought them into a great attention as a novel, reliable tool for cardiovascular disease modelling and safety pharmacology. However, many studies reported that hiPSC-CM are immature and there are major differences in sarcomeric organization and electrophysiological properties, compared to human adult cardiomyocytes. Studies with patch clamp electrodes consistently reported RMP to be less negative in hiPSC-CM than in adult atrial or ventricular myocardium [29,34-38]. This is an alarming finding since correct RMP is mandatory for excitability and refractoriness. One of the possible explanations for a less negative RMP reported in hiPSC-CM is the absence or small amplitude of $\mathrm{I}_{\mathrm{K} 1}$. This current is responsible for the stable, negative RMP in adult CM [39]. In line with this assumption, current densities of $\mathrm{I}_{\mathrm{K} 1}$ were reported to be low or almost absent in hiPSC-CM cell lines [34,35,37]. Generation of Engineered Heart Tissues (EHT) from hiPSC-CM allows those CM to contract in a coupled manner and it showed progress in sarcomeric organization and contractile force [40]. The EHT format is suitable to use the sharp microelectrode technique to measure action potentials [41]. Whether EHT format favours maturation of hiPSC-CM in electrophysiological properties, such as $\mathrm{I}_{\mathrm{K} 1}$ current and RMP, remained unclear und was a subject of this thesis.

Transgenic animals have been used as disease models, including cardiac diseases for a long time. Small rodents, such as mouse, provide a platform where the cardiomyocytes are mature, in vivo experiments can be done, and studies showed great results that those models expressing the mutant phenotype effectively, and it has really enlarged our knowledge about cardiac arrhythmia mechanisms [42,43]. However, the major problem with those models is that the electrophysiological profile of the mouse heart shows major differences compared to human. They have faster heart rates and different repolarizing currents as well [16]. This might result some differences in arrhythmia mechanisms [44,45]. According to these 
discrepancies, there is a need to provide transgenic animals which reflect human heart physiology better than small rodents. One of the possible species for this purpose is the rabbit, which has shown promising results, especially modelling LQT1 and LQT2 diseases [46-48]. The electrophysiological profile of the rabbit heart is more comparable to the human heart. It shows slower heart rates, similar repolarizing currents and is a commonly used model for cardiovascular pharmacology studies $[46,48,49]$. However, only two types of transgenic rabbits have been created (LQT1 and LQT2) so far [50]. In 2003, a novel missense mutation was discovered and characterized in a Chinese family [51]. Due to this mutation, arginine (R) was substituted for glycine $(\mathrm{G})$ at position 52 of the $\operatorname{minK}$ protein, which is the regulatory subunit of the $\mathrm{I}_{\mathrm{Ks}}$ channel [52]. Five of the seven patients showed alterations in ECG, and two of them had no symptoms [51]. Co-expression of the G52R-KCNE1 with KCNQ1 reduced the $\mathrm{I}_{\mathrm{Ks}}$ current by $50 \%$ in Xenopus oocytes and caused a prolongation in the cardiac action potential [51]. The G52R has no effect on the channel-subunit assembly, or trafficking to the cell membrane, but it affects the gating mechanisms of KCNQ1 in CHO-K1 cells [53].

\subsection{Aims of the study}

The aim of this study was to validate two models as possible tools for cardiac safety pharmacology and disease modelling:

1) Compare the $I_{K 1}$ current density in hiPSC-CM under two different culture conditions (ML and EHT) and compare them to CM isolated from human right atrial and left ventricular tissue.

2) Investigate whether hiPSC-CM exhibit a ventricular or atrial phenotype based on channel expression (possible expression and function of acetylcholine-sensitive $\mathrm{K}^{+}$current $\left(\mathrm{I}_{\mathrm{K}, \mathrm{Ach}}\right)$ and specific action potential parameters (repolarization fraction).

3) Study resting membrane potential in hiPSC-CM EHTs using two different approaches (patch clamp and sharp microelectrode technique). 
4) Create and characterise a novel LQT5-TG rabbit model with impaired repolarization reserve and study the cellular electrophysiological profile (in case of potassium currents) of the animals using the patch clamp technique.

5) Evaluate the in vivo electrophysiological parameters of the LQT5-TG rabbit model and its reaction to dofetilide-induced arrhythmia provocation.

\section{Methods}

\subsection{Human samples}

Myocardial tissue was obtained from patients undergoing cardiac surgery at the University Heart Centre Hamburg. The study followed the Declaration of Helsinki. All patients gave written informed consent. Human right atrial appendages were obtained from patients undergoing cardiac surgery. They were immediately placed into cold $\mathrm{Ca}^{2+}$-free transport solution (in mmol/L: $\mathrm{NaCl} 100, \mathrm{KCl} 10, \mathrm{KH}_{2} \mathrm{PO}_{4} 1.2, \mathrm{MgSO}_{4}$ 5, taurine 50, MOPS 5, and glucose 20, with $\mathrm{pH}$ adjusted to 7.0 with $\mathrm{NaOH}$ ) supplemented with 2,3-butanedione monoxime (BDM, $30 \mathrm{mmol} / \mathrm{L}$ ). Before the isolation, the tissue was cut into small pieces, and washed 3 times for 3 minutes with $\mathrm{Ca}^{2+}$-free Tyrode's solution. During the procedures, the solutions were oxygenated with $100 \% \mathrm{O}_{2}$ at $35{ }^{\circ} \mathrm{C}$. Tissue pieces were then transferred into $\mathrm{Ca}^{2+}$-free Tyrode's solution containing $254 \mathrm{U} / \mathrm{mL}$ collagenase type I (Worthington Biochemical Corp. Lakewood, NJ, USA) and $0.5 \mathrm{mg} / \mathrm{mL}$ protease type XXIV (Sigma Chemical $\mathrm{Co}$ ) and gently stirred for additional 15 minutes. Then the $\mathrm{Ca}^{2+}$ concentration was raised to $0.2 \mathrm{mmol} / \mathrm{L}$, and the tissue was stirred for 30 minutes more.

\subsection{Differentiation of hiPSC-CM and EHT generation}

The undifferentiated hiPSC line C25 (kind gift from Alessandra Moretti, Munich, Germany) was expanded in FTDA medium [54] and differentiated in a three step protocol based on growth factors and a small molecule Wnt-inhibitor DS07 (kind gift from Dennis Schade, Dortmund, Germany) as previously published [40,55]. In brief, confluent undifferentiated cells were dissociated (0.5 mM EDTA; $10 \mathrm{~min})$ and cultivated in spinner flasks $(30 * 106$ cells/100 ml; $40 \mathrm{rpm})$ for embryoid body formation overnight [56]. Mesodermal differentiation was initiated in embryoid bodies over three days in suspension 
culture with growth factors (BMP-4 [R\&D Systems, 314-BP], activin-A [R\&D Systems, 338AC], FGF2 [PeproTech, 100-18B]). Cardiac differentiation was performed either in adhesion or in suspension culture with Wnt-inhibitor DS07 [55]. Cells were cultured in a humidified temperature and gas-controlled incubator $\left(37^{\circ} \mathrm{C}, 5 \% \mathrm{CO}_{2}, 5 \% \mathrm{O}_{2} ; 21 \% \mathrm{O}_{2}\right.$ for final cardiac differentiation). At day 14 the spontaneously beating hiPSC-CM were dissociated with collagenase type II (Worthington, LS004176; $200 \mathrm{U} / \mathrm{ml}, 3.5 \mathrm{~h}$ ) and either cultured in ML or EHT format. For three-dimensional culture EHT were generated as previously described with $1 \times 106$ cells / $100 \mu \mathrm{l}$ EHT [57]. EHT as well as ML were cultured in a $37{ }^{\circ} \mathrm{C}, 7 \% \mathrm{CO}_{2}, 40 \%$ $\mathrm{O}_{2}$ humidified cell culture incubator with a medium consisting of DMEM (Biochrom; F0415), $10 \%$ heat-inactivated horse serum (Gibco 26050), 1\% penicillin/streptomycin (Gibco 15140), insulin (10 $\mu \mathrm{g} / \mathrm{ml}$; Sigma 19278) and aprotinin (33 $\mu \mathrm{g} / \mathrm{ml}$; Sigma A1153). For further comparability, experiments were performed in parallel from the same batch of cells.

\subsection{Dissociation of hiPSC-CM from ML and EHT}

HiPSC-CM were cultivated for 28 days in ML or EHT culture before dissociation. The cells were isolated for $3 \mathrm{~h}$ (ML) and $5 \mathrm{~h}$ (EHT) using collagenase type II (200 U/ml, Worthington Biochemical Corp. Lakewood, NJ, USA, LS004176 in HBSS minus $\mathrm{Ca}^{2+} / \mathrm{Mg}^{2+}$, Gibco 14175-053 and $50 \mu \mathrm{M} \mathrm{CaCl}_{2}$ ). At least 3 different batches of hiPSC-CM were used for each culture conditions. During dissociation, we performed a small mechanical friction after $1.5 \mathrm{~h}$ and $3 \mathrm{~h}$. After the enzymatic digestion, we plated the cardiomyocytes on gelatine-coated (0.1\%) glass coverslips (12 mm diameter, Carl Roth GmbH+Co, Karlsruhe, Germany). The cells were used in maximum 48 hours after the plating for patch clamp experiments, to avoid changes in morphology and ion currents due to culture conditions as much as possible.

\subsection{Inward rectifier potassium current recordings in hiPSC-CM}

Inward rectifiers were measured at room temperature (RT), using the whole-cell configuration of the patch clamp technique. Axopatch 200B amplifier (Axon Instruments, Foster City, CA, USA) and ISO2 software were used for data acquisition and analysis (MFK, Niedernhausen, Germany). Heat-polished pipettes were pulled from borosilicate filamented glass (Hilgenberg, Malsfeld, Germany). Tip resistances were 2.5-5 M $\Omega$, seal resistances were 2-4 G $\Omega$. The cell-containing coverslips were settled into a small perfusion chamber, placed on the stage of an inverse microscope. An agarose bridge was placed into a solution containing high KCL to minimize the liquid junction potential. During the measurements, the 
following external solution was used (in mM): $\mathrm{NaCl} 120, \mathrm{KCl} 20$, HEPES 10, $\mathrm{CaCl}_{2} 2, \mathrm{MgCl}_{2}$ 1 and glucose 10 ( $\mathrm{pH} 7.4$, adjusted with $\mathrm{NaOH}$ ). Contaminating $\mathrm{Ca}^{2+}$ currents were inhibited with the selective L-type calcium channel blocker nifedipine $(10 \mu \mathrm{M})$. The internal solution for measuring $\mathrm{I}_{\mathrm{K} 1}$ and $\mathrm{I}_{\mathrm{K}, \mathrm{ACh}}$ included the following (in $\mathrm{mM}$ ): DL-Aspartate potassium salt 80, $\mathrm{KCl}$ 40, $\mathrm{NaCl}$ 8, HEPES 10, Mg-ATP 5, Tris-GTP 0.1, EGTA 5 and $\mathrm{CaCl}_{2}$ 2, pH 7.4, adjusted with $\mathrm{KOH}$. Inward current amplitudes were determined as currents at $-100 \mathrm{mV}$. A single concentration $(2 \mu \mathrm{M})$ of the muscarinic receptor agonist carbachol $(\mathrm{CCh})$ was used to evoke $\mathrm{I}_{\mathrm{K}, \mathrm{ACh}}$.

\subsection{Current clamp recordings in hiPSC-CM}

Action potentials were recorded using the perforated patch (Amphotericin B) configuration of the patch clamp technique. We switched the Axopatch 200B (Axon Instruments, Foster City, CA, USA) to current clamp mode. The experiments were performed at $37^{\circ} \mathrm{C}, 1 \mathrm{~Hz}$, using the following external solution (in $\mathrm{mM}$ ): $\mathrm{NaCl} 120, \mathrm{KCl} 5.4$, HEPES 10, $\mathrm{CaCl}_{2} 2, \mathrm{MgCl}_{2} 1$ and glucose $10(\mathrm{pH} 7.4$, adjusted with $\mathrm{NaOH}$ ). The internal solution was (in $\mathrm{mM}$ ): DL-aspartate potassium salt 80, $\mathrm{KCl}$ 40, $\mathrm{NaCl}$ 8, HEPES 10, Mg-ATP 5, Tris-GTP 0.1,

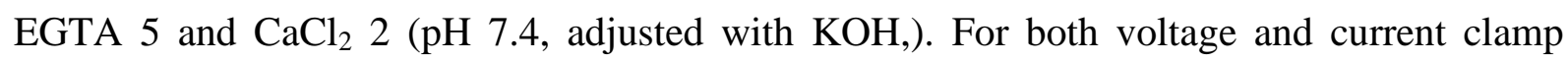
recordings, the liquid junction potential was calculated to $-12 \mathrm{mV}$, using the JPCalcW software (SDR Scientific, Sydney, Australia). To reach the perforated patch configuration the tip of the pipettes were filled with the internal solution complemented with $20 \mu \mathrm{g} / \mathrm{ml}$ Amphotericin B. The perforated patch configuration was reached in a few minutes after gigaseal formation. In action potential recordings the repolarization fraction was calculated by the following way: $\left(\mathrm{APD}_{50}-\mathrm{APD}_{90}\right) / \mathrm{APD}_{90}[58]$.

\subsection{Sharp microelectrode recordings in hiPSC-CM}

We used the sharp microelectrode technique to record action potentials from right atrial and left ventricular trabeculae and from intact EHT. The tip resistance of the microelectrodes were between 20 and $50 \mathrm{M} \Omega$ (when filled with $3 \mathrm{mM} \mathrm{KCl}$ ). Action potentials were elicited by field stimulation at $1 \mathrm{~Hz}$ : $0.5 \mathrm{~ms}$ stimulus, $50 \%$ above threshold intensity. The following bath solution was used (in mM): $\mathrm{NaCl} 125, \mathrm{KCl} 5.4, \mathrm{MgCl}_{2}$ 0.6, $\mathrm{CaCl}_{2} 1, \mathrm{NaH}_{2} \mathrm{PO}_{4} 0.4, \mathrm{NaH}_{2} \mathrm{CO}_{3}$ 22, and glucose 5.5 and was equilibrated with $\mathrm{O}_{2}-\mathrm{CO}_{2}$ (95:5). The experiments were performed at $37^{\circ} \mathrm{C}$. 


\subsection{Quantification of transcript levels}

The RNeasy® Plus Mini Kit (Qiagen, Venlo, The Netherlands) was used to isolate total RNA from human heart tissue, cardiomyocytes cultured in ML and dissociated EHT. For quantification of transcript levels, cDNA was generated using the High-Capacity cDNA Reverse Transcription Kit (Applied Biosystems). Quantitative PCR was performed with the 5x HOT FIREPol® EvaGreen ${ }^{\circledR}$ qPCR Mix Plus (ROX) (Solis BioDyne, Tartu, Estonia) on ABI PRISM 7900HT Sequence detection system (Applied Biosystems, Foster City, California, USA). Relative transcript levels were calculated using the $\Delta \mathrm{CT}$-method with glucuronidase beta (Gusb) as a housekeeping gene.

\subsection{Animals and ethical considerations}

New Zealand White rabbits were obtained from Tetrabbit Kft. (Hungary). The animals, which were used during the experiments, were young adults (approximately $3.5 \mathrm{~kg}$ ) of either sex, unless otherwise indicated. The animals were kept in stainless steel rabbit cages containing an elevated resting place. These parameters are fulfilling the requirements of authorities in terms of size and environmental enrichment. Rabbits were individually housed and were kept at standard temperature, humidity and lighting. Food and water were provided ad libitum. The water was provided in separate drinking bowls allowing each animal to access it. The water was regularly checked for quality and any pathogens. Collection of zygotes and laparoscopic transfer of injected embryos to recipient rabbits was performed as described earlier [59]. Pseudo pregnant animals were moved to a nesting cage 3-4 days before expected delivery date. The rabbits were anaesthetized with ketamine-S/xylazine i.m. (12.5 and 3.5 $\left.\mathrm{mg} / \mathrm{kg}^{-1}\right)$ or thiopental $\left(50 \mathrm{mg} / \mathrm{kg}^{-1}\right)$ through marginal ear vein during in vivo ECG studies. At the end of the arrhythmia provocation experiments, the anaesthetized animals were sacrificed by i.v. administration of pentobarbital sodium (RELEASE) in a dose of $300 \mathrm{mg} / \mathrm{mL}$. All animal care and experimental protocols complied with the Guide for the Care and Use of Laboratory Animals (USA NIH publication NO85-23, revised 1996) and conformed to the Directive 2010/63/EU of the European Parliament; they were approved by the Animal Care and Ethics Committee of the Agricultural Biotechnology Centre and the Ethical Committee for the Protection of Animals in Research of the University of Szeged (approval number: I74-5-2012) and by the Department of Animal Health and Food Control of the Ministry of Agriculture and Rural Development (authority approval numbers 22.1/433/003/2010 and 
XIII/1211/2012). Animal studies are reported in compliance with the ARRIVE guidelines [60] and the editorial on reporting animal studies [61].

\subsection{Creation of LQT5-TG rabbits}

The KCNE1 coding region of the transgene was amplified and analysed by automated sequencing. The MYH7- G52R-KCNE1-bGHpolyA insert was isolated and used to microinject rabbit embryos [62]. Out of 497 injected embryos, 466 were transferred into 21 pseudo pregnant recipients through laparoscopy. Thirty-eight offspring (8\%) were born alive, out of which four (10\%) were transgenic by genomic PCR. Three founders lived till sexual maturity. The female founder did not transmit the transgene to its offspring, suggesting that it was transgenic in somatic tissues but not the germ line. The remaining two transgenic founder males (\# G52R-JTJKK and \#G52R-JKK) transmitted the transgene to their offspring from wild-type (WT) does at 52\% (in the G52R-JTJKK line) and 15\% (in the G52R-JKK line) ratio, respectively, which in case of the G52R-JTJKK founder underlines a Mendelian type inheritance. For the \#G52R- JKK founder, the transgene transmission data indicate a high degree of germ-line mosaicism. Therefore, except where it is otherwise indicated, for electrophysiological examinations, the F1 hemizygote offsprings of \#G52R-JTJKK line were used and are called transgenic animals in the figures. The presence of G52R mutation was checked by sequencing the PCR product isolated from genomic DNA of the founder male \#G52R-JTJKK. In the \#G52R-JTJKK animal, the transgene was integrated at $\Sigma 10$ copies in two different loci on Chr11, namely at positions chr11:18,313,856 and chr11:41,935,523.

\subsection{Isolation of rabbit ventricular myocytes}

Single ventricular myocytes were isolated enzymatically from the left ventricle of WT and LQT5-TG rabbit hearts. Following heparin administration $\left(400 \mathrm{NE} / \mathrm{kg}^{-1}, i . v\right.$.), sedation with xylazine $\left(1 \mathrm{mg} / \mathrm{kg}^{-1}, i . v\right.$. $)$ and thiopental $\left(30 \mathrm{mg} / \mathrm{kg}^{-1}, i . v\right.$. $)$ induced anaesthesia, each heart was rapidly removed through a right lateral thoracotomy and placed into cold $\left(4-8{ }^{\circ} \mathrm{C}\right)$ solution which contained (in $\mathrm{mM}$ ): $\mathrm{NaCl} 135, \mathrm{KCl}$ 4.7, $\mathrm{KH}_{2} \mathrm{PO}_{4}$ 1.2, $\mathrm{MgSO}_{4}$ 1.2, HEPES 10, $\mathrm{NaHCO}_{3} 4.4$, glucose 10 , taurine $20, \mathrm{CaCl}_{2}$ 1, (pH 7.2). The heart was then mounted on a modified, $60 \mathrm{~cm}$ high Langendorff column and perfused with oxygenated perfusate of the same composition warmed to $37^{\circ} \mathrm{C}$. After $3-5 \mathrm{~min}$ of perfusion to flush blood from the coronary vasculature, the perfusate was switched to one having no exogenously added calcium (i.e. to one that was nominally $\mathrm{Ca}^{2+}$-free) until the heart ceased to contract $(\sim 8-10$ 
min). For Enzymatic digestion the heart was perfused with a $\mathrm{Ca}^{2+}$-free solution containing $290 \mathrm{U} / \mathrm{mL}^{-1}$ collagenase type II (Worthington, Biochemical Corp. Lakewood, NJ, USA) and $30 \mu \mathrm{M} \mathrm{CaCl}_{2}$. After 10-15 min perfusion, the heart was removed from the aortic cannula and placed into enzyme-free solution containing $1 \mathrm{mM} \mathrm{CaCl}_{2}$ warmed to $37^{\circ} \mathrm{C}$ for $10 \mathrm{~min}$. After that the tissue was chopped into small pieces, and following a gentle agitation, myocytes were separated by filtering the resulting slurry through a nylon mesh. Myocytes were finally harvested by gravity sedimentation. Once the majority of individual myocytes settled to the bottom of the container, the supernatant was decanted and replaced with Tyrode's solution, and the myocytes were re-suspended by gentle agitation. This procedure was repeated twice more, and the resulting myocyte suspension was stored in HEPES-buffered Tyrode's solution at RT.

\subsection{Voltage-clamp measurements on rabbit ventricular cardiomyocytes}

The freshly isolated cardiomyocytes were placed into a transparent recording chamber mounted on the stage of an inverted microscope (Olympus IX51, Tokyo, Japan). The cells were superfused with a perfusion system maintained by gravity. Only rod-shaped cells with clear striations were used. For the recordings a HEPES-buffered Tyrode's solution (composition in mM: $\mathrm{NaCl} 144, \mathrm{NaH}_{2} \mathrm{PO}_{4}$ 0.4, $\mathrm{KCl} 4.0, \mathrm{CaCl}_{2} 1.8, \mathrm{MgSO}_{4} 0.53$, glucose 5.5 and HEPES 5.0, at $\mathrm{pH}$ of 7.4) was used as an external solution. Micropipettes were pulled from borosilicate glass capillaries (Science Products GmbH, Hofheim, Germany), using a P97 Flaming/Brown micropipette puller (Sutter Co, Novato, CA, USA), with a tip resistance of 1.5-2.5 M $\Omega$. The glass electrodes were filled with the following internal solution (in $\mathrm{mM}$ ): $\mathrm{KOH} \mathrm{110,} \mathrm{KCl} 40, \mathrm{~K}_{2} \mathrm{ATP} 5, \mathrm{MgCl}_{2}$ 5, EGTA 5, GTP 0.1 and HEPES 10, pH was adjusted to 7.2 by aspartic acid. Transmembrane ion currents were recorded using the whole cell configuration of the patch clamp technique. Axopatch-200B amplifiers (Molecular Devices, Sunnyvale, CA, USA) were used for the recordings and the membrane currents were digitized with $250 \mathrm{kHz}$ analogue to digital converters (Digidata 1440A, Molecular Devices, Sunnyvale, CA, USA) under software control (pClamp 8 and pClamp 10, Molecular Devices, Sunnyvale, CA, USA).

The inward rectifier $\left(\mathrm{I}_{\mathrm{K} 1}\right)$, transient outward $\left(\mathrm{I}_{\mathrm{to}}\right)$, rapid $\left(\mathrm{I}_{\mathrm{Kr}}\right)$ and slow $\left(\mathrm{I}_{\mathrm{Ks}}\right)$ delayedrectifier potassium currents were studied in rabbit ventricular myocytes. Nisoldipine $(1 \mu \mathrm{M})$, was used to block $\mathrm{I}_{\mathrm{Ca}, \mathrm{L}}$. During $\mathrm{I}_{\mathrm{Kr}}$ measurements, $\mathrm{I}_{\mathrm{Ks}}$ was inhibited by the selective blocker 
HMR $1556(0.5 \mu \mathrm{M})$. Dofetilide $(0.5 \mu \mathrm{M})$ was used to block $\mathrm{I}_{\mathrm{Kr}}$, when $\mathrm{I}_{\mathrm{Ks}}$ was investigated.. The external solution contained $0.1 \mu \mathrm{M}$ forskolin. All experiments were performed at $37^{\circ} \mathrm{C}$.

\subsection{ECG recording and evaluation}

Rabbits were anaesthetized either with ketamine-S/xylazine i.m. (12.5 and $\left.3.5 \mathrm{mg} \cdot \mathrm{kg}^{-1}\right)$ or thiopental $\left(50 \mathrm{mg} \cdot \mathrm{kg}^{-1}\right)$ with injection through the marginal ear-vein. A catheter was inserted into the carotid artery for blood-pressure measurement. The right jugular vein was cannulated for i.v. drug administration. Blood pressures and electrocardiograms were continuously recorded, digitized and stored for off-line analysis. RR and QT intervals were measured as the average of 30 beats. For QT-interval measurements, published guidelines were followed [63]. The frequency-corrected QT interval $\left(\mathrm{QT}_{\mathrm{c}}\right)$ was calculated by a specific formula for thiopental-anaesthetized rabbits [64]: $\mathrm{QT}_{\mathrm{c}}=\mathrm{QT}-[0.704 *(\mathrm{RR}-250)] . \quad$ In ketamine/xylazine anaesthetized animals, heart rate-corrected QT-indices were calculated as: $\left.\mathrm{QT}_{\mathrm{i}}(\%)=\mathrm{QT}_{\text {measured }} * 100 / \mathrm{QT}_{\text {expected }} ; \mathrm{QT}_{\text {expected }}=86+0.22 * \mathrm{RR}\right)$ as described previously [50]. I.v. infusions were administered with a programmable infusion pump (Terufusion TE-3, Terumo Europe, Leuven, Belgium). Both WT and LQT5-TG rabbits received dofetilide (20 $\mu \mathrm{g} / \mathrm{kg}^{-1}$ ) over $10 \mathrm{~min}$.

\subsection{Short-term variability of $R R$ and QT intervals}

The short-term beat-to-beat variability of the QT interval was calculated to predict arrhythmia-propensity in animal models $[65,66]$ and patients $[67,68]$ reliably. Poincaré plots were constructed by plotting all RR and QT values against their preceding values (Figure 17) to characterize the temporal instability of beat-to-beat heart rate and repolarization. In case of $T d P$ arrhythmia, the measurements were taken prior to $T d P$. Beat-to-beat short-term variability (STV) of RR or QT intervals was calculated as: STV $=\sum\left|\mathrm{Dn}_{+1}-\mathrm{Dn}\right|(30 \mathrm{x} \sqrt{2})^{-1}$, with D the duration of QT or RR interval. STV represents the mean orthogonal distance to the line of identity on the Poincaré plot; the estimation of beat-to-beat instability of RR and QT intervals is as described previously [69]. 


\subsection{Statistical analysis}

Data are shown as means \pm SEM. For graphical and statistical data analysis the ORIGIN 8.1 (Microcal Software, Northampton, MA, USA) and the GraphPad Prism Software 5.02 (GraphPad Software, San Diego, CA, USA) were used. Statistical differences were evaluated by using the Student's t-test (paired or unpaired) or repeated measures ANOVA, followed by Bonferroni test, where appropriate. Linear correlations, concentration-response curves were fitted to mean data points and $-\log \mathrm{IC}_{50}$ values were compared by F-test using the GraphPad Prism Software 5.02. R software (ver. 3.3.1, R Core Team, 2013) was used for the analysis of frequency distribution. Please note that the statistical term "Kernel density estimation" is used in Figure 12, with, a "kernel" defined as a probability density function which must possess the following properties: even non-negative, real-valued and its definite integral over its support set must equal to 1 . Therefore, "kernel density estimation" is a non-parametric method, which allows estimating the probability density function of a random variable (http://scikit-learn.org/ stable/modules/density.html). Differences were considered significant when $\mathrm{P}<0.05$.

\subsection{Drugs and chemicals}

All drugs and chemicals were obtained from Sigma-Aldrich (St. Louis, Missouri, USA), except for dofetilide (Sequoia Research Products Ltd., Pangbourne, UK and Gedeon Richter Ltd., Budapest, Hungary) and nisoldipine (gift from Bayer AG, Leverkusen, Germany).

\section{Results}

\section{Inward rectifiers and RMP in hiPSC cardiomyocytes}

\section{1 hiPSC-CM can possess large inward rectifier potassium currents}

Inward rectifiers were measured with a classical ramp protocol (Figure 5B, inset). To activate larger inward currents, we applied $20 \mathrm{mM}$ extracellular potassium (Figure 5A, B) [70]. It has been reported that applying higher external $\mathrm{K}^{+}$concentration can reduce leakage and improve the stability of the measurements [71]. In every CM (LV and RA) and hiPSCCM from both ML and EHT, inward rectifiers could be observed (Figure 5C). High 
concentration of $\mathrm{Ba}^{2+}$ blocked the inward rectifier current in every CM (ML, EHT, RA and LV).

A
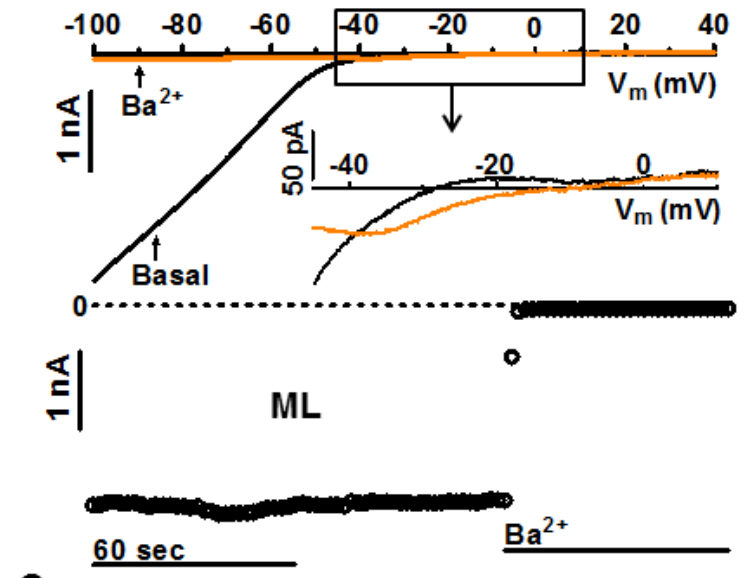

c

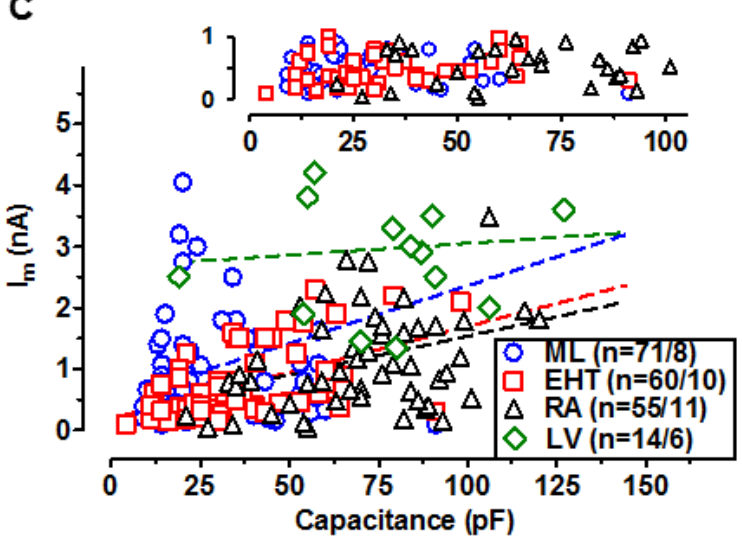

B
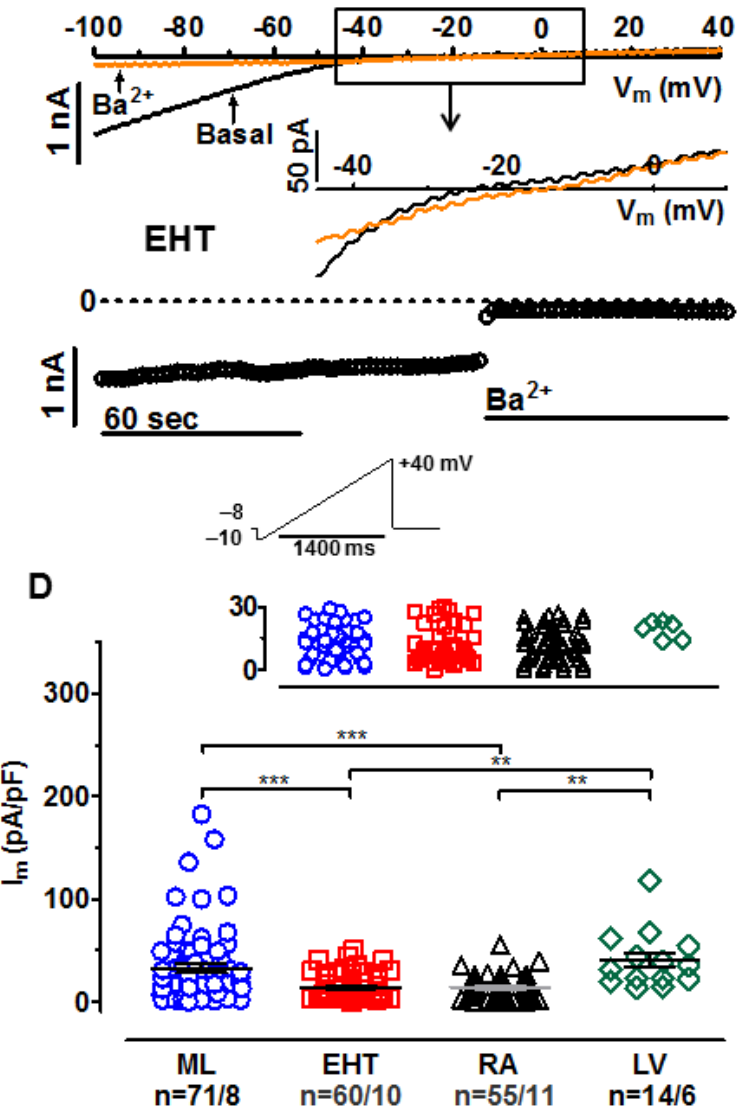

Figure 5. Cell size and inward rectifier potassium current $\left(\mathrm{I}_{\mathrm{K} 1}\right)$ in hiPSC-CM from ML, EHT, RA and LV. A, B: Original traces of and time courses of $\mathrm{I}_{\mathrm{K} 1}$ currents at $-100 \mathrm{mV}$ in hiPSC-CM obtained from ML and EHT exposed to $1 \mathrm{mM} \mathrm{Ba}^{2+}$. Voltage protocol is given as inset in $\mathbf{B}$. C: $\mathrm{Ba}^{2+}$-sensitive $\mathrm{I}_{\mathrm{K} 1}$ current amplitudes measured at $-100 \mathrm{mV}$ plotted against cell capacitance; dotted lines indicate linear regression fit $\left(\mathrm{R}^{2}\right.$ values were: 0.1 for ML, 0.28 for EHT, 0.15 for RA and 0.007 for LV. D: Individual data points and respective mean values \pm SEM for $\mathrm{Ba}^{2+}$-sensitive $\mathrm{I}_{\mathrm{K} 1}$ current densities measured at $-100 \mathrm{mV}$ in hiPSC-CM from ML, EHT and in $\mathrm{CM}$ from RA, and LV $* \mathrm{P}<0.05$, $* * \mathrm{P}<0.01, * * * \mathrm{P}<0.001$ (One-way ANOVA followed by Bonferroni test). $\mathrm{n} / \mathrm{n}=$ number of experiments/number of isolations in hiPSC-CM and number of experiments/number of patients in RA and LV.

Inward current amplitudes were plotted vs. cell capacitance to test if larger cells show more mature phenotype with higher $\mathrm{I}_{\mathrm{K} 1}$ (Figure 5C). As shown before [36,72], hiPSC-CM, isolated from ML or EHT, were smaller than CM from RA or LV $(30.8 \pm 1.5 \mathrm{pF}, \mathrm{n}=167$ in ML, 47.0 $\pm 1.7 \mathrm{pF}, \mathrm{n}=260$ in EHT, $73.6 \pm 4.0 \mathrm{pF}, \mathrm{n}=55$ in RA, $88.8 \pm 13.2 \mathrm{pF}, \mathrm{n}=15$ in LV). Only a weak positive association could be seen between current amplitude and cell membrane capacitance $\left(\mathrm{C}_{\mathrm{m}}\right)$. The steepness of the regression lines was low in all groups and did not differ between hiPSC-CM and human adult $\mathrm{CM}$ (Figure $5 \mathrm{C}, \mathrm{p}=0.6$, one-way ANOVA). 
Statistical significance for slope different from zero was reached only in ML, EHT and RA $\left(\mathrm{R}^{2}\right.$ values were 0.09 for ML, 0.28 for EHT and 0.14 for RA). This argues against the assumption that smaller hiPSC-CM represent a more immature phenotype with smaller $\mathrm{I}_{\mathrm{K} 1}$ current amplitude. To have a direct comparison with previous reports, we normalized current amplitudes to cell size. The density of the current in ML did not differ significantly from LV (Figure 5D). $\mathrm{I}_{\mathrm{K} 1}$ density in EHT was smaller than in ML and LV, but was comparable to the density found in RA (Figure 5D). Thus, $\mathrm{I}_{\mathrm{K} 1}$ current densities in hiPSC-CM were not lower than in human adult CM, when the same experimental conditions were used.

\section{2 $I_{K 1}$ in hiPSC-CM is conducted via highly $\mathrm{Ba}^{2+}$-sensitive Kir channels}

The channel conducting $\mathrm{I}_{\mathrm{K} 1}$ exists as a tetramer assembled from different $\alpha$-subunits (Kir2.1-2.4) [39]. There is a difference in $\mathrm{Ba}^{2+}$-sensitivity of the channel forming subunits of $\mathrm{I}_{\mathrm{K} 1}[73,74]$. Cardiac myocytes express Kir2.1, 2.2 and 2.3, which are highly sensitive to $\mathrm{Ba}^{2+}$ (in the low $\mu \mathrm{M}$ range) [74]. Kir2.4 exhibits lower $\mathrm{Ba}^{2+}$-sensitivity, and it is expressed in neuronal tissue only [73]. To test if $\mathrm{I}_{\mathrm{K} 1}$ in hiPSC-CM is conducted by the cardiac subunits, concentration-response curves were measured for $\mathrm{Ba}^{2+}$-block on the inward $\mathrm{I}_{\mathrm{K} 1}$ current (Figure 7A). The concentration-response curve was monophasic, arguing against the contribution of Kir2.4 in hiPSC-CM (Figure 7B). $\mathrm{I}_{\mathrm{K} 1}$ in hiPSC-CM from both culture conditions showed higher $\mathrm{Ba}^{2+}$-sensitivity than in RA: the $\log \mathrm{IC}_{50}$ values for $\mathrm{Ba}^{2+}$ were -6.09 (95\% confidence interval (CI: -6.27 to -5.91 ) in ML, vs. -6.15 (CI: -6.32 to -5.99 ) in EHT, vs. -5.66 in RA (CI -5.92 to $-5.41, \mathrm{p}<0.01$, F-test for ML vs. RA and for EHT vs. RA, Figure 7B). We found the same during RT-qPCR measurements, which confirms that the cardiac isoforms of the Kir channels (2.1-2.3) are expressed in hiPSC-CM (Figure 6A, B and C), while Kir2.4 is not (Figure 6D). 
A

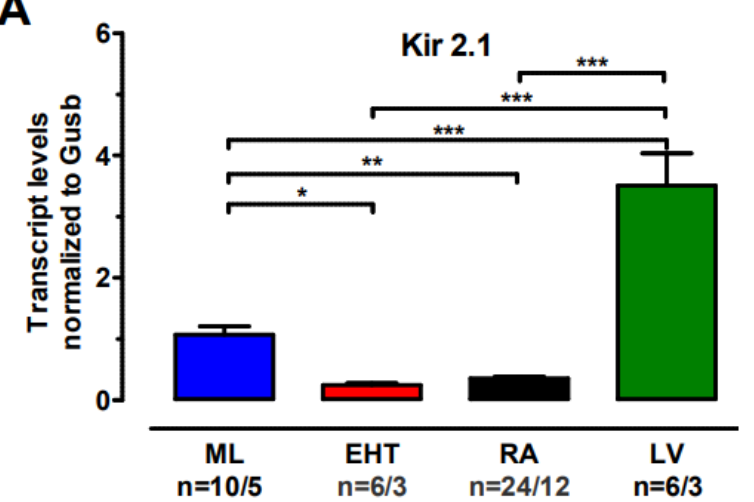

C

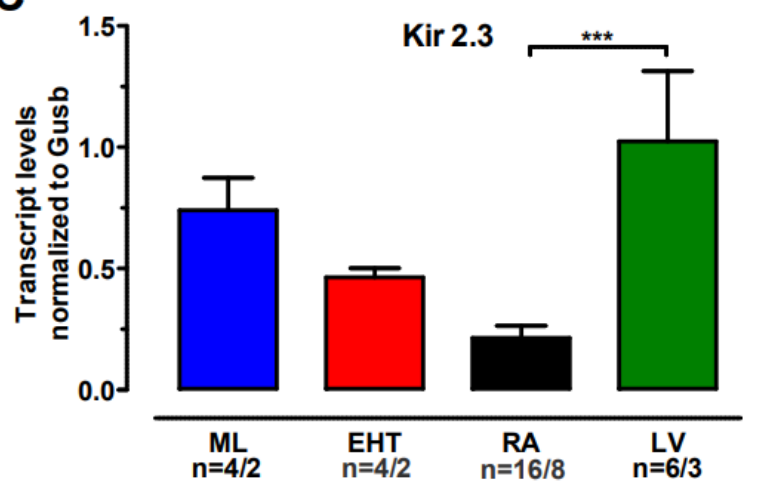

B

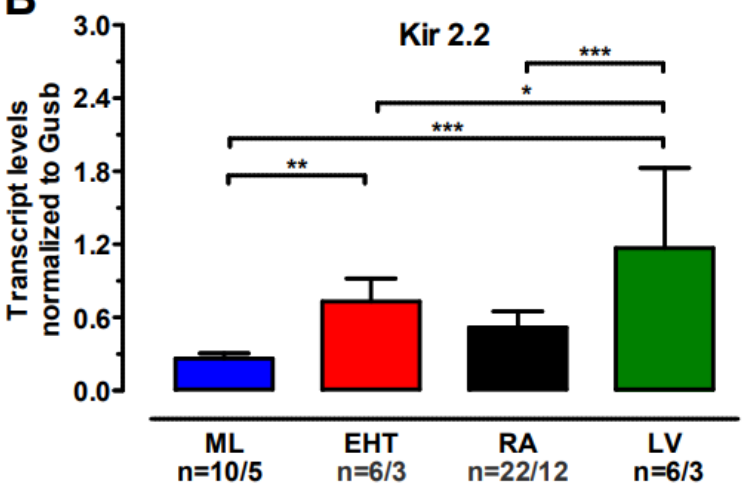

D

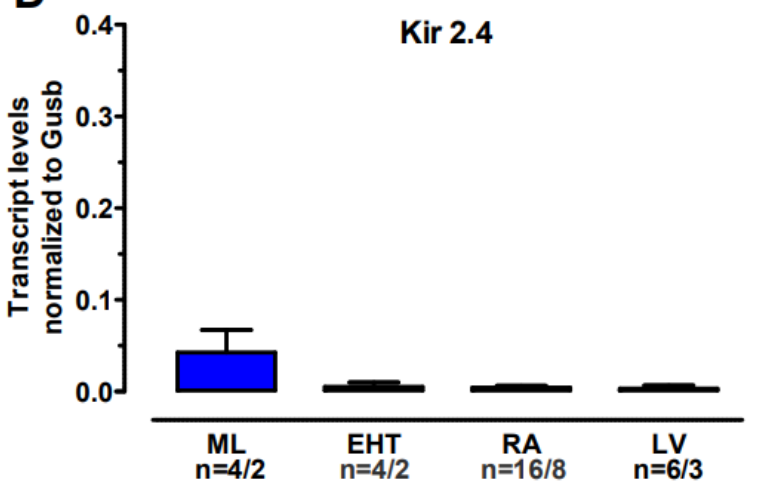

Figure 6. Expression of $I_{K 1}$ channel forming subunits in hiPSC-CM and human adult $C M$.

A, B, C, and D: Transcript levels of $I_{K 1}$ channel-forming subunits Kir 2.1, 2.2, 2.3 and Kir2.4 were normalized to housekeeping gene (GUSB). ${ }^{*} \mathrm{P}<0.05, * * \mathrm{P}<0.01,{ }^{*} * * \mathrm{P}<0.001$ (One-way ANOVA followed by Bonferroni test). $n / n=n u m b e r$ of experiment/number of isolations in hiPSC-CM and number of experiment/number of patients in RA and LV.

\subsection{The outward $I_{K 1}$ is small in hiPSC-CM}

In cardiac myocytes, the outward component of $\mathrm{I}_{\mathrm{K} 1}$ (the $\mathrm{K}^{+}$-conductance in outward direction) contributes to the final phase of the repolarization [75]. Therefore, maximum outward current density of $\mathrm{I}_{\mathrm{K} 1}$ was measured during ramp pulses (Figure $7 \mathrm{C}$ ). In line with the previous findings, in human $\mathrm{CM}$, the outward $\mathrm{I}_{\mathrm{K} 1}$ current density was lower than the inward branch and smaller in human atrial than in ventricular $\mathrm{CM}(0.7 \pm 0.25 \mathrm{pA} / \mathrm{pF}$ vs. $1.7 \pm 0.6$ $\mathrm{pA} / \mathrm{pF}, \mathrm{n}=16$ and 13, Figure 7D). 
A

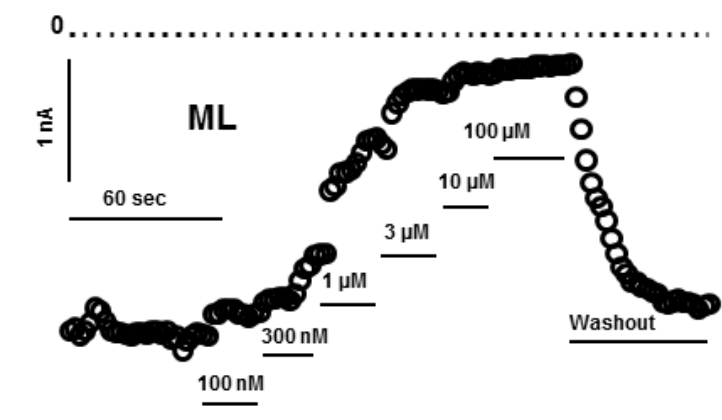

C

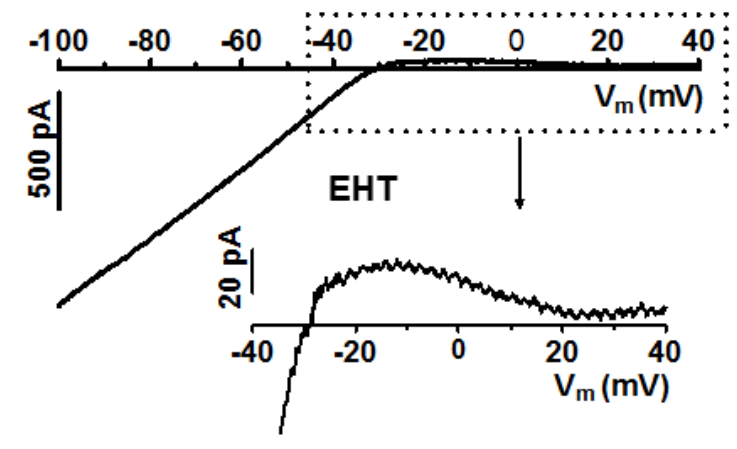

B

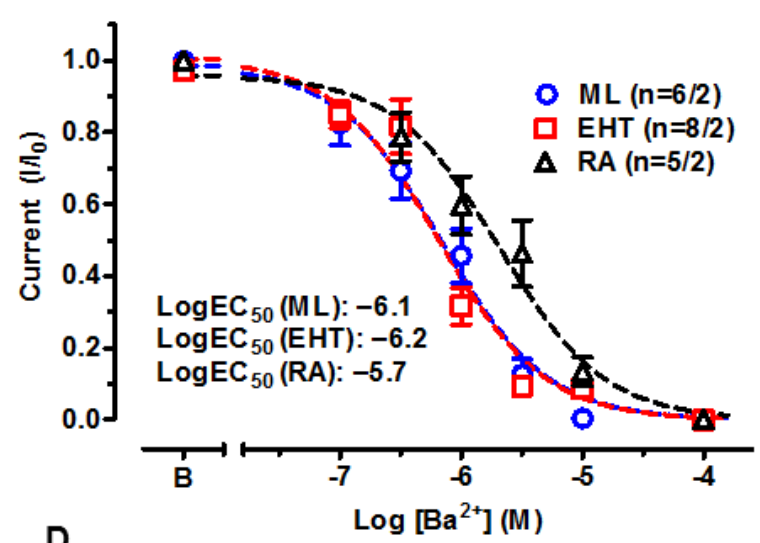

D

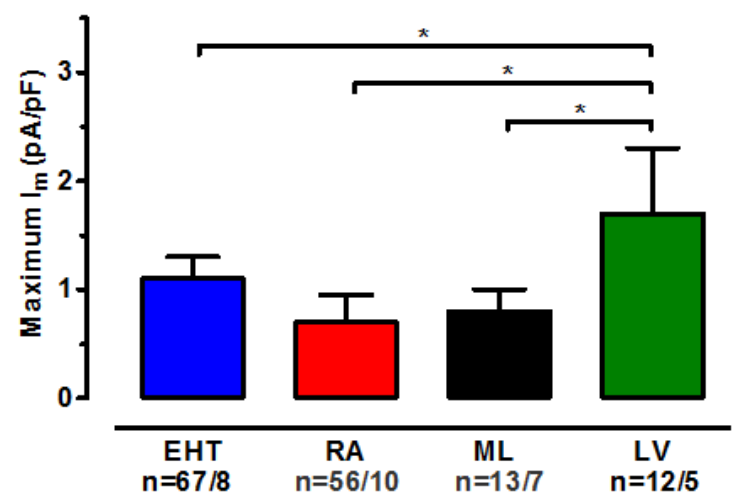

Figure 7. $\mathrm{Ba}^{2+}$-sensitivity and outward component of $\mathrm{I}_{\mathrm{K} 1}$ in hiPSC-CM and human adult $\mathrm{CM}$.

A: Time course of inward currents measured at $-100 \mathrm{mV}$ in a hiPSC-CM from ML exposed to increasing concentrations of $\mathrm{Ba}^{2+} . \mathbf{B}$ : Concentration-response curves for $\mathrm{Ba}^{2+}$ on inward current at $-100 \mathrm{mV}$ in hiPSC-CM from ML, EHT and in CM from RA. Mean values \pm SEM. C: $\mathrm{Ba}^{2+}$-sensitive current trace from hiPSC-CM from ML. Outward component of current given on an extended scale on top. D: Mean values \pm SEM of maximum outward peak currents in hiPSC-CM from ML, EHT and in CM from RA and LV. $n / n=$ number of experiment/number of isolations in hiPSC-CM and number of experiment/number of patients in RA and LV.

The outward component of $\mathrm{I}_{\mathrm{K} 1}$ in hiPSC-CM was as small as in RA $(1.1 \pm 0.2 \mathrm{pA} / \mathrm{pF}$, $\mathrm{n}=67$ in ML, $0.8 \pm 0.2 \mathrm{pA} / \mathrm{pF}, \mathrm{n}=56$ in EHT, Figure 7D). Thus, hiPSC-CM from both ML and EHT showed small outward contribution of $\mathrm{I}_{\mathrm{K} 1}$ as known for human adult $\mathrm{CM}$. The finding that hiPSC-CM have small outward $\mathrm{I}_{\mathrm{K} 1}$ suggests stronger APD prolongation upon block of $\mathrm{I}_{\mathrm{Kr}}$ [75]. Therefore, prediction of QT-prolongation in human by hERG-blockers could be more meaningful, when hiPSC-CM are used instead of canine or rabbit. Further studies are needed to investigate whether hiPSC-CM quantitatively reflect the repolarization reserve in human heart. 


\subsection{Acetylcholine-activated potassium currents ( $\left.\mathrm{I}_{\mathrm{K}, \mathrm{ACh}}\right)$ are not expressed in hiPSC- CM}

A

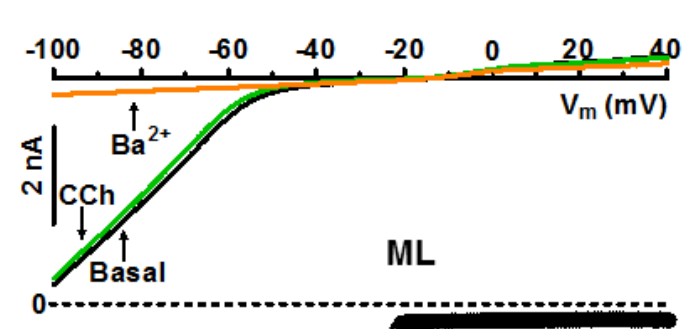

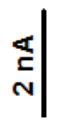

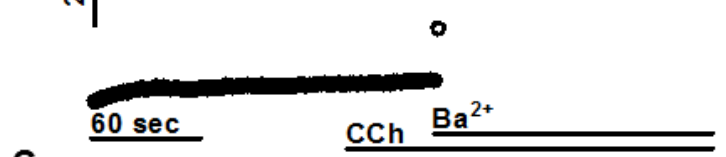

C
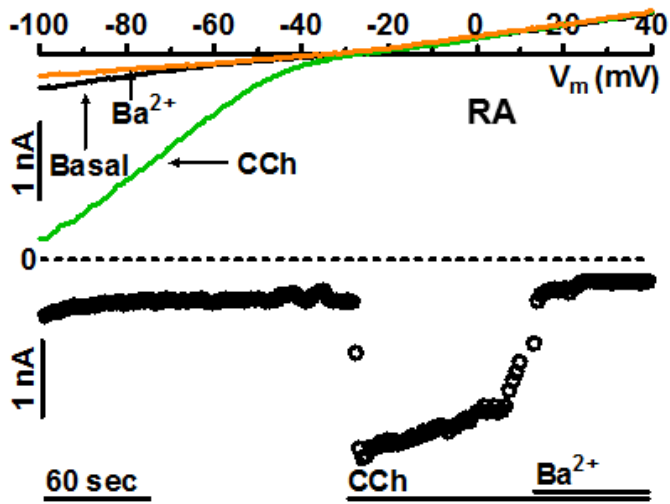

B
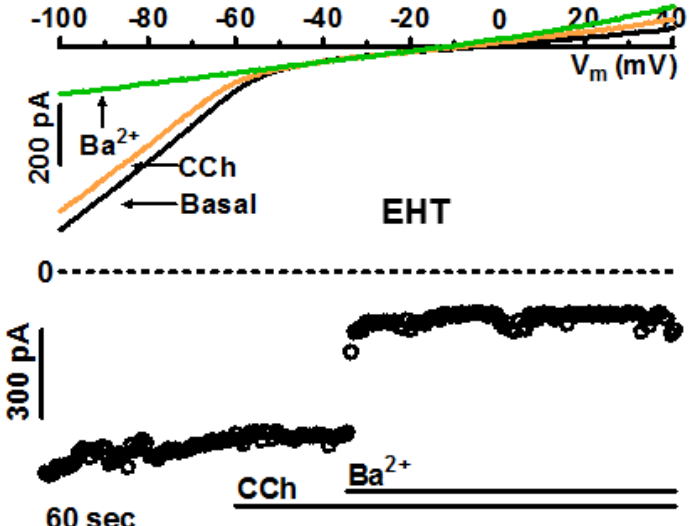

D

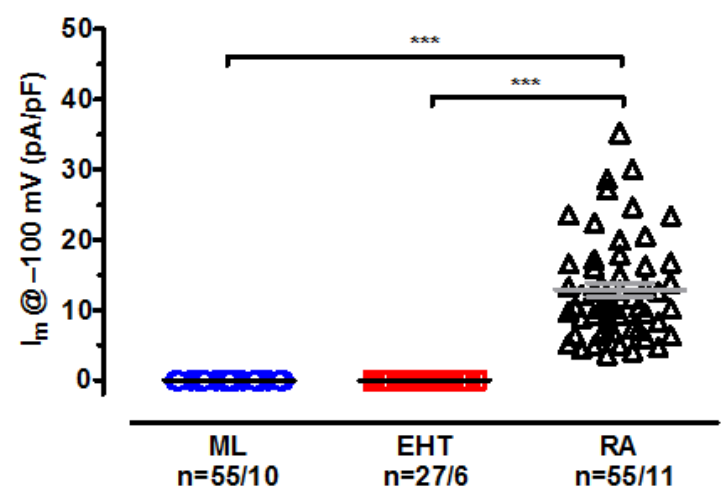

Figure 8. Lack of carbachol effect on inward rectifier in hiPSC-CM.

A: Original traces of inward rectifier currents and time courses of current at $-100 \mathrm{mV}$ in hiPSC-CM obtained from ML exposed to carbachol $(\mathrm{CCh}, 2 \mu \mathrm{M})$. B: CCh effect expressed as absolute current change in response to CCh $(2 \mu \mathrm{M})$ in ML, EHT and in CM from RA. Individual data points and mean values \pm SEM. C: Transcript levels of $\mathrm{I}_{\mathrm{K} . \mathrm{ACh}}$ channel-forming subunits Kir 3.1 and Kir 3.4 in ML, EHT, RA and LV *P<0.05, ** $\mathrm{P}<0.01$, $* * * \mathrm{P}<0.001$ (One-way ANOVA followed by Bonferroni test). $n / n=$ number of experiment/number of isolations in hiPSC-CM and number of experiment/number of patients in RA and LV.

$\mathrm{I}_{\mathrm{K}, \mathrm{ACh}}$ current is typically expressed in atrial tissue [76]. To activate $\mathrm{I}_{\mathrm{K}, \mathrm{ACh}}$, the muscarinic (M2) receptor agonist carbachol (CCh, $2 \mu \mathrm{M})$ was applied during the measurements (Figure 8A and B). In RA-CM, CCh activated a large inward current (Figure 8C and D), which was not present in hiPSC-CM (ML and EHT, Figure 8A, B and D). On the expression level, large expression of Kir3.1 was found in RA, but not in LV, ML or EHT (Figure 9A). Interestingly, Kir3.4 was expressed in hiPSC-CM under both culture conditions at least as high as in RA (Figure 9B).This finding suggests that expression of Kir3.4 in hiPSCCM alone cannot generate $I_{K, A C h}[39]$. The lack of $I_{K, A C h}$ indicates that hiPSC-CM did not exhibit an atrial phenotype. 
A

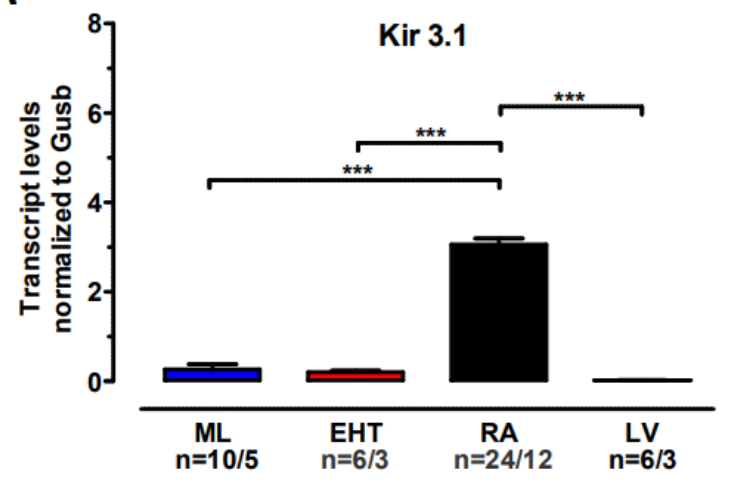

B

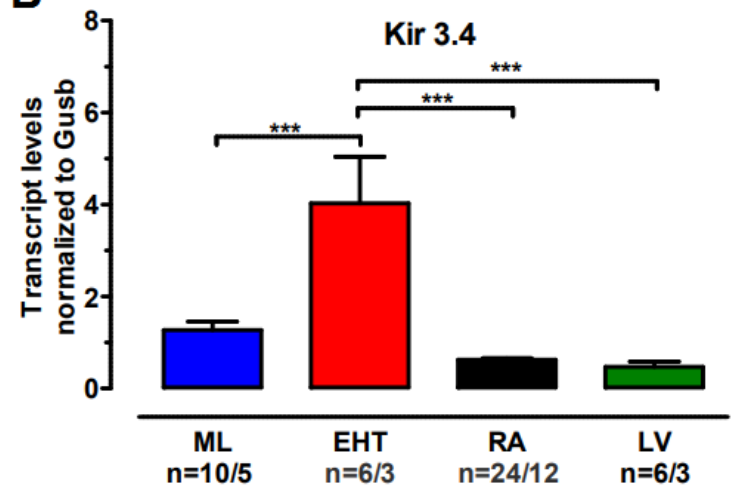

Figure 9. Expression of $\mathrm{I}_{\mathrm{K}, \mathrm{ACh}}$ channel forming subunits in hiPSC-CM and human adult CM.

A, B: Transcript levels of $I_{K . A C h}$ channel-forming subunits Kir 3.1 and Kir 3.4 were normalized to housekeeping gene (Gusb). $* \mathrm{P}<0.05, * * \mathrm{P}<0.01, * * * \mathrm{P}<0.001$ (One-way ANOVA followed by Bonferroni test). $\mathrm{n} / \mathrm{n}=$ number of experiment/number of isolations in hiPSC-CM and number of experiment/number of patients in RA and LV.

\subsection{RMP and AP measurements in single cells and intact tissues}

To decide whether the relatively normal $\mathrm{I}_{\mathrm{K} 1}$ densities observed in hiPSC-CM result in physiological RMP, action potentials were measured in isolated CM by patch clamp technique (Figure 10, left column titled "Patch"). The RMP was low in hiPSC-CM when patch clamp electrodes were applied $(-39.3 \pm 6.1 \mathrm{mV}, \mathrm{n}=12)$. To record a stable AP, holding current needed to be injected in most of the hiPSC-CM (40 out of 41 in EHT). The amount of holding current was in the range of $0.2 \mathrm{nA}$. After that we were able to record AP with a relatively low RMP in EHT $(-59.7 \pm 1.2 \mathrm{mV}, \mathrm{n}=41)$. In contrast, AP could be recorded in human adult CM from RA and LV without application of holding current, and in both, RMP were significantly more negative than in EHT. Respective RMP amounted to $-74.4 \pm 0.5 \mathrm{mV}$ in RA ( $\mathrm{n}=49)$ and to $75.9 \pm 1.1 \mathrm{mV}$ in LV ( $\mathrm{n}=10$, Figure 12B upper panel). To decide if the measured low RMP with lower $\mathrm{I}_{\mathrm{K} 1}$ amplitude is related to methodological issues in hiPSC-CM, we used the sharp microelectrode technique on EHT, and we compared them to a larger number of recordings measured in intact right atrial and left ventricular preparations (Figure 10 column titled “Sharp”, Figure 11C, D). 

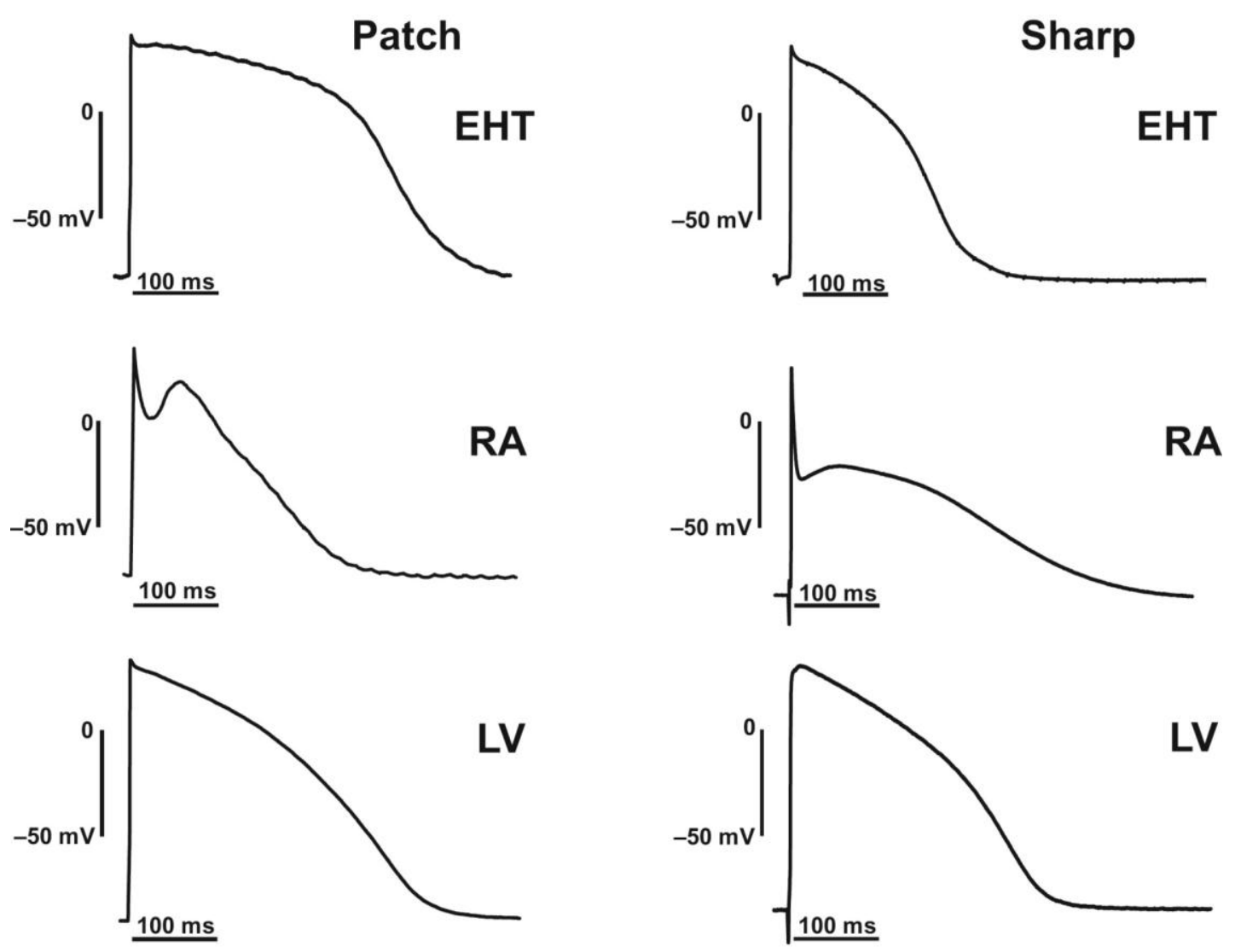

Figure 10. Original AP-recordings taken from EHT, RA and LV. Action potential recorded by patch clamp (left) and sharp microelectrode (right) technique. The patch clamp recordings were measured from isolated CM, while the sharp microelectrode recordings were measured from intact muscle preparations. In case of isolated hiPSC-CM from EHT, the recording was made after injection of holding current.

The EHTs were beating spontaneously, slightly slower than $60 \mathrm{bpm}$, which allowed us to record stimulated AP at $1 \mathrm{~Hz}$. RMP in sharp microelectrode recordings was significantly less negative in RA than in $\mathrm{LV}(-73.3 \pm 0.3 \mathrm{mV}, \mathrm{n}=220$ vs. $-75.9 \pm 0.7 \mathrm{mV}, \mathrm{n}=57 ; \mathrm{p}<0.001$, Figure 12B lower panel). RMP in intact EHT $(-74.6 \pm 1.2 \mathrm{mV}, \mathrm{n}=24)$ was similar to RA and LV (Figure 12B lower panel). At this point, it should be emphasized that $\mathrm{I}_{\mathrm{K} 1}$ density alone does not determine RMP, but the relation of all conductance present near RMP [75]. Two other parameters, $\mathrm{APD}_{90}$ and repolarization fraction - calculated as $\left(\mathrm{APD}_{90}-\mathrm{APD}_{50}\right) / \mathrm{APD}_{90}$ are commonly used as a tool to distinguish between atrial-like and ventricular-like hiPSC-CM [58]. 

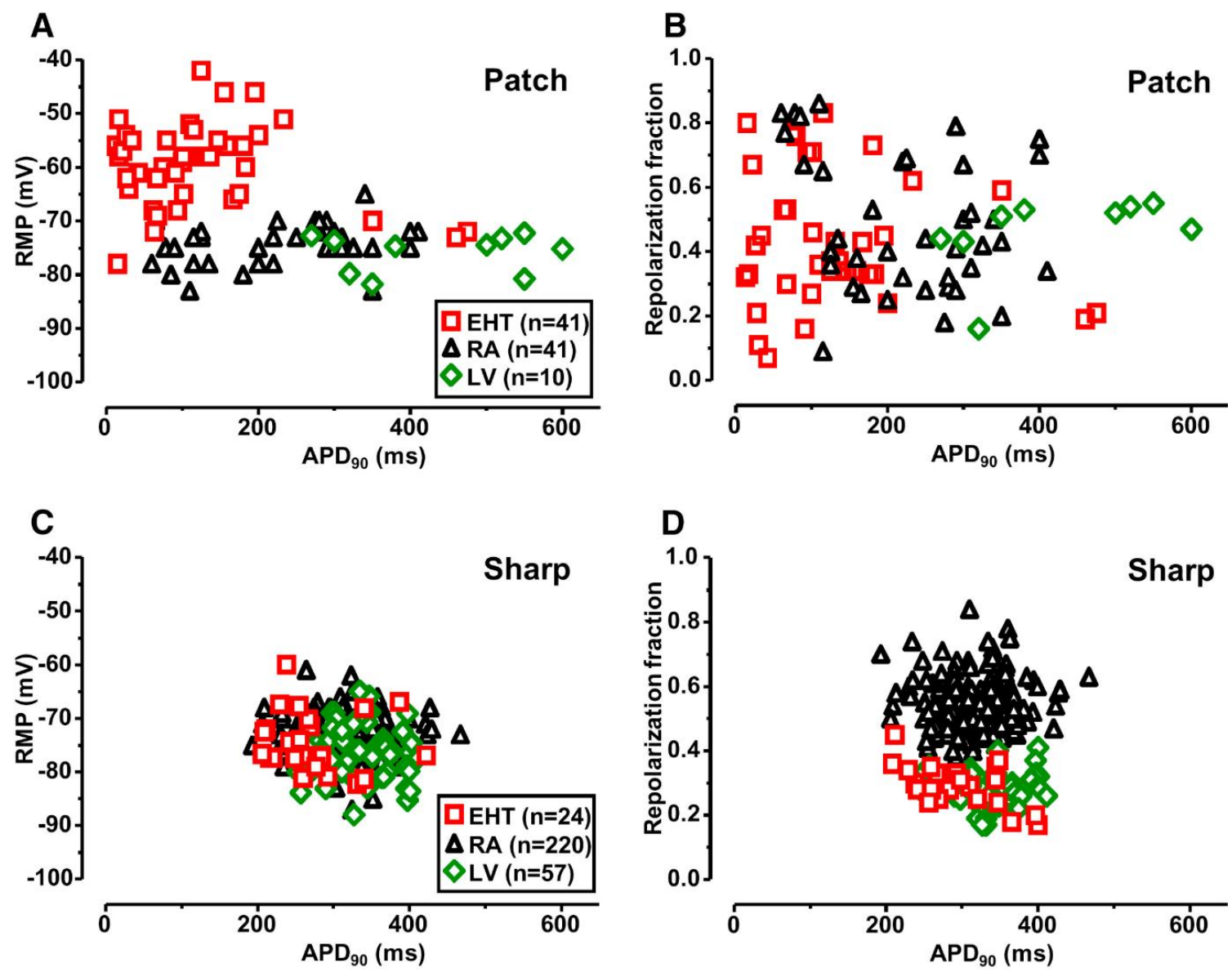

Figure 11. Individual distribution of APD $\mathbf{9 0}_{0}$, RMP and repolarization fraction in EHT, RA and LV.

A, C: Individual data points of $\mathrm{APD}_{90}$ plotted vs. respective RMP values measured by patch clamping of isolated CM from EHT, RA and LV and by sharp microelectrodes in intact tissues from EHT, RA and LV. B, D: Individual data points of repolarization fraction vs. $\mathrm{APD}_{90}$ in isolated $\mathrm{CM}$ : from EHT, RA and LV and in intact tissues: EHT, RA and LV (One-way ANOVA followed by Bonferroni test).

It should be noted that impact of $\mathrm{I}_{\mathrm{K} 1}$ on $\mathrm{APD}_{90}$ in human $\mathrm{LV}$ is very small, and repolarization fraction is mainly dominated by the activity of transient potassium outward currents. Both parameters are probably rather independent of $I_{K 1}$ [75]. Nevertheless, we aimed to determine if adult human cardiac tissue from RA and LV can be classified correctly and, more importantly, whether hiPSC-CM represent atrial-like or ventricular-like phenotype or a mixture of both. Using patch clamp electrodes, APD $_{90}$ was shorter in RA than in LV $(220 \pm 16$ ms, $n=41$ vs. $434 \pm 39 \mathrm{~ms}, \mathrm{n}=10 ; \mathrm{p}<0.001$, and even shorter in hiPSC-CM $(119 \pm 17 \mathrm{~ms}, \mathrm{n}=41$, p $<0.001$ vs. RA p <0.01 vs. LV, Figure 12A upper panel). 

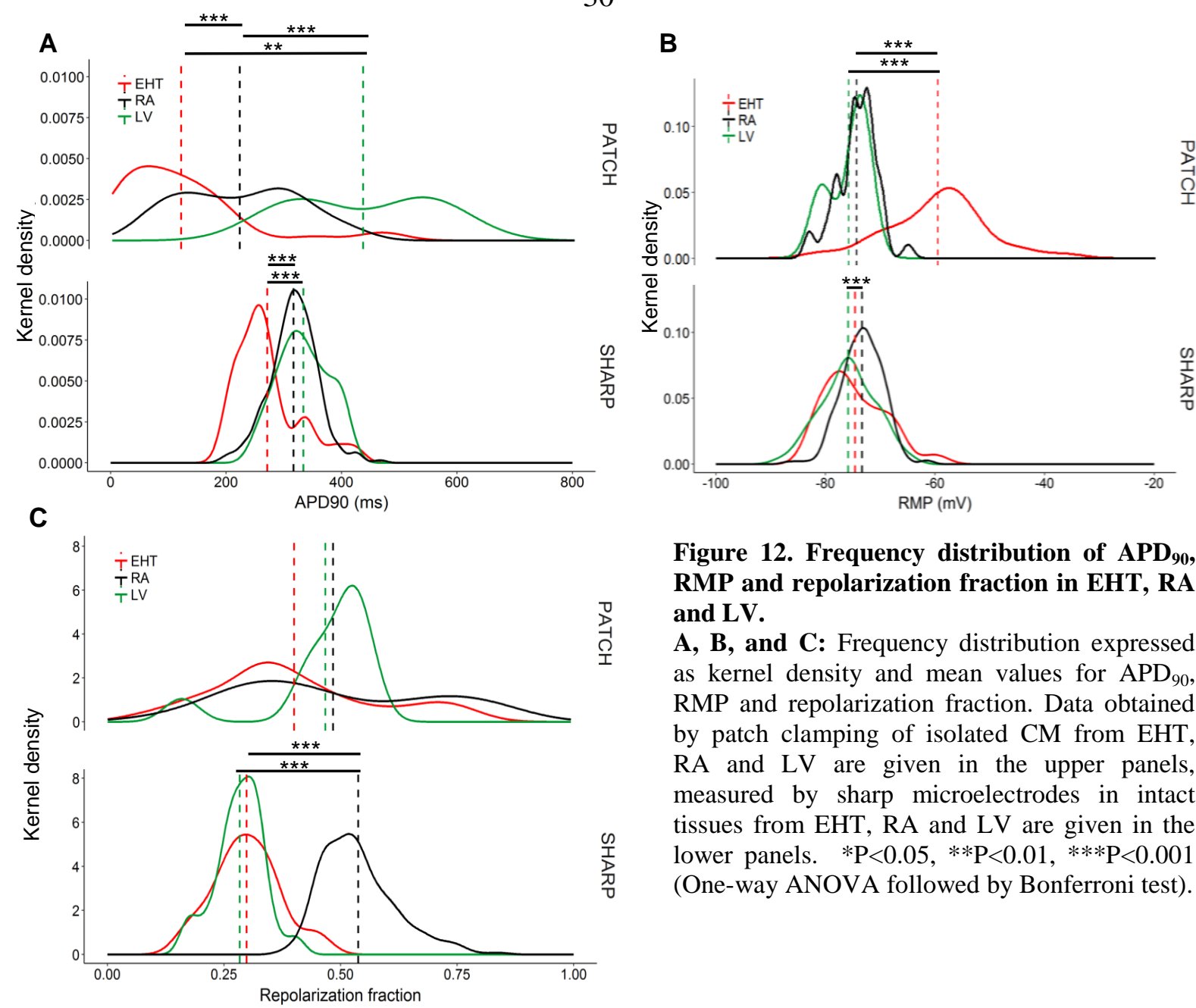

Figure 12. Frequency distribution of $\mathrm{APD}_{90}$, RMP and repolarization fraction in EHT, RA and $L V$.

A, B, and C: Frequency distribution expressed as kernel density and mean values for $\mathrm{APD}_{90}$, RMP and repolarization fraction. Data obtained by patch clamping of isolated CM from EHT, RA and LV are given in the upper panels, measured by sharp microelectrodes in intact tissues from EHT, RA and LV are given in the lower panels. $* \mathrm{P}<0.05, * * \mathrm{P}<0.01, * * * \mathrm{P}<0.001$ (One-way ANOVA followed by Bonferroni test).

We could observe a substantial overlap in $\mathrm{APD}_{90}$, if we took individual data points of RA and LV from patch clamp experiments (Figure 11A, B, Figure 12A upper panel). When sharp microelectrode technique was used, $\mathrm{APD}_{90}$ scatter was lower than in patch clamp recordings (Figure 11C). The mean $\mathrm{APD}_{90}$ was shorter in RA than in LV (317 $\pm 3 \mathrm{~ms}, \mathrm{n}=220$ vs. $334 \pm 6 \mathrm{~ms}, \mathrm{n}=57 ; \mathrm{p}<0.05$ Figure $12 \mathrm{~A}$ bottom panel). Again, $\mathrm{APD}_{90}$ was clearly shorter in EHT $271 \pm 11.4 \mathrm{~ms}, \mathrm{n}=24 ; \mathrm{p}<0.001$ vs. RA and $\mathrm{p}<0.001$ vs. LV, Figure $12 \mathrm{~A}$ bottom panel). Next, it was retrospectively evaluated whether differences in repolarization fraction would be a useful parameter to differentiate between LV and RA. We could only observe a narrow distribution of repolarization fraction in AP measurements from intact muscle preparations (Figure 12C, bottom panel). The overlap between LV and RA was really small, which indicates that repolarization fraction can be a useful approach to distinguish between atrial and ventricular phenotype (Figure 11D). Repolarization fraction of intact EHT was similar to LV and differed significantly from RA (EHT: $0.32 \pm 0.01 \mathrm{n}=24$ vs. RA: $0.54 \pm 0.01 \mathrm{n}=220$ vs. LV $0.28 \pm 0.01 \mathrm{n}=57$, Figure $12 \mathrm{C}$ bottom panel). In contrast to sharp microelectrode recordings, measurements of repolarization fraction in individual CM showed a wide range of distribution (Figure 11B, Figure 12C, upper panel). 
In vitro and in vivo electrophysiological characterization of a novel LQT5-TG rabbit model

\subsection{Potassium currents in healthy and LQT5-TG rabbit ventricular myocytes}

In myocytes, isolated from LQT5-TG, which carries the mutant minK (G52R) subunit of $\mathrm{I}_{\mathrm{Ks}}$, the density of the transient outward potassium current $\left(\mathrm{I}_{\mathrm{to}}\right)$ was moderately, but significantly larger than in WT rabbits (Figure 13A). There was no difference in inwardrectifier potassium current $\left(\mathrm{I}_{\mathrm{K} 1}\right)$ density between the two groups (Figure 13B). The amplitude (Figure 14A) and the inactivation time (Figure 14B) constant of the $\mathrm{I}_{\mathrm{Kr}}$ tail current were not different between the WT and LQT5-TG myocytes. The fast deactivation time constant of $\mathrm{I}_{\mathrm{Kr}}$ (at $-40 \mathrm{mV}$, test potential: $30 \mathrm{mV}$ ) was slightly faster in LQT5-TG rabbit cells compared with WT (Figure 14B).

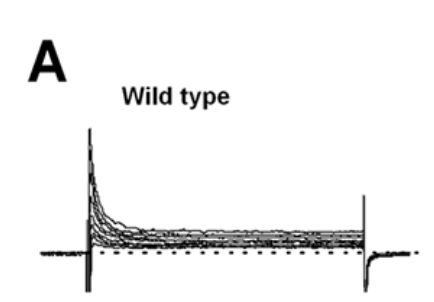

$$
\text { Ito }
$$
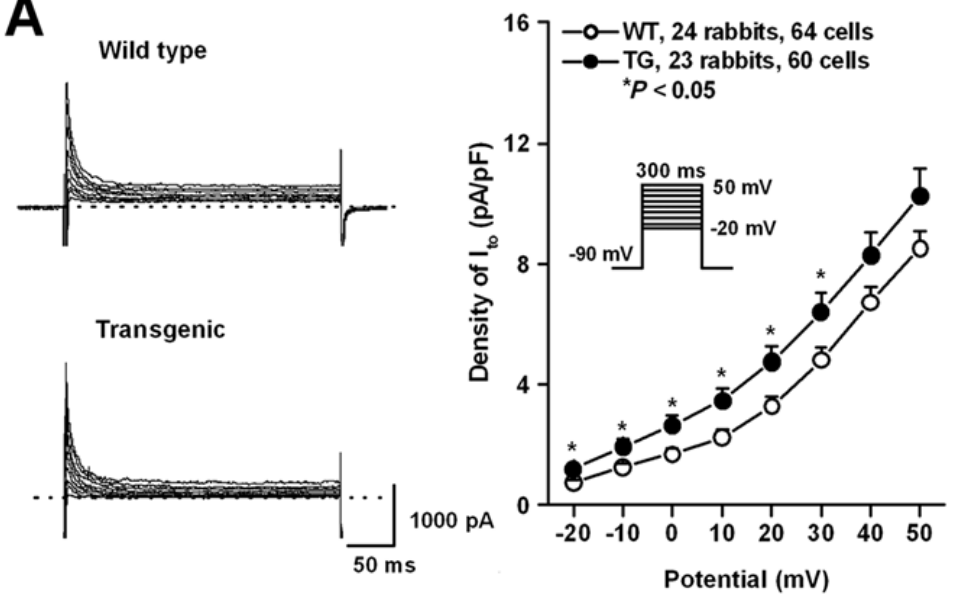

B

$$
I_{K 1}
$$
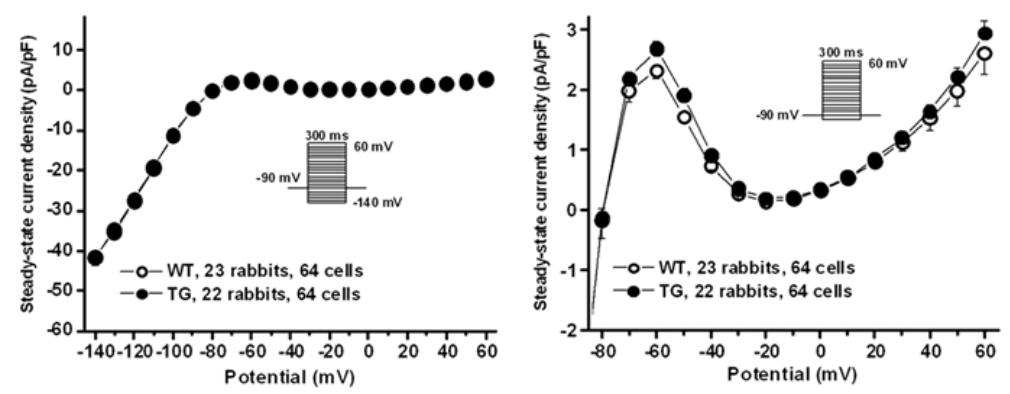

Figure 13. The density of $I_{\text {to }}$ and $I_{K 1}$ in rabbit ventricular myocytes.

A: Representative $I_{\text {to }}$ current traces recorded from WT and LQT5-TG ventricular myocytes are shown left. Current-voltage relations (right) demonstrate higher I density in LQT5-TG rabbits compared with WT rabbits. B: Steady-state current-voltage curves (left) demonstrating no differences in density of $\mathrm{I}_{\mathrm{K} 1}$ between WT and LQT5-TG rabbits. The outward current sections of the curves are enlarged on the right. Insets show the applied voltage protocols. Values are means \pm SEM. $\stackrel{*}{P}<0.05$ versus WT littermates. 
No difference was observed in $\mathrm{I}_{\mathrm{Ks}}$ tail-current amplitude between LQT5-TG and WT rabbits (Figure 15A). The stimulating effect of forskolin on $\mathrm{I}_{\mathrm{Ks}}$ was similar in WT versus LQT5-TG rabbits (Figure 15A). There were no difference in the activation kinetics of $\mathrm{I}_{\mathrm{Ks}}$, however the deactivation kinetics was (at $-40 \mathrm{mV}$, test potential: $50 \mathrm{mV}$ ) was markedly and significantly faster, in LQT5-TG rabbit myocytes compared with WT rabbits (Figure 15B). These changes would be expected to reduce phase- 3 repolarizing current, especially if the repolarization reserve is reduced. The subtle repolarization abnormalities associated with our model were reflected in cellular action-potential recordings, which showed a significant increase in APD-variability, but not in APD-increase resulting from dofetilide exposure in LQT5-TG vs. WT rabbits.

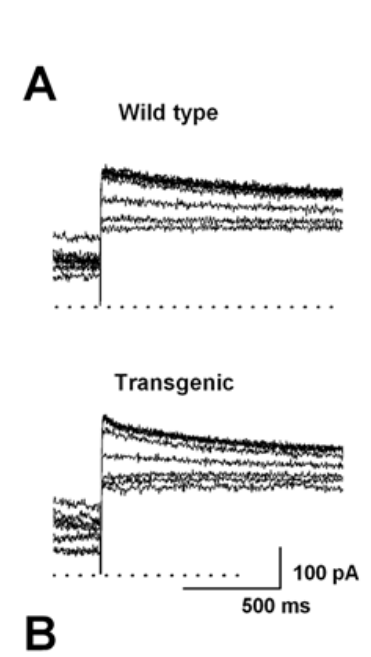

$$
\mathrm{I}_{\mathrm{Kr}}
$$
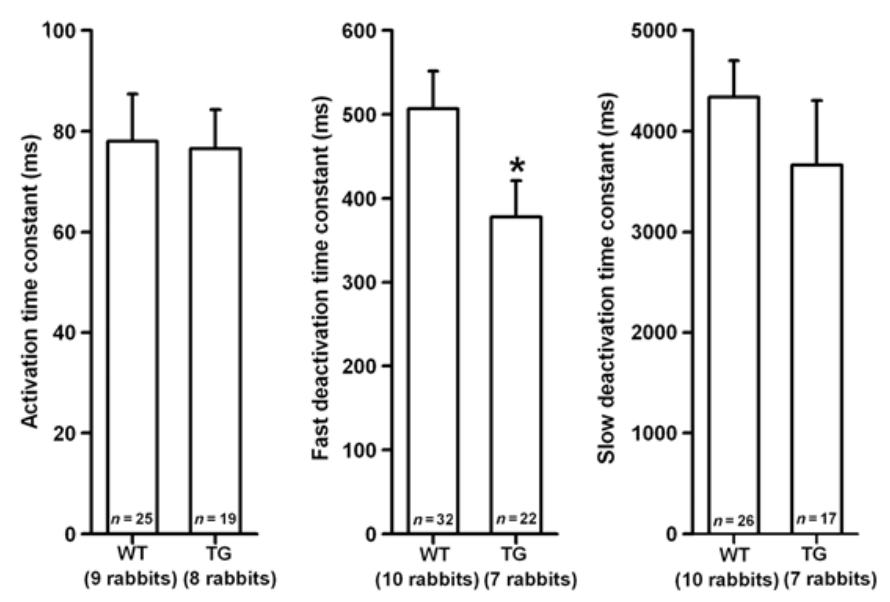

Figure 14. $I_{K r}$ in rabbit ventricular myocytes.

A: Representative $\mathrm{I}_{\mathrm{Kr}}$ tail current traces recorded from WT and LQT5-TG ventricular myocytes are shown on the left. Current-voltage relations (right) demonstrate no differences in density of $\mathrm{I}_{\mathrm{Kr}}$ between WT and LQT5-TG rabbits. Inset shows the applied voltage protocol. B: Bar diagrams illustrating the activation and deactivation (fast and slow) time constants in WT and LQT5-TG ventricular myocytes. Values are means \pm SEM. ${ }^{*} P<0.05$ versus WT littermates. 


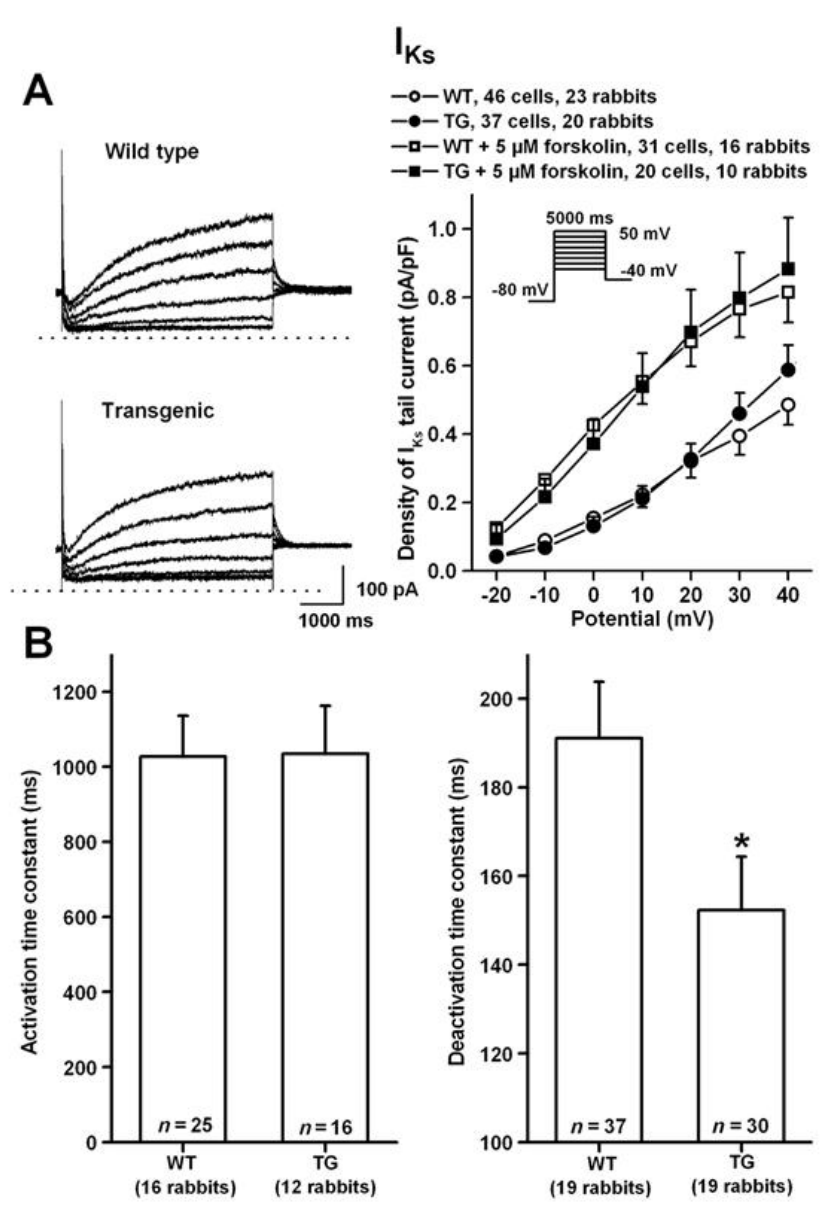

Figure 15. $\mathrm{I}_{\mathrm{Ks}}$ in rabbit ventricular myocytes.

A: Representative $\mathrm{I}_{\mathrm{Ks}}$ current traces recorded from WT and LQT5-TG ventricular myocytes are shown left. Current-voltage relations (right) demonstrate no differences in density of $\mathrm{I}_{\mathrm{Ks}}$ between WT and LQT5-TG rabbits. Inset shows the applied voltage protocol. B: Bar diagrams illustrating the activation and deactivation time constants in WT and LQT5-TG ventricular myocytes. Values are means \pm SEM. ${ }^{*} P<0.05$ versus WT littermates.

\subsection{ECG parameters and arrhythmias in healthy and LQT5-TG rabbits}

During anaesthesia with ketamine/xylazine, which should not affect cardiac repolarization [47], there was a slightly, but significantly longer QT $_{\mathrm{i}}$ in LQT5-TG versus WT littermates $(104 \pm 0.9 \%$ vs. $98.9 \pm 1.0 \%, \mathrm{P}<0.001$, Figure 16). No sex-related differences were observed. 


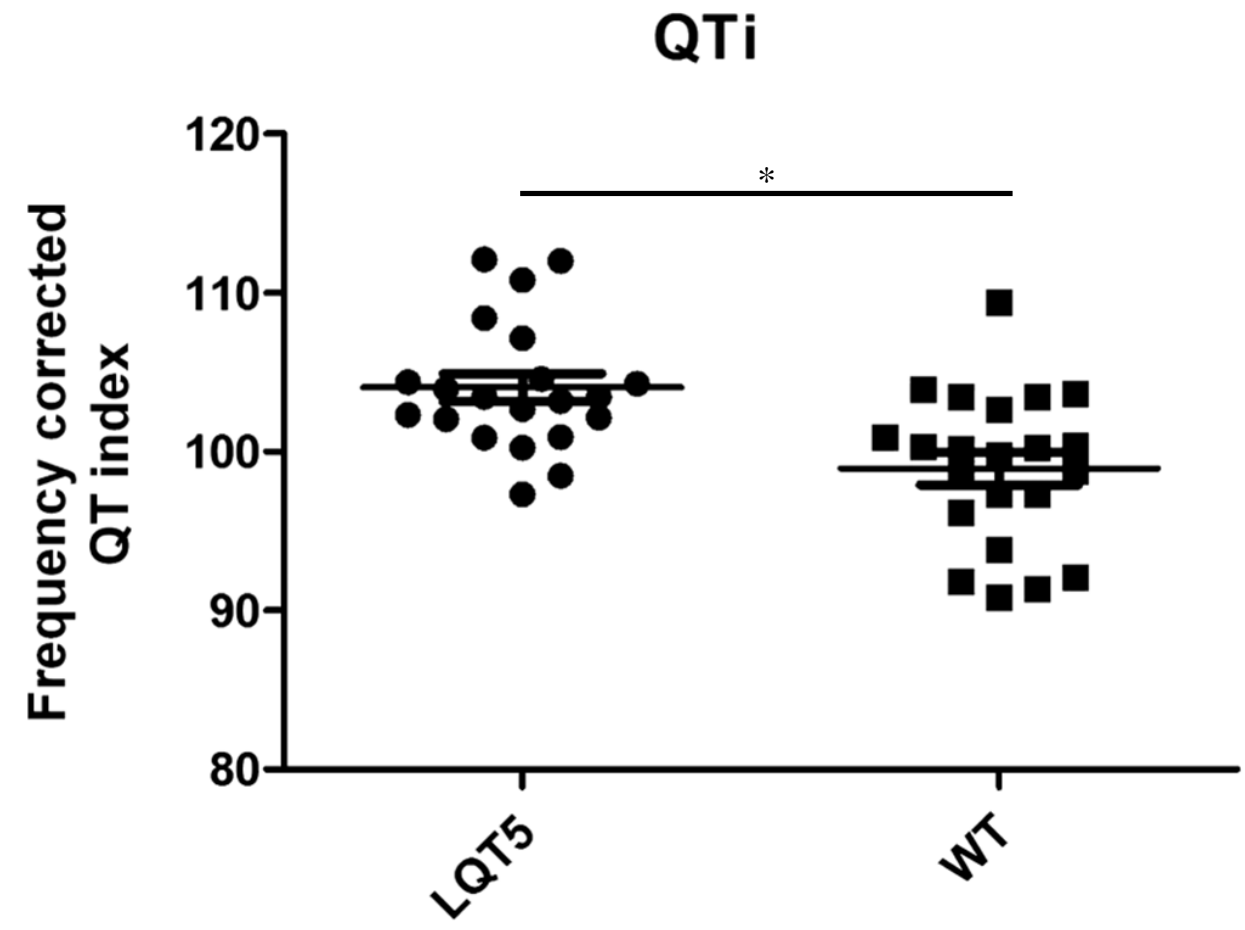

Figure 16. Heart rate corrected QT index in anaesthetized rabbits.

Plots indicating the heart-rate corrected QT-indices $\left(\mathrm{QT}_{\mathrm{i}}\right)$ in LQT5-TG $(n=21)$ and WT littermate $(n=22)$ rabbits under anaesthesia with ketamine/xylazine. Mean \pm SEM are indicated as horizontal lines. $P<0.001$.

There were no difference in the short-term variability of the RR interval $\left(S_{T V} V_{R R}\right)$ between the two groups, both at baseline and following dofetilide injection (Figure 17C). Figure 17A and B shows Poincaré plots of QT-intervals of representative individual WT and LQT5-TG rabbits. As shown on the representative plots (Figure 17A and B) and on the grouped data (Figure 17D), the short-term QT-interval variability ( $\mathrm{STV}_{\mathrm{QT}}$ ) was already greater in LQT5-TG rabbits at baseline. The QT and QTc intervals were significantly prolonged in both groups after dofetilide administration $\left(20 \mu \mathrm{g} / \mathrm{kg}^{-1}\right.$, i.v. $)$. Interestingly, there was a decrease in heart rate in LQT5-TG animals after dofetilide injection. Dofetilide significantly increased the $\mathrm{STV}_{\mathrm{QT}}$ in LQT5-TG animals (Figure 17D). While dofetilide led to similar QTc prolongation in both groups, its $\mathrm{STV}_{\mathrm{QT}}$-increasing effect was more pronounced and accompanied by more arrhythmias in LQT5-TG animals. Dofetilide provoked a greater number of $T d P$ arrhythmias in LQT5-TG rabbits $(12 / 15,80 \%)$ than in WT animals $(3 / 11$, $27 \%, \mathrm{P}<0.001$, Figure 17E). The duration of the $T d P$ episodes were also significantly longer in LQT5-TG animals, compared to WT rabbits (Figure 17F). 
A

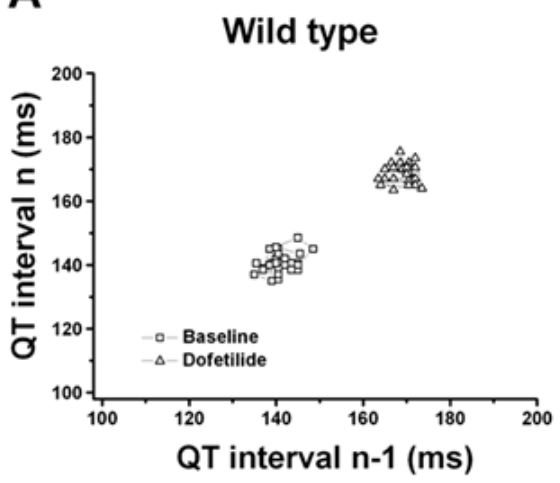

C

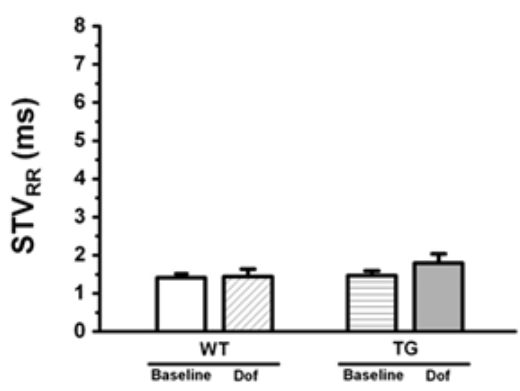

E

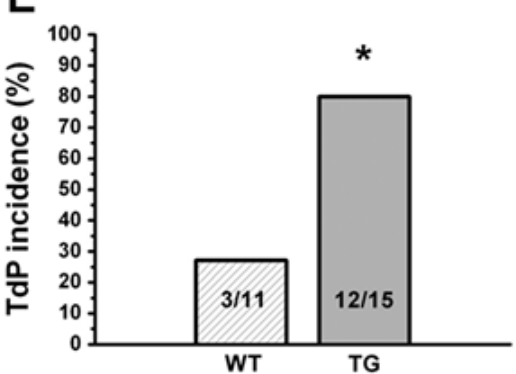

B

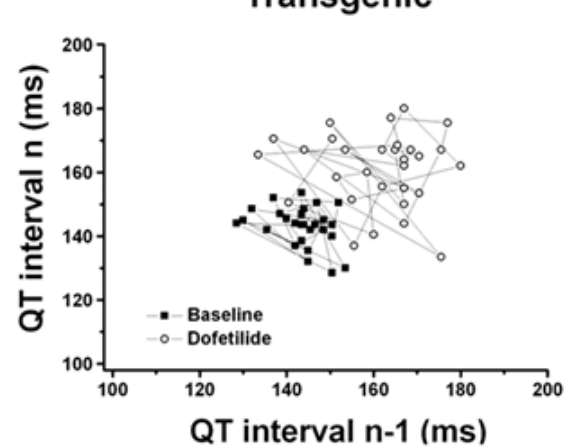

D

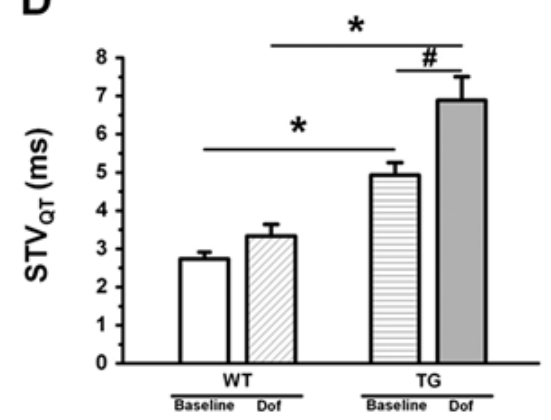

$\mathbf{F}$

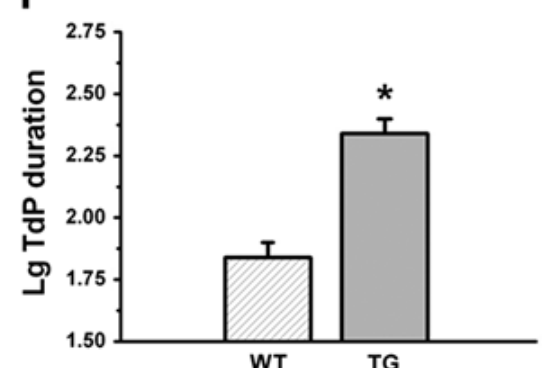

Figure 17. Short-term variability of the RR and QT intervals and Torsade-de-Pointes in thiopental anaesthetized rabbits.

A, B: Representative Poincaré plots demonstrate higher short-term beat-to-beat variability of the QT interval $\left(\mathrm{STV}_{\mathrm{OT}}\right)$ in anaesthetized LQT5-TG rabbits at baseline conditions compared with WT animals. Following the administration of the $\mathrm{I}_{\mathrm{Kr}}$ blocker dofetilide, $\mathrm{STV}_{\mathrm{QT}}$ further and markedly increased only in LQT5-TG animals. C: No differences in short-term variability of the RR interval $\left(\mathrm{STV}_{\mathrm{RR}}\right)$ between WT and LQT5-TG rabbits either at baseline conditions or following the administration of the $\mathrm{I}_{\mathrm{Kr}}$ blocker dofetilide. D: Short-term variability of the QT interval $\left(\mathrm{STV}_{\mathrm{QT}}\right)$ was higher in LQT5-TG animals at baseline conditions and following dofetilide infusion, indicating increased temporal instability of repolarization in LQT5-TG rabbits. E: Accordingly, LQT5-TG animals exhibited Torsade-de-Pointes $(T d P)$ with significantly higher incidence. F: The duration of $T d P$ episodes was significantly longer in LQT5-TG rabbits, expressed as the $\log _{10}$ of duration in seconds (to allow statistical comparison of data with normal distribution). Dofetilide $(20 \mu \mathrm{g} \cdot \mathrm{kg}, i . v.) ; n=11$ and 15 animals in WT and LQT5-TG groups, respectively on panels $\mathbf{C}$ to $\mathbf{E} ; n=3$ and 12 animals on panel (F); ${ }^{*} P<0.05$ versus

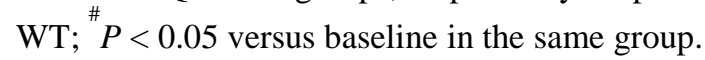




\section{Discussion}

\subsection{Human in vitro models in cardiovascular pharmacology}

This thesis summarizes the evaluation of two promising models in cardiovascular pharmacology. HiPSC-CM are providing great opportunities not just for studying drug effects on human cells, but also to create personalized treatment for patients as well as gene therapy and cardiac repair. However, this is restricted to in vitro experiments and several reports suggested that the cells show immaturity and differ from adult CM [34,36,37]. In the first section of the thesis $\mathrm{I}_{\mathrm{K} 1}$ density, RMP and AP properties in hiPSC-CM and in human atrial and ventricular $\mathrm{CM} /$ tissues were directly compared under identical experimental conditions. The main findings are that the density of inward $\mathrm{I}_{\mathrm{K} 1}$ in hiPSC-CM were similar to human $\mathrm{CM}$ and that sharp microelectrode measurements (of intact 3D heart muscle preparations) provide more reliable data on RMP and repolarization fraction than patch clamp recordings (of isolated cells). As a side result, repolarization fraction can be a more useful tool than RMP and APD in classification of atrial and ventricular cells using sharp microelectrode technique.

\section{2 $I_{K 1}$ in hiPSC-CM and in adult human atrial and ventricular CM}

$\mathrm{I}_{\mathrm{K} 1}$ density is generally larger in ventricular than in atrial $\mathrm{CM}$ [77-80] and very low or absent in nodal cells $[81,82]$. In myocytes, isolated from LV the inward component of the $\mathrm{I}_{\mathrm{K} 1}$ was approximately 2.5 -fold larger than in RA-CM. In some reports the difference was greater $[77,79]$, however one of the first studies and the largest one up to date showed the same disparity between RA and LV [78,76]. In contrast to previous publications reporting very low to absent $\mathrm{I}_{\mathrm{K} 1}$ in hiPSC-CM $[34,35,37]$, the density of $\mathrm{I}_{\mathrm{K} 1}$ in our hiPSC-CM was in the same range as in human adult cardiomyocytes.

$\mathrm{I}_{\mathrm{K} 1}$ density in hiPSC-CM from ML was not different from human LV-CM. In hiPSC-CM dissociated from EHT, the current density was lower than in LV, but still reached the values of RA. As culture of hiPSC-CM in EHT leads to signs of advanced maturation, this was an unexpected finding, while it was shown before that culturing hiPSC-CM on different platforms (for example polydimethylsiloxane) can increase inward $\mathrm{I}_{\mathrm{K} 1}$ density $[35,40]$. The discrepancy why $\mathrm{I}_{\mathrm{K} 1}$ was lower in EHT than in ML is not clarified yet. 


\subsection{Measured RMP can differ in hiPSC-CM due to technical issues}

As shown before in other studies, RMP measured by patch clamp electrodes was much lower in isolated hiPSC-CM than in adult human CM [34-38]. However, using sharp microelectrodes, the RMP value was in a physiological range in intact EHT. This discrepancy raised the question whether RMP measurements with patch clamp electrodes would give a systematic error. High seal resistance (in the range of 1-10 G $\Omega$ ) is critical for the reliability of patch clamp recordings especially in cells with lower capacitance. The remaining leak current is expected to reduce the actual membrane voltage $[78,83]$. The corrected membrane potential $\left(\mathrm{V}_{\mathrm{cM}}\right)$ can be calculated from the actual seal resistance $\left(\mathrm{R}_{\text {seal }}\right)$, the membrane resistance $\left(\mathrm{R}_{\mathrm{M}}\right)$ and the membrane potential, measured during the experiment $\left(\mathrm{V}_{\mathrm{mM}}\right)$. The equation is the following:

$$
\mathrm{V}_{\mathrm{cM}}=\mathrm{V}_{\mathrm{mM}}+\mathrm{V}_{\mathrm{mM}} * \mathrm{R}_{\mathrm{M}} / \mathrm{R}_{\text {seal }},
$$

if $R_{\text {seal }}$ is considered in series with $R_{M}$. $R_{\text {seal }}$ in our experiments was between 1 and $10 \mathrm{G} \Omega$, both in adult CM and in hiPSC-CM. $\mathrm{R}_{\mathrm{M}}$ at the RMP is determined by conductivity via $\mathrm{I}_{\mathrm{K} 1}$. To get an estimate of $\mathrm{R}_{\mathrm{M}}$ generated by $\mathrm{I}_{\mathrm{K} 1}$, we measured the $\mathrm{Ba}^{2+}$-sensitive $(1 \mathrm{mM})$ current under the same experimental conditions we used for AP recordings in hiPSC-CM from EHT (5.4 $\left.\mathrm{mM}\left[\mathrm{K}^{+}\right]_{\mathrm{ext}} 37^{\circ} \mathrm{C}\right)$. As expected, current density of $\mathrm{I}_{\mathrm{K} 1}$ was smaller and the reversal potential was shifted to about $-70 \mathrm{mV}$ under these conditions $\left(1.5 \pm 0.7 \mathrm{pA} / \mathrm{pF}, \mathrm{n}=12\right.$, at $5.4 \mathrm{mM} \mathrm{K}^{+}{ }_{\text {[ext] }}$ vs. $14.1 \pm 12.0 \mathrm{pA} / \mathrm{pF}, \mathrm{n}=60$ at $\left.20 \mathrm{mM} \mathrm{K}^{+}{ }_{\text {[ext }]}, \mathrm{p}<0.05\right)$. Dividing the actual driving force for potassium $(\sim 30 \mathrm{mV})$ by the $\mathrm{Ba}^{2+}$-sensitive absolute current amplitude measured at $-100 \mathrm{mV}$ $(41.1 \pm 13.7 \mathrm{pA}, \mathrm{n}=12)$ gave a membrane resistance of around $0.75 \mathrm{G} \Omega$. If the true RMP is assumed to be around $-73 \mathrm{mV}$ and a typical seal resistance is about $3 \mathrm{G} \Omega$, according to the equation described above, the membrane voltage recorded by patch clamp electrodes will drop down to a value of $-58 \mathrm{mV}$. Since we do not have data for $I_{K 1}$ in LV-CM under physiological conditions, we used data which was published previously. In Amos et al. (1996) the mean $\mathrm{I}_{\mathrm{K} 1}$ current densities were 1.1 and $2.8 \mathrm{pA} / \mathrm{pF}$ in RA and LV [78]. Multiplying the values with the capacitances given in that study (145 for RA and $285 \mathrm{pF}$ for LV), we could calculate absolute $\mathrm{I}_{\mathrm{K} 1}$ current amplitudes of $\sim 160 \mathrm{pA}$ in atrial and $\sim 800 \mathrm{pA}$ in ventricular $\mathrm{CM}$ [78]. If we plot $\mathrm{V}_{\mathrm{cM}}$ vs. $\mathrm{I}_{\mathrm{K} 1}$ amplitudes, it reveals that the error in hiPSC-CM will be larger compared to human $\mathrm{CM}$ due to their small capacitance even at the same seal resistances. If we assume the 2.5 times higher $I_{K 1}$ density in ML, it might still not be sufficient to leave the larger error zone, since the absolute $\mathrm{I}_{\mathrm{K} 1}$ current amplitude will reach only $79 \mathrm{pA}$ after 
calculation. Isolated hiPSC-CM can be fragile, which can cause a dropdown in the seal resistance during an experiment. Importantly, the apparent RMP can drastically change due to a slight change in seal resistance in cells with low $\mathrm{I}_{\mathrm{K} 1}$ conductivity. This can be owing to combination of low current density and small cell size. It should be noted that these calculations are based on mean values for cell size and $I_{K 1}$. Because of the large variability both in cell size and $\mathrm{I}_{\mathrm{K} 1}$ density (Figure 5C), underestimation of RMP may be much larger in an individual cell (Figure 18). Therefore, given the present limitations, measurements of AP with patch clamp pipettes are prone to error and not well suited as an indirect parameter of $\mathrm{I}_{\mathrm{K} 1}$ density. Small cell size is not necessarily an issue, since AP measurements are feasible even in much smaller cells, like pancreatic cells, whose size are in the range of $5 \mathrm{pF}$ [84]. Very high seal resistance up to $10 \mathrm{G} \Omega$ and very large potassium conductance may facilitate AP recording in those cells [85].

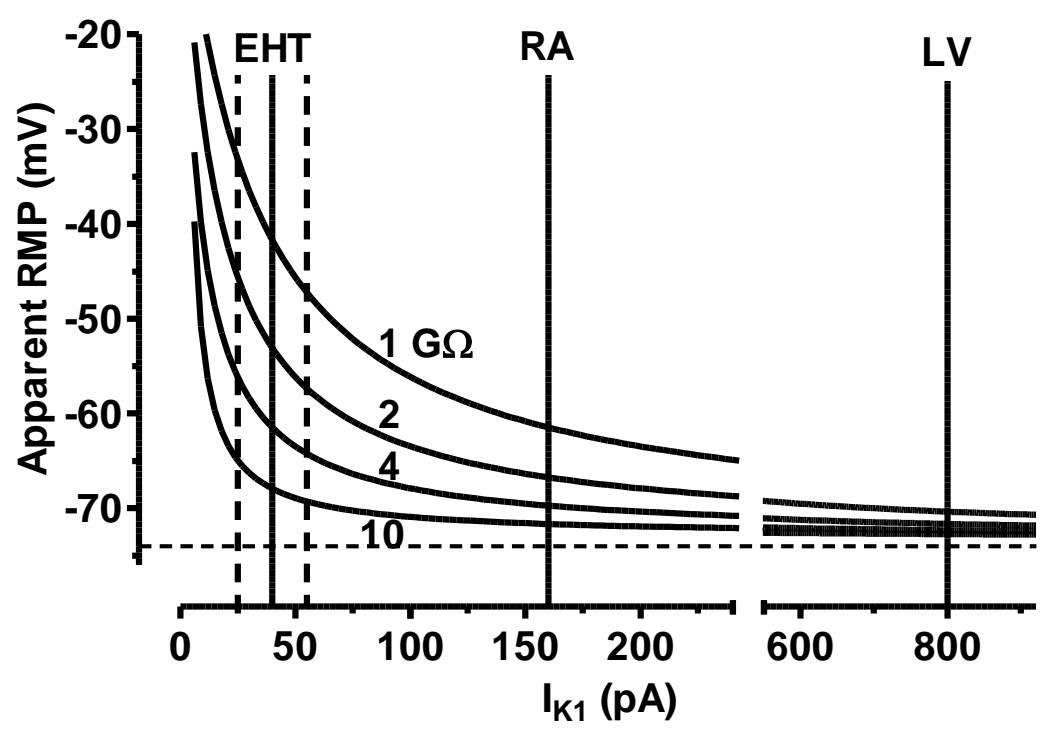

Figure 18. Influence of seal resistance and absolute $I_{K 1}$ amplitude on apparent resting membrane potential in patch clamp experiments.

Curves give calculated apparent RMP as a function of absolute $\mathrm{I}_{\mathrm{K} 1}$ amplitudes and seal resistance. It is assumed that inward current amplitudes are determined by $\mathrm{I}_{\mathrm{K} 1}$ only. True RMP was assumed to be $-73 \mathrm{mV}$, as indicated by the dotted horizontal line. Vertical lines indicate absolute $\mathrm{I}_{\mathrm{K} 1}$ amplitudes at $-100 \mathrm{mV}$. Dotted vertical lines illustrate $95 \%$ confidence interval of $\mathrm{I}_{\mathrm{K} 1}$ measured in EHT. The apparent RMP was calculated by the equation $\mathrm{V}_{\mathrm{cM}}=\mathrm{V}_{\mathrm{mM}}+\mathrm{V}_{\mathrm{mM}} * \mathrm{R}_{\mathrm{M}} / \mathrm{R}_{\text {seal }}$. Please note data for EHT are taken from experiments independent from those presented in Figure 5 (numbers given in the section discussion). Data for RA and LV are taken from the literature [78]. Numbers near the fit curves indicates seal resistance used for calculation. For details, see discussion. 


\subsection{Discrimination of atrial and ventricular cells by $I_{K, A C h}, I_{K 1}, R M P, A_{P D}$ and repolarization fraction}

In previous studies, it was shown that in standard hiPSC-CM cultures ventricular-, nodal and atrial-like myocytes can be found [28,29,36,37,86,87]. In those reports the classification is mainly based on differences in AP parameters. In this study the existence $\mathrm{I}_{\mathrm{K}, \mathrm{ACh}}$ was used as a different approach. Only atrial and nodal $\mathrm{CM}$ express $\mathrm{I}_{\mathrm{K}, \mathrm{ACh}}[88,89]$. There was no response to $\mathrm{CCh}$ with a change of inwardly rectifying current in any of the hiPSC-CM. The absence of $\mathrm{I}_{\mathrm{K}, \mathrm{ACh}}$ cannot be explained by a lack of muscarinic receptors, since $\mathrm{CCh}$ reverses positive inotropic effects of isoprenaline in the same hiPSC-EHT [40], the classical accentuated antagonism [90]. This finding suggests that hiPSC-CM show at least partly ventricular phenotype. As outlined above, different $I_{K 1}$ densities might also discriminate between atrial and ventricular $\mathrm{CM}$. However, we found mean $\mathrm{I}_{\mathrm{K} 1}$ densities to differ only moderately between human RA and LV (2.5-fold) and, importantly, to scatter largely and substantially overlap between the groups (Figure 5D). Thus, our data do not support recent suggestions that $\mathrm{I}_{\mathrm{K} 1}$ density should be used to discriminate between atrial and ventricular phenotype in hiPSC-CM [91].

RMP is also commonly used for discrimination between atrial and ventricular CM. In accordance with the lower $\mathrm{I}_{\mathrm{K} 1}$ density in atrial cells, mean RMP was more negative in $\mathrm{LV}$ than in RA. However, although $\mathrm{I}_{\mathrm{K} 1}$ was 2.5 fold higher in LV than RA, differences in mean RMP values were small. Individual RMP measurements broadly overlapped between RA and LV both in patch clamp and sharp microelectrode recordings. Thus, the power of RMP to discriminate atrial from ventricular CM was modest. If the RMP was more negative than $82 \mathrm{mV}$ in a tissue, it could be classified as ventricular with an accuracy of $80 \%$, this this applied to only approximately $20 \%$ of the ventricular preparations. Mean RMP values in EHT were similar to RA and LV. RMP in EHT was not significantly different from LV and RA. It suggests that RMP is not a useful parameter to decide if EHT possess an atrial or ventricular phenotype. In addition, it should be emphasized that $\mathrm{I}_{\mathrm{K} 1}$ density alone does not determine RMP, but the relation of all conductance's present, like background sodium and calcium currents, NCX and $\mathrm{Na}^{+} / \mathrm{K}^{+}$-ATP-ase [92], many of them not yet studied detailed in hiPSCCM.

AP duration is also often used for classification of hiPSC-CM whether they show atrialor ventricular-like phenotype [34,36-38,86,87]. Such assumptions are based on data from 
previous publications reporting human $\mathrm{APD}_{90}$ values from various preparations [93-98]. It is difficult to use them for direct comparison due to methodological reasons. Here, a greater amount of data was provided and the experimental conditions were identical. While mean $\mathrm{APD}_{90}$ values were indeed shorter in RA than in LV, individual values again largely overlapped. This raises the question again, if individual $\mathrm{APD}_{90}$ values can be a useful tool to discriminate between atrial or ventricular phenotype.

Other approaches were also used for a more precise discrimination between atrial-, and ventricular-like APs such as $\mathrm{APD}_{90} / \mathrm{APD}_{50}[36,99]$. The early phase of repolarization in human heart is dominated by transient potassium outward currents. In contrast to ventricular $\mathrm{CM}$, the transient outward currents in atrial CM exhibit a long lasting component, which results in a larger repolarization fraction [78]. In single RA-CM measured by patch clamping the repolarization fraction showed a wide range of distribution. This finding is in line with the reported wide heterogeneity of transient outward currents in RA-CM [78]. The repolarization fraction measured by sharp microelectrode in tissues likely integrates different AP shapes from individual cells and therefore the scatter is smaller. This interpretation is supported by the observations that mean values did not differ between individual isolated RA-CM and intact RA trabeculae. The same holds true for EHT. Due to the smaller distribution of repolarization fraction in intact tissues we were able to discriminate clearly between RA and LV. Based on this parameter, EHT showed more similarity to LV than RA.

\subsection{Animal models in cardiovascular pharmacology}

There is a high need to develop new animal models with a better predictive value for proarrhythmic risk. This is important to reflect better the clinical situations at risk of drug induced arrhythmias, especially in patient with remodelled myocardium [100] and impaired repolarization reserve [101]. In vivo proarrhythmia models with impaired repolarization reserve are already existing, including a dog model with chronic atrioventricular block [102]. Those animals, develop ventricular hypertrophy and bradycardia, and the $\mathrm{I}_{\mathrm{Ks}}$ is consequently downregulated, which leads to a reduced repolarization reserve and increased arrhythmia susceptibility [102,103]. Acute pharmacological inhibition of $\mathrm{I}_{\mathrm{Ks}}$ by HMR-1556 [66] can also imitate reduced repolarization reserve. Loss-of-function mutations in repolarizing and gainof-function mutations in depolarizing currents cause congenital long QT syndromes with impaired repolarization and increased risk of sudden death [104]. The two most common forms of congenital LQT (LQT1 and LQT2) were modelled by expression of human mutant 
KCNQ1 and KCNH2 genes in transgenic rabbits in a landmark study by Brunner et al. [50]. A remarkable prolongation of the QT interval was observed in both LQT1 and LQT2, and LQT2 transgenic rabbits showed a high incidence of sudden death $[50,105]$. These two transgenic rabbit models effectively express the human LQT1 and LQT2 phenotypes, and they are valuable tools to investigate the mechanisms of sudden cardiac death. On the other hand, it is also important to study 'silent' or 'subclinical' LQT cases, where impairment of repolarization reserve does not necessarily result in clinically obvious QT-prolongation, but the heart is more susceptible to arrhythmia development. Here, we would like to introduce and characterize a novel transgenic rabbit model with hidden repolarization reserve complications, which do not necessarily result in QT-prolongation, but the heart is more sensitive to arrhythmia development $[101,106]$.

\subsection{Effects of the G52R-KCNE1 mutation on repolarizing potassium currents in left ventricular myocytes, obtained from WT and LQT5-TG rabbit hearts.}

The amplitude of the $I_{K 1}$ current and the tail current of $I_{K r}$ and $I_{K s}$ were not different between the two groups. The isolation procedure might have an effect on the current amplitudes and densities, which may attenuate differences between study groups, even in relatively large numbers of rabbits (8-24) and cells (20-64). On the other hand, $\mathrm{I}_{\mathrm{Kr}} / \mathrm{I}_{\mathrm{Ks}}$ deactivation kinetics were significantly affected in LQT5-TG rabbits, potentially accounting for the in vivo phenotype. The functional importance of the moderate augmentation of $\mathrm{I}_{\mathrm{to}}$ in LQT5-TG rabbits is difficult to interpret, because in the rabbit heart the $\mathrm{I}_{\text {to }}$ is mainly, but not completely carried by the Kv 1.4 channels [17]. These channels recover slowly (>1s timeconstant) from inactivation. Due to the fast heart rate of the rabbit (in the range of 200-250 beats $\min ^{-1}$ ), the possible contribution of $I_{t o}$ to the repolarization of the ventricle is questionable, while it might be broadly inactivated at normal heart rates. The faster deactivation kinetics of $\mathrm{I}_{\mathrm{Kr}}$ and $\mathrm{I}_{\mathrm{Ks}}$ currents in LQT5-TG animals compared to WT is the most important difference at cellular level. Due to the more rapid deactivation, the channels close faster and it results in lower densities of $\mathrm{I}_{\mathrm{Ks}}$ and $\mathrm{I}_{\mathrm{Kr}}$ during the action potential. According to those changes in kinetic parameters, the repolarization reserve is impaired, which might be a possible explanation behind the greater susceptibility of LQT5-TG rabbits to arrhythmias during in vivo studies. This faster deactivation of $\mathrm{I}_{\mathrm{Ks}}$ in ventricular myocytes expressing the mutant G52R-KCNE1 gene contradicts with the observations in Xenopus oocytes, where the co-expression of the wild type KCNE1 and the G52-KCNE1 results in a 50\% reduction in the 
$\mathrm{I}_{\mathrm{Ks}}$ current amplitude [51]. In CHO cells, co-expression of KCNQ1 with G52R-KCNE1 produced a current devoid of the characteristic slow activation of $\mathrm{I}_{\mathrm{Ks}}$, and the current density was similar to those in cells expressing only KCNQ1 [53]. The possible explanation behind the controversial results in rabbit $\mathrm{CM}$ compared to expression systems is unknown. Nevertheless, there is growing evidence suggesting that other subunits such as KCNE2, KCNE3 and maybe KCNE4 and KCNE5 might interact with the KCNQ1, not only KCNE1 [107,108]. In addition, although KCNE1 is established primarily as a KCNQ1 subunit, there is evidence that it may also play a role in $\mathrm{I}_{\mathrm{Kr}}$ function [109-111]. The varying contributions of different accessory subunits may account for the different effects of mutations in different expression systems.

\subsection{The in vivo results show that LQT5-TG rabbits are sensitive to arrhythmia provocation}

There were no spontaneous sudden deaths in LQT5-TG animals during in vivo experiments. During ECG studies, a small, but significant prolongation of the heart ratecorrected QT index could be observed in xylazine/ketamine-anaesthetized LQT5-TG rabbits, suggesting mild prolongation of repolarization (Figure 16). Contrasting with observations during anaesthesia with ketamine/xylazine, which does not affect repolarizing ion-currents [47], during thiopental-anaesthesia, there were no differences in the QT or frequencycorrected QTc intervals between TG rabbits and their WT littermates. Thiopental can block $\mathrm{I}_{\mathrm{Ks}}$ current [112], while xylazine/ketamine does not [113]. It seems that during thiopental anaesthesia, the minor baseline repolarization difference can perish. The short-term variability of the QT interval (which is an ECG biomarker for proarrhythmic risk [114,115]), was significantly larger in LQT5-TG rabbits (Figure 17 A,B and D) under thiopental anaesthesia, suggesting increased repolarization instability already at baseline. We used the selective $\mathrm{I}_{\mathrm{Kr}}{ }^{-}$ blocker dofetilide to compare the arrhythmia-susceptibility of LQT5-TG rabbits having reduced repolarization reserve with WT littermates. Dofetilide caused a marked prolongation in the QT interval in both groups and an additional increase of the STV $\mathrm{QT}_{\mathrm{QT}}$ in LQT5-TG rabbits. The drug also provoked typical drug-induced polymorphic ventricular tachycardia, $T d P$, in a greater number of LQT5-TG animals compared with WT (Figure 17E), and the duration of those episodes were significantly longer (Figure 17F). These observations agree with other proarrhythmia studies in models with reduced repolarization reserve, such as dogs with chronic AV-block [65] and anaesthetized rabbits subjected to pharmacological block of 
$\mathrm{I}_{\mathrm{Ks}}$ [66]. We were not able to see any evidence of cardiac structural or functional disorders in LQT5-TG rabbits. Further studies with echocardiographic assessment of cardiac structure are needed to exclude any subtle alterations occurring in the model. Additional experiments should be performed in the future to characterize the cellular electrophysiological mechanisms responsible for the increased arrhythmia susceptibility observed in LQT5-TG rabbits, especially in the light of data indicating that ( $i$ ) chronic loss of function of one repolarizing current can lead to compensatory up-regulation of other $\mathrm{K}^{+}$-channels [116] and (ii) different KCNE-encoded proteins do not exclusively associate with KvLQT1 to form $\mathrm{I}_{\mathrm{Ks}}$ channels, but may be involved in the assembly of other ion channels [117,118]. All the main ionic currents should be studied in a large number of native ventricular cardiomyocytes isolated from LQT5TG and WT rabbits at different voltage levels, focusing on kinetic properties of the channels. In addition, it would be interesting to create a study involving wild-type KCNE1 overexpression, to compare the resulting phenotype with animals, which overexpress the mutant KCNE1. Furthermore, studies of the effects of additional repolarization-stresses, such as adrenergic stimulation, would be appropriate. Finally, it would be useful to examine whether changes occur in other ion-currents like $\mathrm{I}_{\mathrm{Na}}$ and $\mathrm{I}_{\mathrm{Ca}, \mathrm{L}}$, because they might be altered as part of the cellular adaptation to changes in electrical function induced by the mutation.

\subsection{Potential role of the two introduced models in the future}

In cardiovascular pharmacology it is very important to have reliable models, which reflect human heart physiology not only in undiseased, but also in diseased conditions. Both models introduced in this thesis have their own strengths and weaknesses, but their potential is large.

The use of hiPSC-CM is a unique opportunity, because they are programmed from human cells, relatively easy to handle them, and provides a great opportunity to create diseased cell lines $[27,28,36,86]$ and also to apply gene therapy such as the CRISPR/Cas9 technique in vitro [32]. To improve the maturity of these cell lines is still a very important issue, and a detailed electrophysiological characterization is suggested even in the control cell lines, before using them for disease modelling. As shown in the first part of the thesis, the measured low RMP values might be due to technical problems, which are also important issues, so choosing the right approach during the studies is crucial. This technical issue is not that pronounced in native mature cardiomyocytes where the capacitance of the cells and the potassium conductance are high. On the other hand, several reports showed promising results 
in case of structural and electrophysiological maturation $[34,35,38,40]$, so there is no doubt that those cells will become important and standard tools for cardiovascular research in the future.

Creating transgenic animals have also a great significance in cardiovascular pharmacology. Small rodents are commonly used to model various heart diseases, and those models can provide a platform not only for in vitro, but also for in vivo studies $[42,119]$. Studies in rodent models have greatly improved our knowledge about the mechanisms of arrhythmias. To overcome the reported differences in heart physiology in rodents, compared to human, there is a growing interest to use larger rodents such as rabbits for this purpose. The physiology of the rabbit heart is more similar to the human, and creation of transgenic rabbits which are modelling heart diseases was already successful, and showed great results [4648,62].

Our LQT5-TG rabbit model is representing a very challenging clinical case called “silent" LQT. We are confident that this model provides an outstanding tool to understand not only the underlying mechanism of this disease, but also to develop new diagnostic approaches and potentially novel alternatives for the prevention and treatment of life threatening arrhythmias.

In conclusion, both models may play a significant future role in cardiovascular research, and can increase our understanding in the underlying mechanisms of cardiac diseases. They also represent valuable platforms in the development and testing of novel, safe antiarrhythmic drugs in order to reduce the risk of sudden cardiac death. 


\section{Conclusions and potential significance}

The conclusions and main findings of the present thesis are as follows:

(a) HiPSC-CM can possess robust $\mathrm{I}_{\mathrm{K} 1}$ current densities, which, in ML, reached values of human LV-CM and, in EHT, that of RA-CM under identical experimental conditions.

(b) Technical issues related to patch clamping of small cells probably contribute to the reported low RMP in hiPSC-CM. HiPSC-CM exhibit features of both an atrial ( $\mathrm{I}_{\mathrm{K} 1}$ and RMP) and ventricular phenotype (absence of $\mathrm{I}_{\mathrm{K}, \mathrm{ACh}}$ and low repolarization fraction). Low $\mathrm{I}_{\mathrm{K} 1}$ and depolarized RMP are not inherent characteristics of hiPSC-CM.

(c) A novel LQT5-TG rabbit model based on the cardiac-specific overexpression of human KCNE1 carrying a G52R missense was successfully created. These rabbits exhibit reduced repolarization reserve, but no striking repolarization disturbances or serious ventricular arrhythmias at baseline. However, LQT5-TG rabbits are more susceptible to arrhythmias than WT littermates upon repolarization stress, indicating that they may be suitable to model the challenging clinical situation of 'silent' LQT.

(d) This model can also provide further insights into the mechanisms underlying arrhythmias and sudden cardiac death based on repolarization disturbances and may represent a novel model for testing the proarrhythmic potential of new drugs under development.

(e) Both models can be a reliable future tool for cardiovascular pharmacology and disease modelling studies in vitro and in vivo, because their large similarity to human heart. 


\section{Acknowledgements}

I am very grateful to Professor Julius Gy. Papp MD, DSc, academician, for his continuous support, his kindness, inspiring comments and constructive criticism, his suggestions which were always of help and are greatly appreciated. I would like to express my thankfulness to Professor András Varró MD, DSc and Professor Thomas Eschenhagen MD, DSc for providing me the opportunity for research as $\mathrm{PhD}$ student at the Department of Pharmacology and Pharmacotherapy, University of Szeged and the Department of Experimental Pharmacology and Toxicology, University Medical Center Hamburg-Eppendorf and for the helpful discussions which were exceptionally useful during my work.

I am especially thankful to my PhD supervisors Dr. László Virág, Dr. Norbert Jost and PD Dr. Torsten Christ for personal guidance, continuous support of my work and for introducing me to the fascinating world of cardiac cellular electrophysiology.

I wish to thank my senior colleagues, Dr. István Baczkó, Professor András Tóth, Professor Zsuzsanna Bősze and Professor Arne Hansen, my postdoc colleagues, Dr. Károly Acsai, Dr. Balázs Ördög, Dr. Norbert Nagy, Dr. Ingra Mannhardt, Dr. Kaja Breckwoldt, Dr. Frederik Flenner, Dr. Christiane Neuber and my PhD student colleagues Dr. Claudia Corici, Dr. Amir Geramipour, Dr. Zsófia Nagy, Attila Kristóf, Dr. Viktor Juhász, Dr. Marc Daniel Lemoine, Ahmet Umur Uzun for their continuous support and help in my work, for creating a cheerful and social milieu in the laboratory, and to Mrs. Zsuzsanna Molnár, Mr. Gábor Dobai and Mr. Gábor Girst, Mr. Klaus-Dieter Söhren, Ms. Anna Steenpass, for their helpful technical assistance. I am also grateful to or inspiring discussions and lots of excellent advices.

I also wish to thank my parents (Viola Ujvári and György Horváth), my brother (György Horváth Jr.), my grandparents (Erzsébet Szabó and István Ujvári) and Dr. József Háromszéki, whom I want to dedicate this thesis for their endless love, trust and support.

I am also thankful to my dear friends for their support and encouragement.

This work was supported by the Hungarian Scientific Research Fund (OTKA K-119992 and OTKA ANN-113273), by the Szechenyi 2020 programme supported by the European Union and co-financed by the European Social Fund and State of Hungary (GINOP-2.3.2-152016-00006 and EFOP-3.6.2-16-2017-00006 projects), the HU-RO Cross-Border Cooperation Programmes (HURO/1001/086/2.2.1 HURO-TWIN), the Hungarian Academy of Sciences, 
the Campus Hungary Program (CHP/200-7/2014), AFib-TrainNet (675351), the German Centre for Cardiovascular Research (DZHK), the German Ministry of Education and Research (BMBF), the German Research Foundation (DFG Es 88/12-1), the European Research Council (ERC AG IndivuHeart - 340248), the Canadian Heart Foundation and the Canadian Institutes of Health Research. The research was also supported in the framework of TÁMOP 4.2.4. A/2-11-1-2012-0001 „National Excellence Program - Elaborating and operating an inland student and researcher personal support system". 


\section{References}

1. Lehnart SE, Ackerman MJ, Benson DW, Brugada R, Clancy CE, Donahue JK, et al. Inherited arrhythmias: A National Heart, Lung, and Blood Institute and Office of Rare Diseases workshop consensus report about the diagnosis, phenotyping, molecular mechanisms, and therapeutic approaches for primary cardiomyopathies of gene mutations affe. Circulation. 2007;116: 2325-2345. doi:10.1161/CIRCULATIONAHA.107.711689

2. Ördög B, Hategan L, Kovács M, Seprényi G, Kohajda Z, Nagy I, et al. Identification and functional characterisation of a novel KCNJ2 mutation, Val302del, causing Andersen-Tawil syndrome. Can J Physiol Pharmacol. NRC Research Press; 2015;93: 569-575. doi:10.1139/cjpp-2014-0527

3. Zhang L, Benson DW, Tristani-Firouzi M, Ptacek LJ, Tawil R, Schwartz PJ, et al. Electrocardiographic features in Andersen-Tawil syndrome patients with KCNJ2 mutations: Characteristic T-U-wave patterns predict the KCNJ2 genotype. Circulation. 2005;111: 2720-2726. doi:10.1161/CIRCULATIONAHA.104.472498

4. Viitasalo M, Oikarinen L, Swan H, Väänänen H, Glatter K, Laitinen PJ, et al. Ambulatory electrocardiographic evidence of transmural dispersion of repolarization in patients with long-QT syndrome type 1 and 2. Circulation. 2002;106: 2473-2478. doi:10.1161/01.CIR.0000036369.16112.7D

5. Schulze-Bahr E, Zoelch KA, Eckardt L, Haverkamp W, Breithardt G, Borggrefe M. Electrical Alternans in Long QT Syndrome Resembling a Brugada Syndrome Pattern. PACE - Pacing Clin Electrophysiol. 2003;26: 2033-2035. doi:10.1046/j.14609592.2003.00313.x

6. $\quad$ Khan IA. Long QT syndrome: Diagnosis and management. Am Heart J. 2002;143: 714. doi:10.1067/mhj.2002.120295

7. Investigators TCI. Effect of the antiarrhythmic agent moricizine on survival after myocardial infarction. N Engl J Med. 1992;327: 146-150. doi:10.1056/NEJM199207163270302

8. Investigators TCAST (CAST). Preliminary Report: Effect of Encainide and Flecainide on Mortality in a Randomized Trial of Arrhythmia Suppression after Myocardial Infarction. N Engl J Med. 1989;321: 406-412. doi:10.1056/NEJM198908103210629

9. Vaughan Williams EM. A Classification of Antiarrhythmic Actions Reassessed After a Decade of New Drugs. J Clin Pharmacol. 1984;24: 129-147.

10. Gambit TS. The Sicilian gambit. A new approach to the classification of antiarrhythmic drugs based on their actions on arrhythmogenic mechanisms. Task Force of the Working Group on Arrhythmias of the European Society of Cardiology. Circulation. 1991;84: 1831-1851. doi:10.1161/01.CIR.84.4.1831

11. Singh BN, Vaughan Williams EM. A third class of anti-arrhythmic action. Effects on atrial and ventricular intracellular potentials, and other pharmacological actions on cardiac muscle, of MJ 1999 and AH 3474. Br J Pharmacol. 1970;39: 675-687. doi:10.1111/j.1476-5381.1970.tb09893.x

12. Nattel S, Carlsson L. Innovative approaches to anti-arrhythmic drug therapy. Nat Rev Drug Discov. 2006;5: 1034-1049. doi:10.1038/nrd2112

13. Nattel S, Duker G, Carlsson L. Model systems for the discovery and development of antiarrhythmic drugs. Prog Biophys Mol Biol. Pergamon; 2008;98: 328-339. doi:10.1016/J.PBIOMOLBIO.2008.10.009

14. Singh BN. Current antiarrhythmic drugs: an overview of mechanisms of action and potential clinical utility. J Cardiovasc Electrophysiol. 1999;10: 283-301. 
15. Waldo AL, Camm AJ, DeRuyter H, Friedman PL, MacNeil DJ, Pauls JF, et al. Effect of d-sotalol on mortality in patients with left ventricular dysfunction after recent and remote myocardial infarction. Lancet. 1996;348: 7-12. doi:10.1016/S01406736(96)02149-6

16. Nerbonne JM, Kass RS. Molecular physiology of cardiac repolarization. Sci STKE. 2005;85: 1205. doi:10.1152/physrev.00002.2005.

17. Zicha S, Moss I, Allen B, Varro A, Papp J, Dumaine R, et al. Molecular basis of species-specific expression of repolarizing $\mathrm{K}+$ currents in the heart. Am J Physiol Heart Circ Physiol. 2003;285: H1641-H1649. doi:10.1152/ajpheart.00346.2003

18. Nerbonne JM, Guo W. Heterogeneous expression of voltage-gated potassium channels in the heart: roles in normal excitation and arrhythmias. J Cardiovasc Electrophysiol. 2002;13: 406-409. doi:10.1046/j.1540-8167.2002.00406.x

19. Ravens U, Cerbai E. Role of potassium currents in cardiac arrhythmias. Europace. 2008;10: 1133-1137. doi:10.1093/europace/eun193

20. Antzelevitch C. Molecular basis for thetransmural distribution of thetransient outward current. Am J Physiol. 2001; 2001.

21. Allessie M, Ausma J, Schotten U. Electrical, contractile and structural remodeling during atrial fibrillation. Cardiovasc Res. 2002;54: 230-246. doi:10.1016/S00086363(02)00258-4

22. Boyden PA, Hirose M, Dun W. Cardiac Purkinje cells. Hear Rhythm. Elsevier Inc.; 2010;7: 127-135. doi:10.1016/j.hrthm.2009.09.017

23. Roden DM. Taking the "Idio" out of "Idiosyncratic": Predicting Torsades de Pointes. Pacing Clin Electrophysiol. 1998;21: 1029-1034. doi:10.1111/j.15408159.1998.tb00148.x

24. Biliczki P, Virág L, Iost N, Papp JG, Varró A. Interaction of different potassium channels in cardiac repolarization in dog ventricular preparations: Role of repolarization reserve. $\mathrm{Br} \quad \mathrm{J}$ Pharmacol. 2002;137: 361-368. doi:10.1038/sj.bjp.0704881

25. Jost N, Nagy N, Corici C, Kohajda Z, Horváth A, Acsai K, et al. ORM-10103, a novel specific inhibitor of the $\mathrm{Na}+\mathrm{Ca} 2+$ exchanger, decreases early and delayed afterdepolarizations in the canine heart. $\mathrm{Br} \mathrm{J}$ Pharmacol. 2013;170: 768-778. doi:10.1111/bph.12228

26. Jost N, Virág L, Bitay M, Takács J, Lengyel C, Biliczki P, et al. Restricting excessive cardiac action potential and QT prolongation: A vital role for IKs in human ventricular muscle. Circulation. 2005;112: 1392-1399. doi:10.1161/CIRCULATIONAHA.105.550111

27. Carvajal-vergara X, Sevilla A, Souza SLD, Ang Y, Lee D, Yang L, et al. Patientspecific induced pluripotent stem-cell-derived models of LEOPARD syndrome. Nature. Nature Publishing Group, a division of Macmillan Publishers Limited. All Rights Reserved.; 2010;465: 808-812. doi:10.1038/nature09005.Patient-specific

28. Itzhaki I, Maizels L, Huber I, Zwi-Dantsis L, Caspi O, Winterstern A, et al. Modelling the long QT syndrome with induced pluripotent stem cells. Nature. Nature Publishing Group; 2011;471: 225-229. doi:10.1038/nature09747

29. Liang P, Sallam K, Wu H, Li Y, Itzhaki I, Garg P, et al. Patient-Specific and GenomeEdited Induced Pluripotent Stem Cell-Derived Cardiomyocytes Elucidate Single-Cell Phenotype of Brugada Syndrome. J Am Coll Cardiol. 2016;68: 2086-2096. doi:10.1016/j.jacc.2016.07.779

30. Wu Y, Wang L, Ma J, Song Y, Zhang P, Luo A, et al. Protein kinase C and Ca(2+) calmodulin-dependent protein kinase II mediate the enlarged reverse INCX induced by ouabain-increased late sodium current in rabbit ventricular myocytes. Exp Physiol. 
2015;100: 399-409. doi:10.1113/expphysiol.2014.083972

31. Karakikes I, Stillitano F, Nonnenmacher M, Tzimas C, Sanoudou D, Termglinchan V, et al. Correction of human phospholamban R14del mutation associated with cardiomyopathy using targeted nucleases and combination therapy. Nat Commun. Nature Publishing Group; 2015;6: 6955. doi:10.1038/ncomms7955

32. Ran FA, Hsu PD, Wright J, Agarwala V, Scott DA, Zhang F. Genome engineering using the CRISPR-Cas9 system. Nat Protoc. 2013;8: 2281-2308. doi:10.1038/nprot.2013.143

33. Goversen B, Becker N, Stoelzle-Feix S, Obergrussberger A, Vos MA, van Veen TAB, et al. A hybrid model for safety pharmacology on an automated patch clamp platform: Using dynamic clamp to join iPSC-derived cardiomyocytes and simulations of Ik1 ion channels in real-time. Front Physiol. 2018;8: 1-10. doi:10.3389/fphys.2017.01094

34. Doss MX, Di Diego JM, Goodrow RJ, Wu Y, Cordeiro JM, Nesterenko V V., et al. Maximum diastolic potential of human induced pluripotent stem cell-derived cardiomyocytes depends critically on IKr. PLoS One. 2012;7. doi:10.1371/journal.pone.0040288

35. Herron TJ, Da Rocha AM, Campbell KF, Ponce-Balbuena D, Willis BC, GuerreroSerna $\mathrm{G}$, et al. Extracellular matrix-mediated maturation of human pluripotent stem cell-derived cardiac monolayer structure and electrophysiological function. Circ Arrhythmia Electrophysiol. 2016;9: e003638. doi:10.1161/CIRCEP.113.003638

36. Liang P, Lan F, Lee AS, Gong T, Sanchez-Freire V, Wang Y, et al. Drug Screening Using a Library of Human Induced Pluripotent Stem Cell - Derived Cardiomyocytes Reveals Disease-Specific Patterns of Cardiotoxicity. Circulation. 2013;127: 16771691. doi:10.1161/CIRCULATIONAHA.113.001883

37. Ma J, Guo L, Fiene SJ, Anson BD, Thomson JA, Kamp TJ, et al. High purity humaninduced pluripotent stem cell-derived cardiomyocytes : electrophysiological properties of action potentials and ionic currents. Am J Physiol Hear Circ Physiol. 2011;301: 2006-2017. doi:10.1152/ajpheart.00694.2011.

38. Vaidyanathan R, Markandeya YS, Kamp TJ, Makielski JC, January CT, Eckhardt LL, et al. IK1-enhanced human-induced pluripotent stem cell-derived cardiomyocytes: an improved cardiomyocyte model to investigate inherited arrhythmia syndromes. Am J Physiol - Hear Circ Physiol. 2016; 1611-1621. doi:10.1152/ajpheart.00481.2015

39. Hibino H, Inanobe A, Furutani K, Murakami S, Findlay I, Kurachi Y. Inwardly Rectifying Potassium Channels: TheirHibino, H., Inanobe, A., Furutani, K., Murakami, S., Findlay, I., and Kurachi, Y. (2010). Inwardly Rectifying Potassium Channels: Their Structure, Function, and Physiological Roles. Physiol. Rev. 90, 291-366. S. Physiol Rev. 2010;90: 291-366. doi:10.1152/physrev.00021.2009.

40. Mannhardt I, Breckwoldt K, Letuffe-Brenière D, Schaaf S, Schulz H, Neuber C, et al. Human Engineered Heart Tissue: Analysis of Contractile Force. Stem Cell Reports. 2016;7: 29-42. doi:10.1016/j.stemcr.2016.04.011

41. Horváth A, Lemoine MD, Löser A, Mannhardt I, Flenner F, Uzun AU, et al. Low Resting Membrane Potential and Low Inward Rectifier Potassium Currents Are Not Inherent Features of hiPSC-Derived Cardiomyocytes. Stem Cell Reports. 2018;10: 112. doi:10.1016/j.stemcr.2018.01.012

42. Salama G, London B. Mouse models of long QT syndrome. J Physiol. 2007;578: 4353. doi:10.1113/jphysiol.2006.118745

43. Drici MD, Arrighi I, Chouabe C, Mann JR, Lazdunski M, Romey G, et al. Involvement of IsK-associated $\mathrm{K}+$ channel in heart rate control of repolarization in a murine engineered model of Jervell and Lange-Nielsen syndrome. Circ Res. 1998;83: 95-102. doi:10.1161/01.RES.83.1.95 
44. Kaese S, Verheule S. Cardiac electrophysiology in mice: A matter of size. Front Physiol. 2012;3 SEP: 1-19. doi:10.3389/fphys.2012.00345

45. London B. Cardiac Arrhythmias: From (Transgenic) Mice to Men. J Cardiovasc Electrophysiol. 2001;12: 1089-1091. doi:10.1046/j.1540-8167.2001.01089.x

46. Baczkó I, Jost N, Virág L, Bősze Z, Varró A. Rabbit models as tools for preclinical cardiac electrophysiological safety testing: Importance of repolarization reserve. Prog Biophys Mol Biol. 2016;121: 157-168. doi:10.1016/j.pbiomolbio.2016.05.002

47. Odening KE, Hyder O, Chaves L, Schofield L, Brunner M, Kirk M, et al. Pharmacogenomics of anesthetic drugs in transgenic LQT1 and LQT2 rabbits reveal genotype-specific differential effects on cardiac repolarization. Am J Physiol Heart Circ Physiol. 2008;295: H2264-H2272. doi:10.1152/ajpheart.00680.2008

48. Duranthon V, Beaujean N, Brunner M, Odening KE, Santos AN, Kacskovics I, et al. On the emerging role of rabbit as human disease model and the instrumental role of novel transgenic tools. Transgenic Res. 2012;21: 699-713. doi:10.1007/s11248-0129599-x

49. Nánási PP, Bárándi L, Virág L, Jost N, Horváth Z, Koncz I, et al. Reverse ratedependent changes are determined by baseline action potential duration in mammalian and human ventricular preparations. Basic Res Cardiol. 2010;105: 315-323. doi:10.1007/s00395-009-0082-7

50. Brunner M, Peng X, Liu G, Ren X. Mechanisms of cardiac arrhythmias and sudden death in transgenic rabbits with long QT syndrome. J Clin ... 2008;118: 2246-2259. doi:10.1172/JCI33578.2246

51. Ma L, Lin C, Teng S, Chai Y, Bähring R, Vardanyan V, et al. Characterization of a novel Long QT syndrome mutation G52R-KCNE1 in a Chinese family. Cardiovasc Res. 2003;59: 612-619. doi:10.1016/S0008-6363(03)00510-8

52. Murai T, Kakizuka A, Takumi T. Molecular cloning and sequence analysis of human genomic DNA encoding A novel membrane protein which exhibits a slowly activating potassium channel activity. Biochem Biophys Res Commun. 1989;161: 176-181.

53. Harmer SC, Wilson AJ, Aldridge R, Tinker A. Mechanisms of disease pathogenesis in long QT syndrome type 5. Am J Physiol Cell Physiol. 2010;298: C263-C273. doi:10.1152/ajpcell.00308.2009

54. Frank S, Zhang M, Schöler HR, Greber B. Small molecule-assisted, line-independent maintenance of human pluripotent stem cells in defined conditions. PLoS One. 2012;7. doi:10.1371/journal.pone.0041958

55. Lanier M, Schade D, Willems E, Tsuda M, Spiering S, Kalisiak J, et al. Wnt Inhibition Correlates with Human Embryonic Stem Cell Cardiomyogenesis: A Structure Activity Relationship Study Based on Inhibitors for the Wnt Response. J Med Chem. American Chemical Society; 2012;55: 697-708. doi:10.1021/jm2010223

56. Zweigerdt R, Olmer R, Singh H, Haverich A, Martin U. Scalable expansion of human pluripotent stem cells in suspension culture. Nat Protoc. Nature Publishing Group; 2011;6: 689-700. doi:10.1038/nprot.2011.318

57. Schaaf S, Eder A, Vollert I, Stöhr A, Hansen A, Eschenhagen T. Generation of StripFormat Fibrin-Based Engineered Heart Tissue (EHT). In: Radisic M, Black III DL, editors. Cardiac Tissue Engineering: Methods and Protocols. New York, NY: Springer New York; 2014. pp. 121-129. doi:10.1007/978-1-4939-1047-2_11

58. Du DTM, Hellen N, Kane C, Terracciano CMN. Action potential morphology of human induced pluripotent stem cell-derived cardiomyocytes does not predict cardiac chamber specificity and is dependent on cell density. Biophys J. Biophysical Society; 2015;108: 1-4. doi:10.1016/j.bpj.2014.11.008

59. Besenfelder U, Brem G. Laparoscopic embryo transfer in rabbits. J Reprod Fertil. 
1993;99: 53-56. doi:10.1530/jrf.0.0990053

60. Kilkenny C, Browne W, Innes, C C, Emerson M, Douglas, G A. Animal research: Reporting in vivo experiments: The ARRIVE guidelines. Br J Pharmacol. 2010;160: 1577-1579. doi:doi:10.1111/j.1476-5381.2010.00872.x

61. McGrath JC, Lilley E. Implementing guidelines on reporting research using animals (ARRIVE etc.): New requirements for publication in BJP. Br J Pharmacol. 2015;172: 3189-3193. doi:10.1111/bph.12955

62. Major P, Baczkó I, Hiripi L, Odening KE, Juhász V, Kohajda Z, et al. A novel transgenic rabbit model with reduced repolarization reserve: Long QT syndrome caused by a dominant-negative mutation of the KCNE1 gene. Br J Pharmacol. 2016;173: 2046-2061. doi:10.1111/bph.13500

63. Farkas A, Batey AJ, Coker SJ. How to measure electrocardiographic QT interval in the anaesthetized rabbit. J Pharmacol Toxicol Methods. 2004;50: 175-185. doi:https://doi.org/10.1016/j.vascn.2004.05.002

64. Batey AJ, Coker SJ. Proarrhythmic potential of halofantrine, terfenadine and clofilium in a modified in vivo model of torsade de pointes. Br J Pharmacol. 2002;135: 10031012. doi:10.1038/sj.bjp.0704550

65. Thomsen MB, Verduyn SC, Stengl M, Beekman JDM, De Pater G, Van Opstal J, et al. Increased short-term variability of repolarization predicts d-sotalol-induced torsades de pointes in dogs. Circulation. 2004;110: 2453-2459. doi:10.1161/01.CIR.0000145162.64183.C8

66. Lengyel C, Varró A, Tábori K, Papp JG, Baczkó I. Combined pharmacological block of I Kr and I Ks increases short-term QT interval variability and provokes torsades de pointes. Br J Pharmacol. 2007;151: 941-951. doi:10.1038/sj.bjp.0707297

67. Hinterseer M, Beckmann BM, Thomsen MB, Pfeufer A, Ulbrich M, Sinner MF, et al. Usefulness of short-term variability of QT intervals as a predictor for electrical remodeling and proarrhythmia in patients with nonischemic heart failure. Am J Cardiol. Elsevier Inc.; 2010;106: 216-220. doi:10.1016/j.amjcard.2010.02.033

68. Hinterseer M, Beckmann BM, Thomsen MB, Pfeufer A, Dalla Pozza R, Loeff M, et al. Relation of Increased Short-Term Variability of QT Interval to Congenital Long-QT Syndrome. Am J Cardiol. Elsevier Inc.; 2009;103: 1244-1248. doi:10.1016/j.amjcard.2009.01.011

69. Brennan M, Palaniswami M, Kamen P. Do existing measures of Poincareé plot geometry reflect nonlinear features of heart rate variability? IEEE Trans Biomed Eng. 2001;48: 1342-1347. doi:10.1109/10.959330

70. Anumonwo JMB, Lopatin AN. Cardiac strong inward rectifier potassium channels. J Mol Cell Cardiol. Elsevier Inc.; 2010;48: 45-54. doi:10.1016/j.yjmcc.2009.08.013

71. Wilson JR, Clark RB, Banderali U, Giles WR. Measurement of the membrane potential in small cells using patch clamp methods. Channels (Austin). 2011;5: 530-537. doi:10.4161/chan.5.6.17484

72. Uzun AU, Mannhardt I, Breckwoldt K, Horváth A, Johannsen SS, Hansen A, et al. Ca2+-Currents in Human Induced Pluripotent Stem Cell-Derived Cardiomyocytes Effects of Two Different Culture Conditions. Front Pharmacol. 2016;7. doi:10.3389/fphar.2016.00300

73. Liu GX, Derst C, Schlichthörl G, Heinen S, Seebohm G, Brüggemann A, et al. Comparison of cloned Kir2 channels with native inward rectifier $\mathrm{K}+$ channels from guinea-pig cardiomyocytes. J Physiol. 2001;532: 115-126. doi:10.1111/j.14697793.2001.0115g.X

74. Schram G, Pourrier M, Wang Z, White M, Nattel S. Barium block of Kir2 and human cardiac inward rectifier currents: Evidence for subunit-heteromeric contribution to 
native currents. Cardiovasc Res. 2003;59: 328-338. doi:10.1016/S00086363(03)00366-3

75. Jost N, Virág L, Comtois P, Ördög B, Szuts V, Seprényi G, et al. Ionic mechanisms limiting cardiac repolarization reserve in humans compared to dogs. J Physiol. 2013;591: 4189-206. doi:10.1113/jphysiol.2013.261198

76. Dobrzynski H, Marples DD, Musa H, Yamanushi TT, Henderson Z, Takagishi Y, et al. Distribution of the muscarinic K+ channel proteins Kir3.1 and Kir3.4 in the ventricle, atrium, and sinoatrial node of heart. J Histochem Cytochem. 2001;49: 1221-1234. doi:10.1177/002215540104901004

77. Koumi S, Backer CL, Arentzen CE. Characterization of Inwardly Rectifying K+ Channel in Human Cardiac Myocytes. Circulation. 1995;92: 164-174. Available: http://circ.ahajournals.org/content/92/2/164.abstract

78. Amos GJ, Wettwer E, Metzger F, Li Q, Himmel HM, Ravens U. Differences between outward currents of human atrial and subepicardial ventricular myocytes. J Physiol. 1996;491: 31-50. doi:10.1113/jphysiol.1996.sp021194

79. Wang Z, Yue L, White M, Pelletier G, Nattel S. Differential distribution of inward rectifier potassium channel transcripts in human atrium versus ventricle. Circulation. 1998;98: 2422-8. doi:10.1161/01.CIR.98.22.2422

80. Varró A, Nánási PP, Lathrop DA. Potassium currents in isolated human atrial and ventricular cardiocytes. Acta Physiol Scand. 1993;149: 133-42. doi:10.1111/j.17481716.1993.tb09605.x

81. Schram G, Pourrier M, Melnyk P, Nattel S. Differential distribution of cardiac ion channel expression as a basis for regional specialization in electrical function. Circ Res. 2002;90: 939-950. doi:10.1161/01.RES.0000018627.89528.6F

82. Guo J, Mitsuiye T, Noma A. The sustained inward current in sino-atrial node cells of guinea-pig heart. Pflugers Arch Eur J Physiol. 1997;433: 390-396. doi:10.1007/s004240050293

83. Schneider MF, Chandler WK. Effects of membrane potential on the capacitance of skeletal muscle fibers. J Gen Physiol. 1976;67: 125-163. Available: http://www.ncbi.nlm.nih.gov/entrez/query.fcgi?cmd=Retrieve \&db=PubMed\&dopt=Cit ation\&list_uids $=1082924$

84. Rorsman Patrik TG. Calcium and delayed potassium currents in mouse pancreatic betacells under voltage-clamp conditions. J Physiol. 1986; 531-550.

85. Keizer J, Magnus G. ATP-sensitive potassium channel and bursting in the pancreatic beta cell. Biophys J. 1989;56: 229-242.

86. Moretti A, Bellin M, Welling A, Jung CB, Lam JT, Bott-Flügel L, et al. PatientSpecific Induced Pluripotent Stem-Cell Models for Long-QT Syndrome. N Engl J Med. Massachusetts Medical Society ; 2010;363: 1397-1409. doi:10.1056/NEJMoa0908679

87. Ma D, Wei H, Zhao Y, Lu J, Li G, Sahib NBE, et al. Modeling type 3 long QT syndrome with cardiomyocytes derived from patient-specific induced pluripotent stem cells. Int J Cardiol. Elsevier Ireland Ltd; 2013;168: 5277-5286. doi:10.1016/j.ijcard.2013.08.015

88. Sakmann B, Noma A, Trautwein W. Acetylcholine activation of single muscarinic K+ channels in isolated pacemaker cells of the mammalian heart. Nature. 1983;303: 250-3. doi:10.1038/303250a0

89. Heidbüchel H, Vereecke J, Carmeliet E. The electrophysiological effects of acetylcholine in single human atrial cells. J Mol Cell Cardiol. 1987;19: 1207-1219. doi:10.1016/S0022-2828(87)80531-X

90. Levy MN. Sympathetic-Parasympathetic Interactions in the Heart. Circ Res. 1971;29: 437-445. doi:10.1161/01.RES.29.5.437 
91. Giles WR, Noble D. Rigorous Phenotyping of Cardiac iPSC Preparations Requires Knowledge of Their Resting Potential(s). Biophysical Journal. 2016. pp. 278-280. doi:10.1016/j.bpj.2015.06.070

92. Maleckar MM, Greenstein JL, Giles WR, Trayanova NA. K+ current changes account for the rate dependence of the action potential in the human atrial myocyte. AJP Hear Circ Physiol. 2009;297: H1398-H1410. doi:10.1152/ajpheart.00411.2009

93. Drouin E, Lande G, Charpentier F. Amiodarone reduces transmural heterogeneity of repolarization in the human heart. J Am Coll Cardiol. Elsevier Masson SAS; 1998;32: 1063-1067. doi:10.1016/S0735-1097(98)00330-1

94. Jakob H, Oelert H, Rupp J, Nawrath H. Functional role of cholinoceptors and purinoceptors in human isolated atrial and ventricular heart muscle. Br J Pharmacol. 1989;97:

1199-208.

Available:

http://www.pubmedcentral.nih.gov/articlerender.fcgi?artid=1854632\&tool=pmcentrez \&rendertype $=$ abstract

95. Dobrev D, Graf E, Wettwer E, Himmel HM, Hála O, Doerfel C, et al. Molecular Basis of Downregulation of G-Protein-Coupled Inward Rectifying K+ Current IK,ACh in Chronic Human Atrial Fibrillation. Circulation. 2001;104: 2551-2557. Available: http://circ.ahajournals.org/content/104/21/2551.abstract

96. Wang Z, Fermini B, Nattel S. Delayed rectifier outward current and repolarization in human atrial myocytes. Circ Res. 1993;73: 276-285.

97. Li GR, Feng J, Yue L, Carrier M. Transmural heterogeneity of action potentials and Ito1 in myocytes isolated from the human right ventricle. Am J Physiol. 1998;275: H369-H377.

98. Verkerk AO, Van Borren MMGJ, Peters RJG, Broekhuis E, Lam KY, Coronel R, et al. Single cells isolated from human sinoatrial node: Action potentials and numerical reconstruction of pacemaker current. Annu Int Conf IEEE Eng Med Biol - Proc. 2007; 904-907. doi:10.1109/IEMBS.2007.4352437

99. Zhang H, Zou B, Yu H, Moretti a., Wang X, Yan W, et al. Modulation of hERG potassium channel gating normalizes action potential duration prolonged by dysfunctional KCNQ1 potassium channel. Proc Natl Acad Sci. 2012;109: 1186611871. doi:10.1073/pnas.1205266109

100. Nattel S, Maguy A, Le Bouter S, Yeh Y-H. Arrhythmogenic ion-channel remodeling in the heart: heart failure, myocardial infarction, and atrial fibrillation. Physiol Rev. 2007;87: 425-456. doi:10.1152/physrev.00014.2006.

101. Varró A, Baczkó I. Cardiac ventricular repolarization reserve: A principle for understanding drug-related proarrhythmic risk. Br J Pharmacol. 2011;164: 14-36. doi:10.1111/j.1476-5381.2011.01367.x

102. Vos MA, De Groot SHM, Verduyn SC, Van Der Zande J, Leunissen HDM, Cleutjens JPM, et al. Enhanced susceptibility for acquired torsade de pointes arrhythmias in the dog with chronic, complete AV block is related to cardiac hypertrophy and electrical remodeling. Circulation. 1998;98: 1125-1135. doi:10.1161/01.CIR.98.11.1125

103. Volders PGA, Sipido KR, Vos MA, Spätjens RLHMG, Leunissen JDM, Carmeliet E, et al. Downregulation of Delayed Rectifier K\&lt;sup\&gt;+\&lt;/sup\&gt; Currents in Dogs With Chronic Complete Atrioventricular Block and Acquired Torsades de Pointes. Circulation. 1999;100: 2455 LP-2461. Available: http://circ.ahajournals.org/content/100/24/2455.abstract

104. Moss AJ, Kass RS. Review series Long QT syndrome: from channels to cardiac arrhythmias. J Clin Invest. 2005;115: 2018-2024. doi:10.1172/JCI25537.2018

105. Odening KE, Kirk M, Brunner M, Ziv O, Lorvidhaya P, Liu GX, et al. Electrophysiological studies of transgenic long QT type 1 and type 2 rabbits reveal 
genotype-specific differences in ventricular refractoriness and His conduction. Am J Physiol Heart Circ Physiol. 2010;299: H643-H655. doi:10.1152/ajpheart.00074.2010

106. Roden DM. Long QT syndrome: Reduced repolarization reserve and the genetic link. J Intern Med. 2006;259: 59-69. doi:10.1111/j.1365-2796.2005.01589.x

107. Bendahhou S, Marionneau C, Haurogne K, Larroque MM, Derand R, Szuts V, et al. In vitro molecular interactions and distribution of KCNE family with KCNQ1 in the human heart. Cardiovasc Res. 2005;67: 529-538. doi:10.1016/j.cardiores.2005.02.014

108. Lundquist AL, Manderfield LJ, Vanoye CG, Rogers CS, Donahue BS, Chang PA, et al. Expression of multiple KCNE genes in human heart may enable variable modulation of IKs. J Mol Cell Cardiol. 2005;38: 277-287. doi:10.1016/j.yjmcc.2004.11.012

109. Yang T, Kupershmidt S, Roden DM. Anti-minK Antisense Decreases the Amplitude of the Rapidly Activating Cardiac Delayed Rectifier K\&lt;sup\&gt;+\&lt;/sup\&gt; Current. Circ Res. 1995;77: 1246 LP-1253. Available: http://circres.ahajournals.org/content/77/6/1246.abstract

110. McDonald TV, Yu Z, Ming Z, Palma E, Meyers MB, Wang KW, et al. A minK-HERG complex regulates the cardiac potassium current $\mathrm{I}(\mathrm{Kr})$. Nature. 1997;388: 289-92. doi: $10.1038 / 40882$

111. Ohno S, Zankov DP, Yoshida H, Tsuji K, Makiyama T, Itoh H, et al. N- and Cterminal KCNE1 mutations cause distinct phenotypes of long QT syndrome. Hear Rhythm. 2007;4: 332-340. doi:10.1016/j.hrthm.2006.11.004

112. Sakai F, Hiraoka M, Amaha K. Comparative actions of propofol and thiopentone on cell membranes of isolated guineapig ventricular myocytes. Br J Anaesth. 1996;77: 508-516. doi:10.1093/bja/77.4.508

113. Baum VC. Distinctive Effects of Three Intravenous Anesthetics on the Inward Rectifier and Delayed Rectifier Potassium Currents. Anesthesiology. 1992;77: A423. doi:10.1097/00000542-199209001-00423

114. Atiga WL, Calkins H, Lawrence JH, Tomaselli GF, Smith JM, Berger RD. Beat-to-beat repolarization lability identifies patients at risk for sudden cardiac death. J Cardiovasc Electrophysiol. 1998;9: 899-908.

115. Varkevisser R, Wijers SC, Van Der Heyden MAG, Beekman JDM, Meine M, Vos MA. Beat-to-beat variability of repolarization as a new biomarker for proarrhythmia in vivo. Hear Rhythm. Elsevier Inc.; 2012;9: 1718-1726. doi:10.1016/j.hrthm.2012.05.016

116. Xiao L, Xiao J, Luo X, Lin H, Wang Z, Nattel S. Feedback remodeling of cardiac potassium current expression: A novel potential mechanism for control of repolarization reserve. Circulation. 2008;118: 983-992. doi:10.1161/CIRCULATIONAHA.107.758672

117. Abbott GW, Goldstein SAN. Disease-associated mutations in KCNE potassium channel subunits (MiRPs) reveal promiscuous disruption of multiple currents and conservation of mechanism. FASEB J. 2002;16: 390-400. doi:10.1096/fj.01-0520hyp

118. Um SY, McDonald T V. Differential association between HERG and KCNE1 or KCNE2. PLoS One. 2007;2. doi:10.1371/journal.pone.0000933

119. Flenner F, Geertz B, Reischmann-Düsener S, Weinberger F, Eschenhagen T, Carrier L, et al. Diltiazem prevents stress-induced contractile deficits in cardiomyocytes, but does not reverse the cardiomyopathy phenotype in Mybpc3-knock-in mice. J Physiol. 2017;595: 3987-3999. doi:10.1113/JP273769 


\section{Annex}

Publication related to the subject of the $\mathrm{PhD}$ thesis 